Aus der Klinik für M und-, Kiefer- und Gesichtschirurgie

(Prof. Dr. med. Dr. med. dent. H. Schliephake)

Zentrum Zahn-, M und- und Kieferheilkunde

der M edizinischen Fakultät der Universität Göttingen

\title{
Radiomorphometrische Untersuchung der Knochenregeneration in vivo durch kombinierte Freisetzung von VEGF und BMP aus den $\mathrm{PDLA} / \mathrm{CaCO}_{3}$-Komposit-Scaffolds.
}

\author{
INAUGURAL-DISSERTATION \\ zur Erlangung des Doktorgrades \\ der M edizinischen Fakultät der \\ Georg-August-Universität zu Göttingen
}

vorgelegt von

Anna Rau

aus

Shajrem (KAZ)

Göttingen 2020 
Dekan:

Referent/in:

Ko-Referent/in:

Drittreferent/in:
Prof. Dr. med. W. Brück

Prof. Dr. med. Dr. med. dent. H. Schliephake

Prof. Dr. med. N. M iosge

Prof. Dr. med. dent.R. Mausberg....

Datum der mündlichen Prüfung: 22.02.2021. 
Hiermit erkläre ich, die Dissertation mit dem Titel "Radiomorphometrische Untersuchung der Knochenregeneration in vivo durch kombinierte Freisetzung von VEGF und BM P aus den PDLLA/ $\mathrm{CaCO}_{3}$-Komposit-Scaffolds" eigenständig angefertigt und keine anderen als die von mir angegebenen Quellen und Hilfsmittel verwendet zu haben.

Göttingen, den 


\section{Inhaltsverzeichnis}

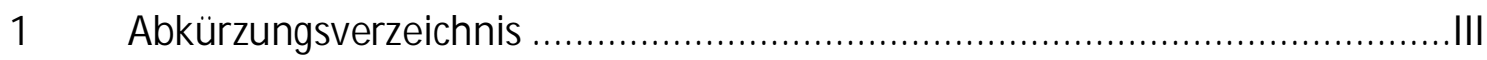

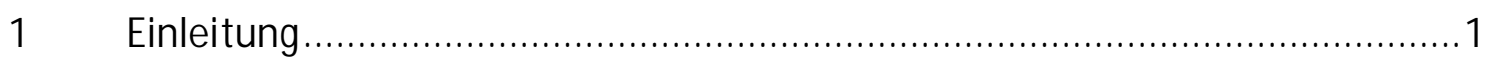

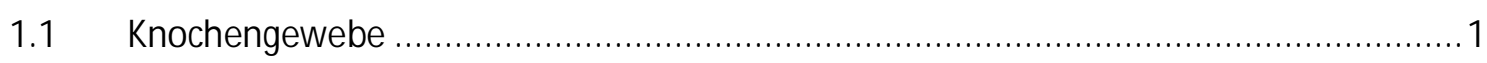

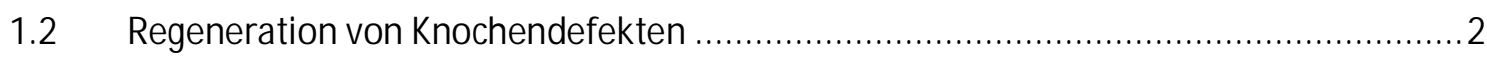

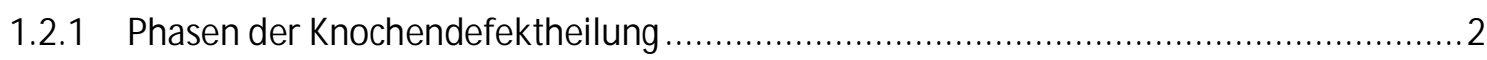

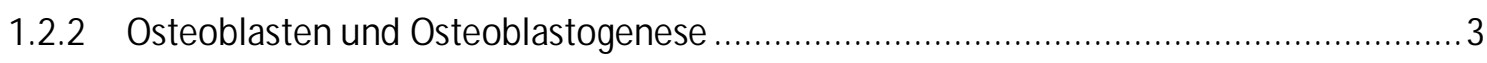

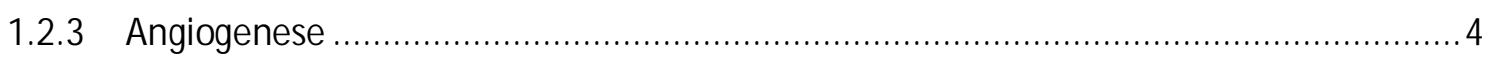

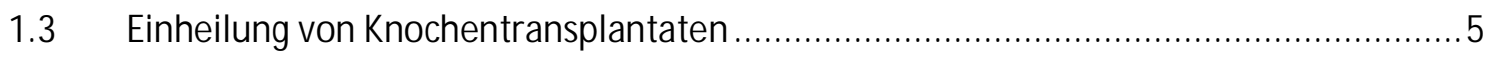

1.3.1 Osteoinduktion und Physiologie der Osteoinduktion ............................................... 5

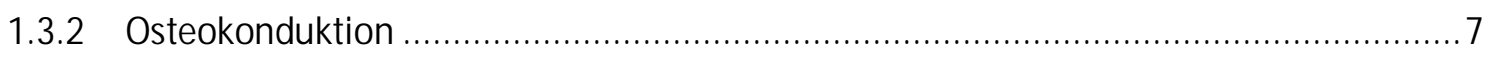

1.4 Übersicht verschiedener Knochenersatzmaterialien ........................................... 8

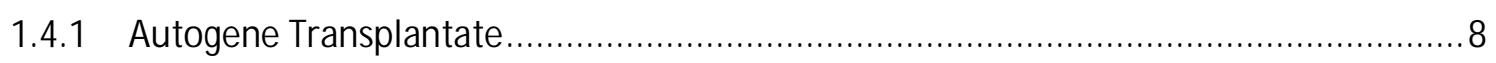

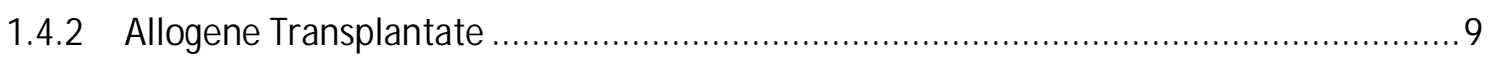

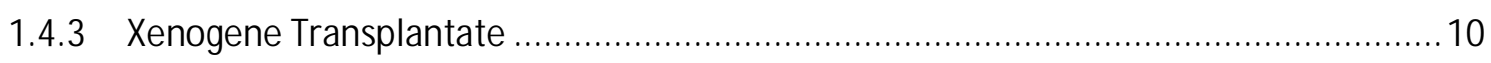

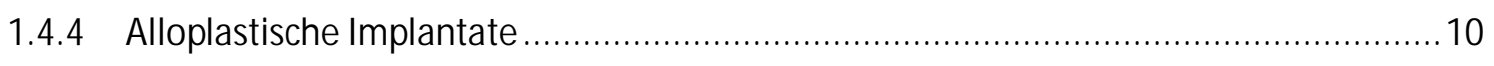

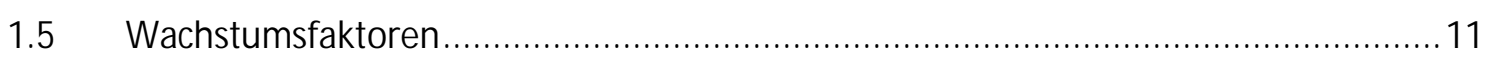

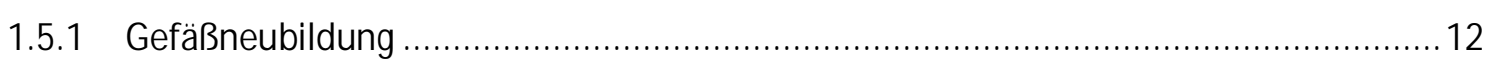

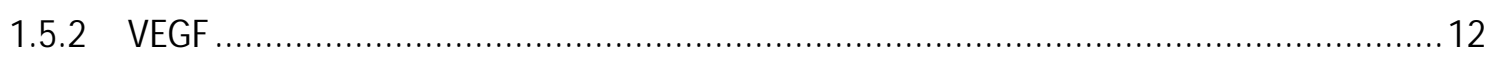

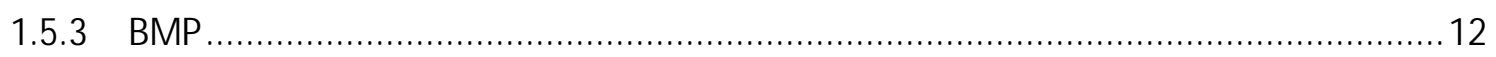

1.6 Trägersysteme für Wachstumsfaktoren................................................... 13

$1.7 \quad$ Freisetzungsphysiologie von Wachstumsfaktoren ........................................... 15

$1.8 \quad$ Fazit und Zielsetzung der Arbeit ................................................................. 16

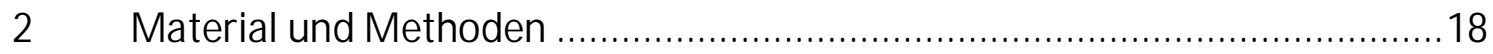

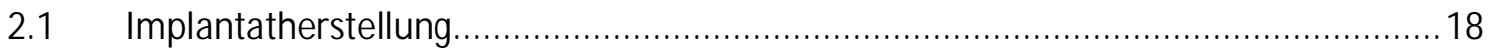

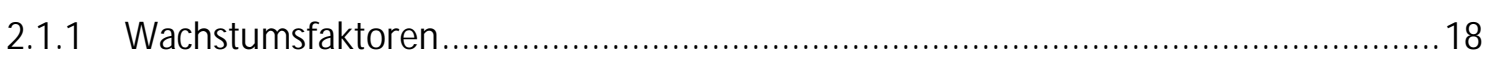

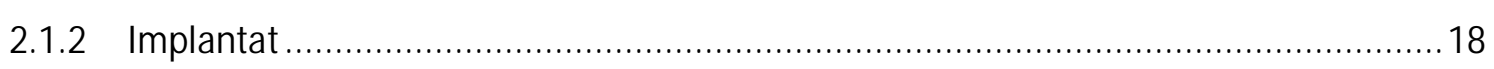

2.2 Versuchstiere und Tierhaltungsbedingungen.................................................. 19

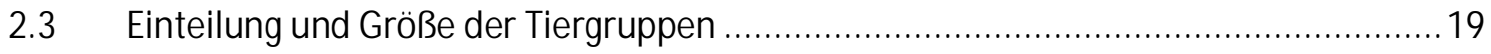

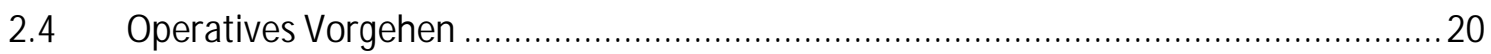

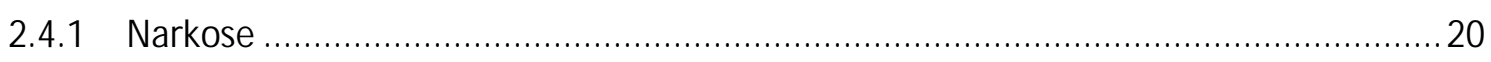

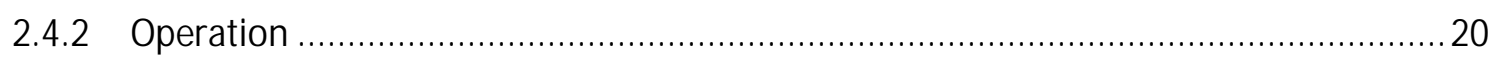

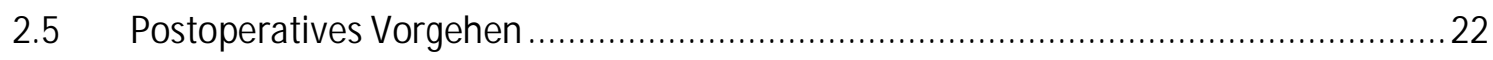

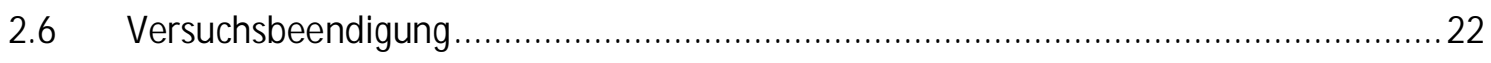

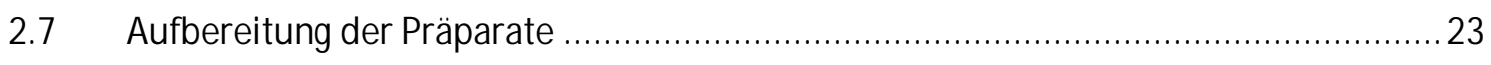

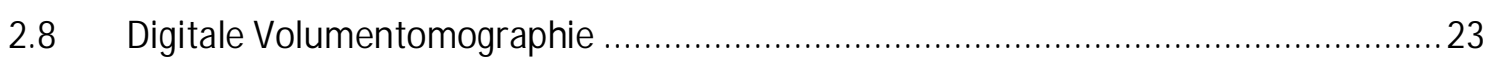




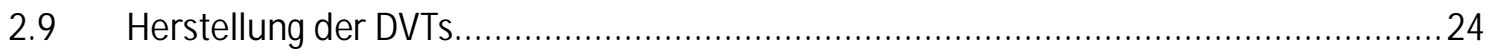

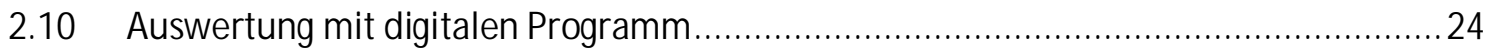

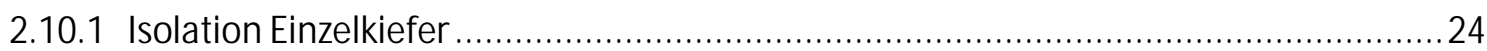

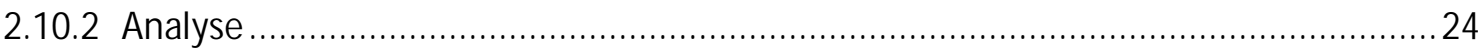

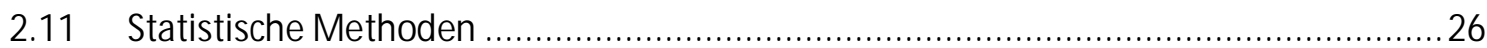

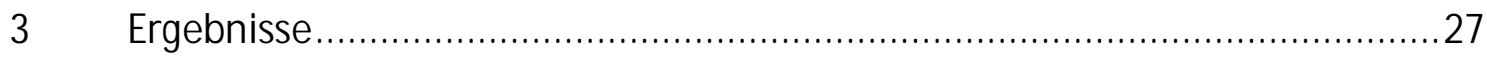

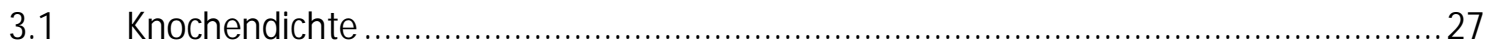

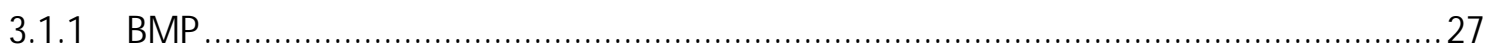

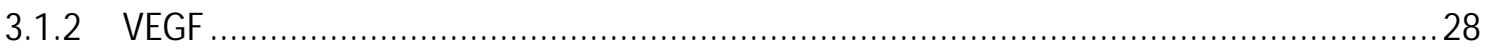

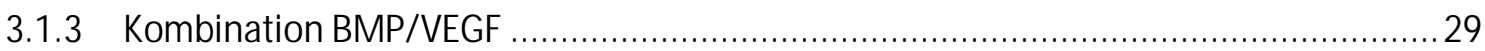

3.1.4 Vergleich der Knochendichte der Einzeldosierungen von BM P und Kombinationen

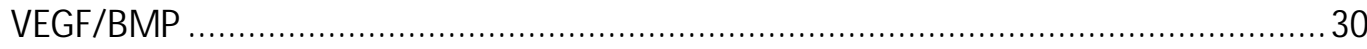

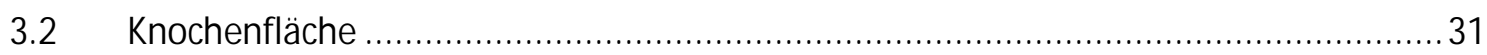

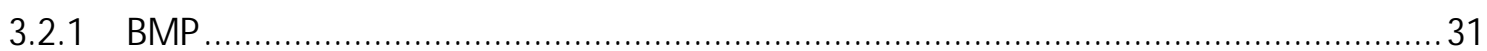

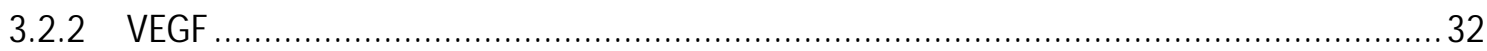

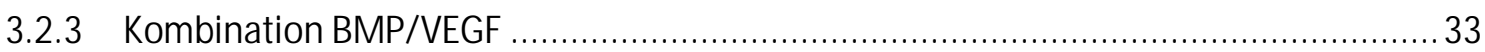

3.2.4 Vergleich der Knochenfläche der Einzeldosierungen von BM P und Kombinationen

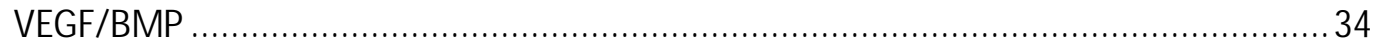

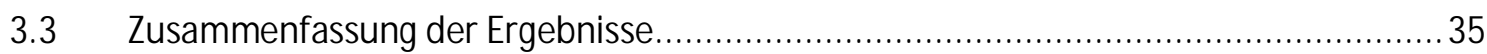

4 Diskussion ............................................................................................ 36

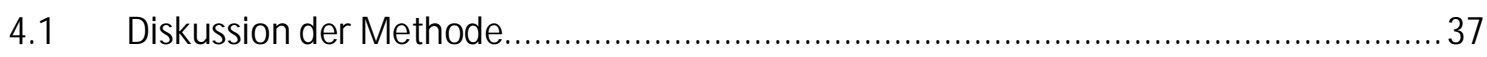

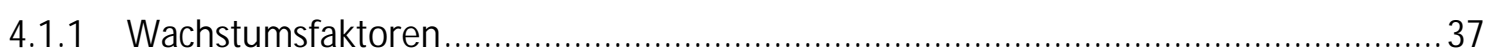

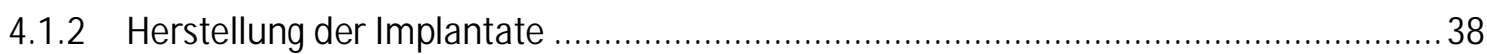

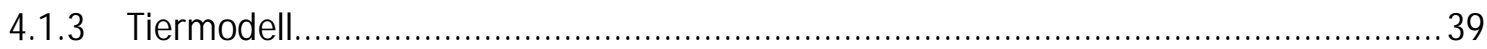

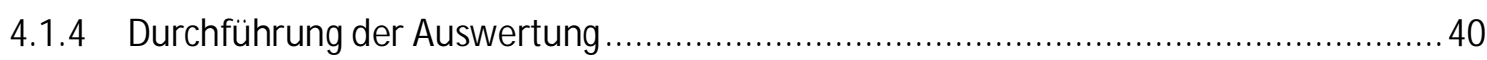

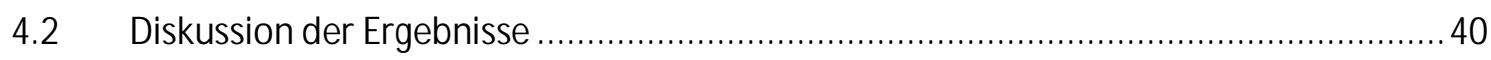

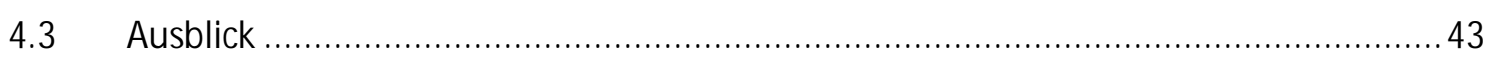

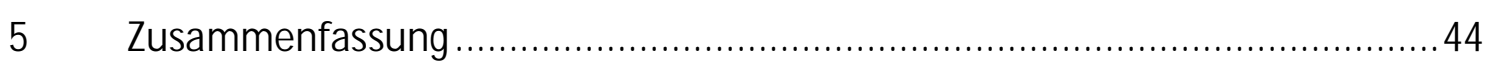

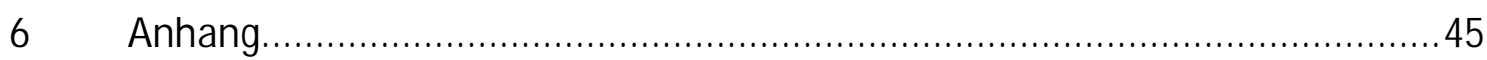

6.1 Tabellen zur statistischen Analyse der Knochendichte ......................................... 45

6.2 Tabellen zur statistischen Analyse der Knochenfläche ............................................ 48

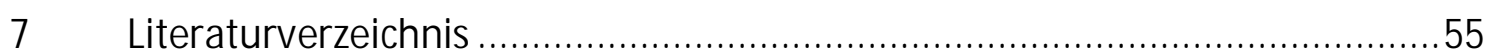




\section{Abkürzungsverzeichnis}

AP alkalische Phosphatase

BMP bone morphogenic protein

BSP bone sialoprotein

Colla Kollagen-I

Co-Smad common-Smad

D ICOM digital imaging and comunications in medicine

D lx5 distal-less homebox 5

DVT dentales V olumentomogramm

ERK ex tracellular signal-regulated kinase

FGF fibroblast growth factor

FOV field of view

HA Hydroxylapatit

HIF Hypoxie-induzierbarer Faktor

IL Interleukin

I-Smad inhibitorisches Smad

MAPK mitogen-aktivierte Proteinkinase

MSC mesenchymal stemm oell

Osx osterix

PD GF platelet- derived growth factor

PD LLA/ $\mathrm{CaCO}_{3}$ poly-d l-lactic acid/ calciumcarbonat

RANKL receptor activator of necrosefactor $k$ appaB-ligand

rh recombinant human

R-Smad rezeptorreguliertes Smad

Runx2 runt-related transcription factor 2

Smad screening for mutans (sma), mothers against decapentaplexic (mad)

Smurf Smad-ubiquitination related factors

TAK 1 transforming growth factor beta-adivated kinase

TCP Trikalziumphosphat

TGF-ß transforming growth factor beta

TG F- $\beta$ transforming growth factor beta

TNF $\alpha$ tumor necrosis fador alpha 
$\mathrm{TNF} \alpha$ tumor necrosis factor alpha

VEGF vascular endothelial growth factor 


\section{Einleitung}

\section{$1.1 \quad$ Knochengewebe}

Das Knochengewebe ist ein hochdifferenziertes Binde- und Stützgewebe, welches sich an die biomechanischen Anforderungen durch Zug, Druck, Biegung und Torsion anpasst. Als spezialisiertes Bindegewebe besteht die extrazelluläre Matrix des Knochengewebes zu 25\% aus Wasser, zu 30\% aus organischem Material und zu $45 \%$ aus den Mineralien Kalzium, Phosphor, Magnesium und Natrium. Die mineralisierte extrazelluläre Matrix, in die die Knochenzellen eingebettet sind, besteht überwiegend aus den Mineralien Kalzium, Phosphor, Magnesium und Natrium, kollagenen und nicht kollagenen Proteinen. Das Strukturprotein des Knochens ist Kollagen-I, welches $90 \%$ des organischen Materials ausmacht. Die übrigen $10 \%$ der Proteine übernehmen verschiedene regulierende Funktionen, wie z. B. Wachstumsfaktoren deren Anteil auf unter $1 \%$ sich beläuft (Gradinger und Gollwitzer 2006). Das Kollagen ist im reifen Knochen lamellenartig (Lamellenknochen) und im unreifen Knochen als Geflecht (Geflechtknochen) konfiguriert. Beide Anteile des Knochengewebes, Spongiosa und Kortikalis bestehen aus Lamellenknochen. Die Lamellen des kortikalen Knochengewebes sind konzentrisch um die Blutgefäße angeordnet. Die so gebildeten zylindrischen Einheiten werden als Havers-Kanäle oder Osteone genannt. Im Gegensatz dazu weisen die Spongiosabälkchen eine unregelmäßige Anordnung der Lamellen ohne zentrale Gefäßkonfiguration auf. In den so entstandenen Hohlräumen befindet sich das Knochenmark (Welsch 2006).

Die Zellen der Knochenmatrix sind Osteoblasten, die das Knochengewebe bilden, Osteoklasten, die für den Knochenabbau zuständig sind und Osteozyten, welche den Knochenstoffwechsel unterhalten. Die Osteoblasten sind vollständig ausdifferenzierte Zellen und befinden sich an der Oberfläche des Geflechtknochens. Sie sind für die Produktion von Knochenmatrix verantwortlich und sezernieren Kollagen-I und andere nichtkollagene Proteine. Damit bilden sie das nichtmineralisierte Osteoid.

Die Osteoklasten gehören dem Monozyten-Makrophagen-System an und kommen in geringer Zahl an Knochenoberflächen vor. Sie sind vor allem an Orten der Umbauvorgänge zu finden. Dabei lösen sie den mineralisierten Knochenanteil auf und führen durch Degradation von Proteinen zur Resorption des Knochens (Junqueira und Carneiro 2005).

Die Osteozyten gehen aus Osteoblasten hervor und sind von verkalkter Grundsubstanz umgeben. Es werden osteoblastische und osteolytische Osteozyten unterschieden. Die osteoblastischen Osteozyten dienen dem Erhalt der Grundsubstanz durch die Speicherung von Kalziumphosphat im Zytoplasma. Die osteolytischen Osteozyten bauen Hartsubstanz ab und setzen Kalzium frei.

Das Knochengewebe ist von einer Bindegewebsschicht, dem Periost umgeben. Dieses trägt zur Ernährung des Knochens mit Hilfe der enthaltenen Gefäße bei und ist reich an Nerven. 
Von Innen liegt der Kortikalis das Endost an, das wie das Periost an den Umbauvorgängen des Knochens beteiligt ist (Junqueira und Carneiro 2005). Das Knochengewebe mit einem Hohlraumanteil passt sich in seiner Architektur den Anforderungen an und wirkt somit formgebend und stabilisierend (Speckmann 2008).

\subsection{Regeneration von Knochendefekten}

Die biologischen Prozesse in der Knochenneubildung, der Einheilung von Knochen und Knochenersatzmaterialien und die Osseointegration von Implantaten haben einen identischen Heilungsablauf. Sie sind chronologisch gekennzeichnet durch die Herabregulation der Osteoklastenaktivität, das chemotaktische Anlocken und Proliferation von Osteoprogenitorzellen, die Differenzierung zu kollagensezernierenden Osteoblasten, die Bildung einer mineralisierten Knochenmatrix und letztendlich die Reduktion der Osteoblastenaktivität (Summers 1994).

Für die Defektheilung des Knochens gelten grundsätzlich die gleichen Prinzipien wie für die sekundäre Knochenheilung (Towfigh et al. 2011).

Nach der Entstehung eines Knochendefektes wird zunächst bindegewebiger Kallus gebildet und führt im Defektbereich zur Stabilisierung und zum Auffüllen des Defektvolumens. Dieser wird anschließend in stabilen Knochen umgewandelt. Eine erforderliche strenge Ruhigstellung und anatomische Annäherung sind oft nicht realisierbar und nachgewiesenermaßen führen Mikrobewegungen und Gewichtsbelastung zur besseren Regeneration. Es muss jedoch ein Mittelweg zwischen zu viel und zu wenig Bewegung gefunden werden, denn zu viel Bewegung und Gewichtsbelastung führen zur Pseudarthrosenbildung und Fehlstellung (Green et al. 2005).

\subsubsection{Phasen der Knochendefektheilung}

Der Regenerationsprozess beginnt unmittelbar nach dem Trauma. Nach Bildung eines Hämatoms und Nekrose des frakturnahen Gewebes kommt es zur Phase der Inflammation. Die akute inflammatorische Reaktion erreicht ihren Höhepunkt nach 24 Stunden und ist nach 7 Tagen abgeklungen (Cho et al. 2002).

In der initialen proinflammatorischen Phase werden Akute-Phase-Proteine (Tumornekrosefaktor alpha (TNF $\alpha$ ), Interleukin (IL)-1, IL-6, IL-11 und IL-18) in inflammatorischen Zellen im Hämatom gebildet und dienen zum Fortschreiten der Entzündungsreaktion und Gefäßneubildung (Gerstenfeld et al. 2003). TNF $\alpha$, welches von Makrophagen und anderen Entzündungszellen exprimiert wird erreicht seinen Konzentrationshöhepunkt 24 Stunden nach Trauma. Es führt zur Induktion der zweiten inflammatorischen Kaskade und zur Differenzierung von mesenchymalen Stammzellen (M SC) (Kon et al. 2001). Im weiteren Verlauf differenzieren die mesenchymale Stammzellen, welche aus dem Knochenmark und den umgebenden Weichgewebe stammen zu 
osteogenen Zellen (Zhang 2010; Lüllmann-Rauch 2006). Diese Differenzierung unterliegt einer komplexen molekularen Kaskade, welche noch nicht in Gänze verstanden ist (Marsell und Einhorn 2011).

IL-1 wird von den Makrophagen produziert, induziert die IL-6 Produktion in Osteoblasten, fördert die Angiogenese und die Bildung des primären Knorpels (Kon et al. 2001; Lee und Lorenzo 2006).

IL-6 stimuliert die Produktion von vascular endothelial growth factor (VEGF) und die Differenzierung von Osteoklasten und Osteoblasten (Yang et al. 2007).

Wichtige Rolle in der Umwandlung von Knorpelgewebe in einen stabilen mineralisierten Knochen spielen die desmale und die chondrale Ossifikation. Bei der desmalen Ossifikation kommt es nach Differenzierung von MSCs zu osteogenen Zellen zur Bildung von Osteoid. Dieses verkalkt durch Einlagerung von Kalziumphosphat und bildet Geflechtknochen. Durch anschließende Umbauprozesse wird der Geflechtknochen in den Lamellenknochen umgewandelt.

Die chondrale Ossifikation beschreibt die Knochenregeneration über die Bildung eines knorpeligen Gerüstes. Das gebildete Knorpelgewebe wird abgebaut und durch Knochengewebe ersetzt (Welsch 2006).

\subsubsection{Osteoblasten und Osteoblastogenese}

Osteoblasten sind mesenchymale Zellen und werden zeitlebens neu gebildet. Sie sind zuständig für die Synthese von Kollagen und die Steuerung der M ineralisation. Sie regulieren nicht nur den Knochenaufbau sondern auch den Knochenabbau durch die Überwachung des Osteoklastenhaushalts mit Hilfe von Botenstoffen. So fördert z.B. das von Osteoblasten sezernierte Zytokin macrophag colony-stimulating factor (M-CSF) die Proliferation der Osteoklastenvorläufer. Das membranständige Protein receptor activator of necrosefactor kappaB-ligand (RANKL), welches sich auf der Oberfläche von Präosteoblasten befindet, ist für die Fusion, Differenzierung und Aktivierung der Osteoklasten zuständig. Dabei interagiert der RANK-Ligand mit dem RANK-Rezeptor auf den Osteoklasten und Osteoklastenvorläufern. Die Steuerung des Prozesses vollzieht sich über die kompetitive Bindung von Osteoprotegerin (OPG), Wachstumsfaktoren und Hormonen an den Rezeptoren (LüllmannRauch 2006).

Die Differenzierung der mesenchymalen Stammzellen in Osteoblasten wird durch Transkriptionsfaktoren und Signalmoleküle beeinflusst. Unter den Einfluss von transforming growth factor beta (TGF-ß) und bone morphogenic protein (BMP) startet die Osteoblastendifferenzierung (Abbildung 1) und wird in jedem Schritt von den Wachstumsfaktoren beeinflusst. Den Differenzierungsweg der Osteoblasten starten Initiatorproteine. Sie führen zur Differenzierung der Osteoprogenitorzellen. In diesen Zellen startet die runt-related transcription factor 2 (Runx2)-Expression. Runx2 ist ein Transkriptionsfaktor der frühen Differenzierungsphase. Die Runx2 - exprimierenden Zellen können sich je nach Zellsignal in Osteoblasten oder Chondrozyten differenzieren und damit 
in die desmale sowie chondrale Osteogenese eingreifen. Anschließend bilden sich mit Hilfe von Runx2-Expression Präosteoblasten. Es kommt außerdem zur Expression von Markerproteinen alkalische Phosphatase (AP) und Kollagen-I (Colla). Im nächsten Schritt bilden sich aus Präosteoblasten Osteoblasten, welche für die Osteoblasten typischen Markerproteine AP, Col1a, Runx2, Osteocalcin (OC), Knochensialoprotein (BSP), Osteopontin und Osterix (Osx) exprimieren. Dabei spielt Osx als osteoblastenspezifischer Transkriptionsfaktor für die Rückkopplung bei der Osteoblastendifferenzierung eine wichtige Rolle. Die Proteine AP, Colla und BSP dienen der Produktion der extrazellulären Matrix. Osteocalcin und Osteopontin dienen der Mineralisation der extrazellulären Matrix (Zhang 2010).

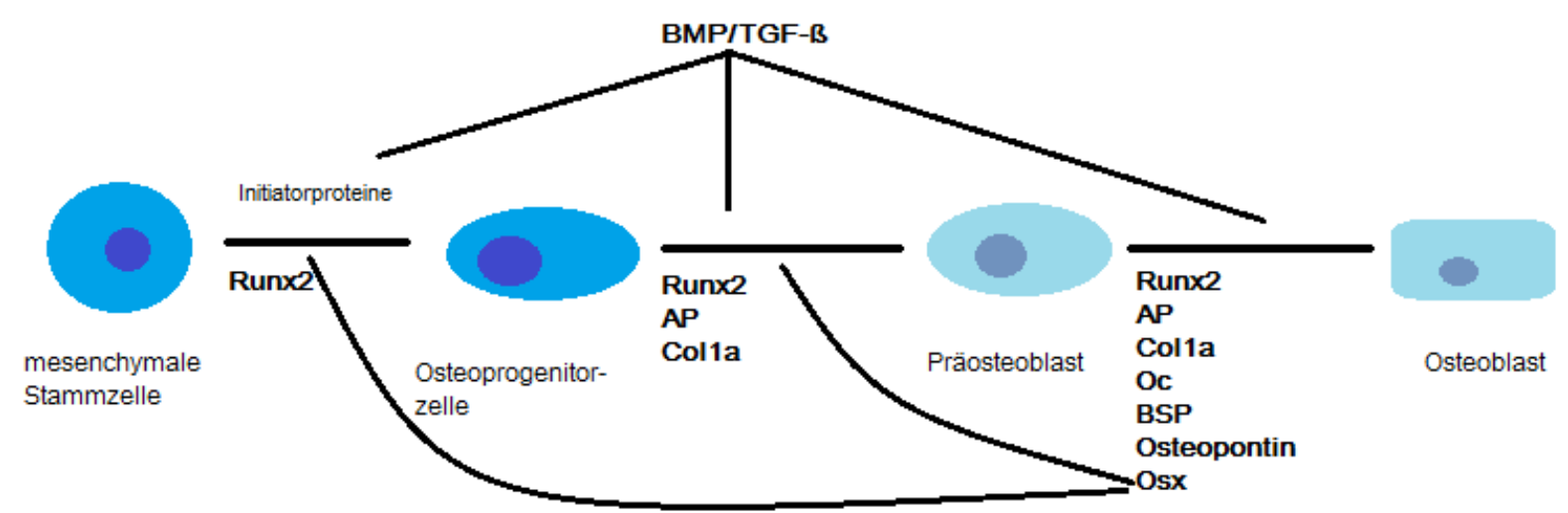

Abbildung 1: Osteoblastendifferenzierung

\subsubsection{Angiogenese}

Für die erfolgreiche Osteogenese ist die Blutversorgung durch Vaskularisation unerlässlich. Bei der chondralen Ossifikation organisiert sich das initial entstandenes Hämatom und neben den Fibroblasten wandern Endothelzellen v.a. aus dem Periost ein. Diese führen zur Bildung neuer Kapillaren.

Der Vaskularisationsprozess (Abbildung 2) wird auf zwei unterschiedlichen Wegen reguliert, zum einen durch Angiopoetin und zum anderen durch VEGF. Die Angiopoetin-abhängige Angiogenese gehört zu der frühen Phase der Frakturheilung. Es bedingt die frühe Gefäßeinsprossung aus dem Periost (Keramaris et al. 2008).

Das hypoxische Areal des Hämatoms und des frühen Frakturkallus aktivieren den Hypoxieinduzierbaren Faktor (HIF). Dieser Transkriptionsfaktor steuert M echanismen zur Anpassung an das Hypoxiegebiet. Eines der Zielgene des HIF ist VEGF (Fan et al. 2014). Das gebildete VEGF führt zur Invasion der Blutgefäße und Umwandlung des gebildeten Knorpels in vaskularisierten Knochen (Keramaris et al. 2008). 


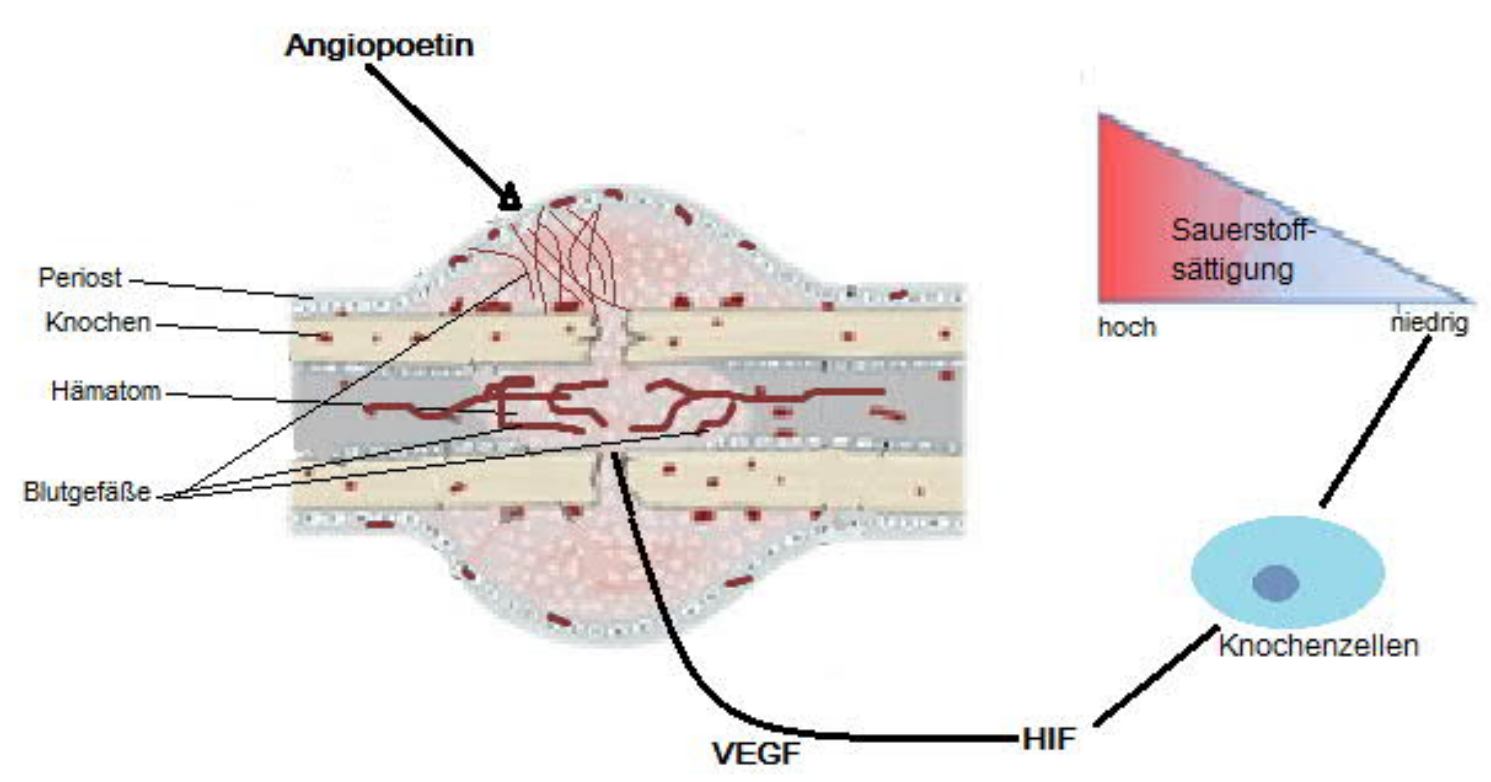

Abbildung 2: Angiogenese

\subsection{Einheilung von Knochentransplantaten}

\subsubsection{Osteoinduktion und Physiologie der Osteoinduktion}

Die Integration des körpereigenen oder körperfremden implantierten Materials im Knochen läuft in einer ähnlichen Reaktion wie die Frakturheilung ab. Die Integration eines Implantates wird in drei Phasen unterteilt: Osteoinduktion, Osteokonduktion, Osteointegration (Albrektsson und Johansson 2001).

Osteoinduktion als Teil der physiologischen Knochenheilung ist verantwortlich für den größten Teil an neu gebildeten Knochen. Es beschreibt einen Prozess bei dem die Osteogenese durch M igration und Differenzierung der M SCs induziert wird.

Durch den operativen Eingriff gelangt Blut an die Implantatoberfläche und die Zerstörung der Knochensubstanz führt zur Freisetzung von gespeicherten Wachstumsfaktoren. Die im initialen Hämatom enthaltenen Thrombozyten sind ebenfalls Quelle für Wachstumsfaktoren (Gradinger und Gollwitzer 2006).

Die TGF-ß-Faktorenfamilie und BMPs transduzieren intrazelluläre Signale über SmadKomplex und mitogen-aktivierte Proteinkinase (M APK)-Kaskade.

Smad ist das humane Homolog von screening for mutans (sma) aus Caenorhabditis elegans (Fadenwurm) und mothers against decapentaplegic (mad) aus Drosophila zur Regulation am Serin/Threonin-Rezeptor.

Smad-M oleküle lassen sich in drei Gruppen unterteilen: rezeptorreguliertes Smad (R-Smad), common-Smad (Co-Smad) und inhibitorisches Smad (I-Smad). Die R-Smad1/5/8 übertragen BM P-Signale, Smad2 und Smad3 sind für die Übermittlung der TGF-ß-Signale verantwortlich. 
Das Co-Smad4 bildet mit R-Smad einen Komplex zur Aktivierung der Transduktion. I-Smad sind Smad6 und Smad7, sie inhibieren zusammen mit Smad-ubiquitination related factors (Smurf) 1 und 2 die Kaskaden.

Die Smad-Kaskade (Abbildung 3) wird durch die Bindung von aktivierten TGF-ß 3 und BM P aus der extrazellulären Matrix an spezifische Rezeptoren in der Zellmembran gestartet. Diese Bindung führt zur Phosphorylierung und Aktivierung der Rezeptorkomplexe, welche die jeweiligen R-Smad-Untereinheiten von TGF- $\$$ und BMP aktivieren. Die aktivierten R-Smad bilden mit Co-Smad einen Komplex, welcher die Signalübertragung in den Zellkern durch Phosphorylierung ermöglicht. Im Zellkern wird die Transkription von Zelgenen Runx2, Osx und Dlx5 gestartet.

Bei der Smad-unabhängigen Kaskade (Abbildung 3) rekrutiert phosphorylierte Kinase 1 (TAK1), welche durch Bindung von Wachstumsfaktoren BMP und TGF-B an Rezeptorkomplexen aktiviert wurde, das TAK1-Bindungsprotein (TAB1) und startet mitogen aktivierte Proteinkinase (MKK) p38- oder den MKK-extracellular-signal-regulated-kinase (ERK)1/2-Signalweg. Nach der Signaltransduktion erfolgt die Aktivierung durch Phosphorylierung und Beginn der Transkription von Zelgenen im Zellkern (Wu et al. 2016).

Die Signalkaskaden werden auf unterschiedliche Art und Weise durch extrazelluläre M atrixproteine, I-Smads, Ubiquitin (Ub)-Proteasom-System, mikroRNAs, Co-Repressoren und Co-Faktoren kontrolliert.

Die extrazellulären Matrixproteine binden kovalent an die Wachstumsfaktoren und beschränken deren Verfügbarkeit zur Bindung an den spezifischen Rezeptoren. Die Abspaltung der Matrixproteine führt zur Bindung und anschließender Aktivierung der Kaskade.

Die I-Smad binden kompetitiv an den Rezeptoren und verhindern damit die Phosphorylierung von R-Smad. Außerdem führen sie zur Degradation von R-Smads durch Rekrutierung von Ubiquitinligasen Smurf1 und Smurf2 über Ubiquitin-Proteasom-System.

Die Stabilität der Weiterleitungsproteine von BMP und TGF- $\$$ wird durch die Ubiquitinenzyme kontrolliert. Smurf als Ubiquitinligase bindet an R-Smad-Rezeptoren, an RSmad-Komplexe, an Runx2, an M KK und führt damit zum Abbau der Proteine. Die Kaskaden werden nicht nur negativ durch das Ubiquitin-Proteasom-System kontrolliert, sondern können über andere Ligasen z.B. Arkadia, die I-Smads als Repressoren abbauen und damit die Signalwege positiv beeinflussen.

Intranukleär wird die Expression und Transduktion von Zielgenen durch mikroRNAs, KoRepressoren und Co-Faktoren beeinflusst. Die Co-Faktoren wie P300 greifen positiv in die Zielgenexpression ein, in dem sie im Chromatin Histone azetylieren.

Die TGF-ßs- und BM P-Signalkaskaden interagieren mit anderen Signalmolekülkaskaden wie z. B. Wingless (Wnt)-Signalweg. Sie initiieren und inhibieren auf unterschiedlichen Stufen die M oleküle (Wu et al. 2016). 


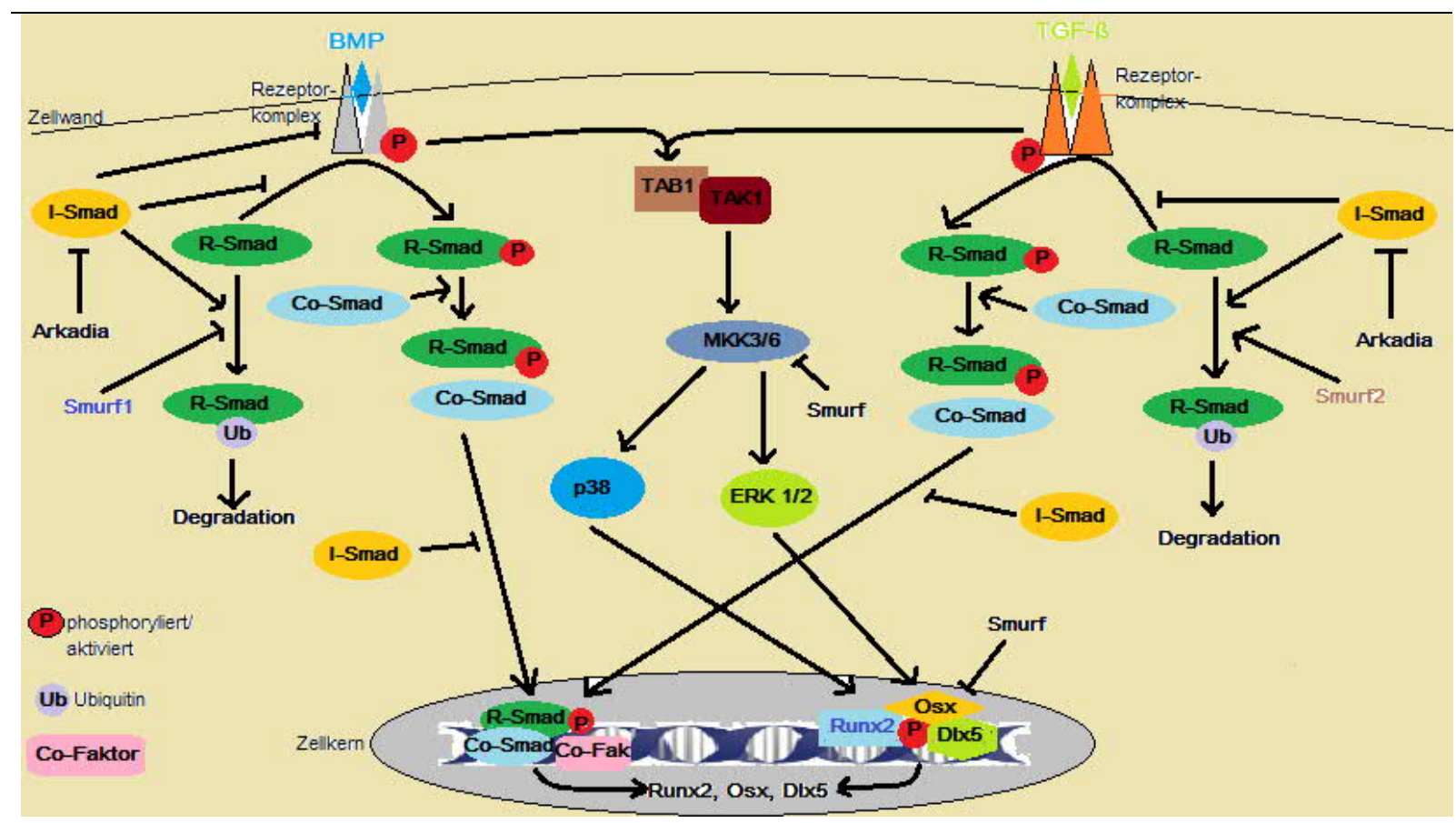

Abbildung 3: Smad-abhängige und Smad-unabhängige Kaskade

\subsubsection{Osteokonduktion}

Beim knöchernen Einbau von Implantaten ist die Osteokonduktivität unerlässlich. Die Osteokonduktion beschreibt einen passiven Prozess, bei dem durch eine mikrostrukturierte und poröse Implantatoberfläche die knöcherne Integration ermöglicht wird. Diese Eigenschaften von Implantaten führen über Fibrinogenabsorption, Thrombozytenaktivierung sowie -adhäsion zum Anhaften von osteoblastären Zellen und zur Knochenbildung an der Implantatoberfläche. Dabei ist die erfolgreich verlaufene Osteoinduktion ein wichtiges Kriterium für Osteokonduktion (Albrektsson und Johansson 2001).

Im Gegensatz dazu dienen resorbierbare Implantate lediglich als dreidimensionale Leitschiene für die Gefäßeinsprossung und Einwanderung von Osteoprogenitorzellen (Gradinger und Gollwitzer 2006).

Entscheidend für die Integration oder Abstoßung von Implantaten ist die biologische Reaktion auf Rauhigkeit, Ladung und chemische Zusammensetzung. Die Absorption von Proteinen an der Implantatoberfläche vollzieht sich unmittelbar nach Implantation durch chemische, dispersive (van-der-Wals) und elektrochemische Wechselwirkung. Dadurch ändern die Proteine ihre Struktur und werden teilweise abgebaut. Die so entstandene Proteinschicht an der Implantatoberfläche bildet das Substrat für die Zellanhaftung über spezifische Ligandrezeptorbindungen. Im Folgenden kommt es zur Auslösung intrazellulärer Kaskaden, welche Auswirkungen auf die Adhäsion, Proliferation und Differenzierung der Zellen haben (Gradinger und Gollwitzer 2006). 


\section{4 Übersicht verschiedener Knochenersatzmaterialien}

Der Verlust von Knochengewebe, der durch Verletzungen, Fehlbildungen, Infektionen oder Tumorerkrankungen entsteht, führt zu einer erhöhten Morbidität sowie zu einer Vielzahl sozioökonomischer Probleme. Der demographische Wandel und die steigenden Patientenerwartungen führen zur steigenden Komplexität der klinischen Szenarien und bieten somit die Voraussetzung zur Entwicklung zuverlässiger Knochendefektheilungsstrategien.

Um verbesserte und reproduzierbare Strategien zur Knochendefektheilung zu schaffen wird aktuell an Stammzellen, innovativen Gerüsten und biologischen Faktoren geforscht (Black et al. 2015).

Zur Knochendefektregeneration wurden verschiedene Verfahren entwickelt. Diese haben als Ziel nicht nur die Wiederherstellung der Form und der Funktion, sondern auch die Verbesserung der Regeneration des Knochengewebes. Es stehen verschiedene Materialien mit unterschiedlichen Eigenschaften bezüglich Funktionswiederherstellung, Biokompatibilität und Stabilität zur Verfügung. Prinzipiell werden synthetische Materialien von biologischen Transplantaten unterschieden. Die durch das Ersatzmaterial begünstigte Knochenheilung soll einen vitalen und belastungsfähigen Knochen hervorbringen.

Theoretisch lassen sich folgende Eigenschaften eines „idealen“ Knochenersatzmaterials formulieren (Rueger 1992): guter knöcherner Ein- und Umbau, chemische und physikalische Stabilität, keine immunologischen Abstoßungsreaktionen, frei von toxischen und mutagenen Nebenwirkungen, Sterilisierbarkeit, einfache Bearbeitung, keine Lagerungs- oder M engenbeschränkung, freie Form- und Größenauswahl, niedrige Kosten.

Es werden jährlich mehr als 2,2 Millionen Knochentransplantationen weltweit durchgeführt. Als aktueller Goldstandard gilt die Transplantation von autogenen Knochen von einer anderen Körperregion des Patienten (Hannik und Arts 2011). Allogene, xenogene und alloplastische Ersatzmaterialien bilden die Alternativen bei der Behandlung von Knochendefekten.

\subsubsection{Autogene Transplantate}

Autogene Transplantate stammen vom gleichen Individuum und werden in vaskularisierte und nicht vaskularisierte Spongiosa-, Monokortikal- und Bikortikaltransplantate eingeteilt. Bei korrekter Operationstechnik (Entnahme und Verpflanzung) stellen die autogenen Transplantate nicht nur das Knochengerüst, sondern enthalten neben osteogenen Vorläuferzellen und Osteoblasten auch Wachstumsfaktoren zur Osteoinduktion (Biberthaler und van Griensven 2017).

Für die Entnahme der Spongiosa eignen sich Beckenkamm, Oberschenkelknochen, lateraler Anteil und distaler Anteil des Schienenbeins. Der kortikale Knochen wird von Wadenbein, Rippen und Beckenkamm entnommen. Bei kleineren Mengen wird zur Defektfüllung 
Knochengewebe aus der Umgebung der Defektzone entnommen (Finkemeier 2002). Die biologischen und mechanischen Eigenschaften der autogenen Transplantate und v.a. das Fehlen der immunologischen Reaktion bieten den größten Vorteil gegenüber den anderen Knochenersatzmaterialien (Biberthaler und van Griensven 2017). Der Nachteil der autogenen Knochenübertragung liegt zum einen an der Verfügbarkeit, da das entnehmbare Knochenvolumen beschränkt ist und zum anderen an der operativen Prozedur der Entnahme des Knochentransplantats. Diese ist nicht nur mit der längeren Narkosezeit, sondern auch mit einer erheblichen M orbidität, wie Schmerzen an der Entnahmestelle, Infektionsrisiko des Donorgebiets und Hämatombildung assoziiert. Auch Frakturen und Verletzung anatomisch wichtiger Strukturen zählen zu Komplikationen der autogenen Transplantation (Wippermann et al. 1997; Gielkens et al. 2008; Biberthaler und van Griensven 2017).

\subsubsection{Allogene Transplantate}

Beim allogenen Knochenersatz handelt es sich um Transplantat von einem Spender der gleichen Spezies. Durch allogene Transplantate können infektiöse Erkrankungenm mit Eregern wie HIV (humanes Immundefizienzvirus), Hepatitisvirus und TSE (transmissible spongiform enzephalopathy, z.B. Creuzfeld-Jakob-Enzephalopathie) übertragen werden. Außerdem sind durch die Fremdspende immunologische Reaktionen zu erwarten. Um dieses Risiko zu begrenzen sind unterschiedliche Verfahren zur Spenderknochenbehandlung entwickelt worden. Das Ziel ist die zellulären Bestandteile zu entfernen und die biomechanischen Eigenschaften zu erhalten (De Long et al. 2007). Dazu stehen zahlreiche chemische und physikalische Verfahren zur Verfügung. Neben der Sterilisation mit Säure, Ethanol, Hitze und Gammastrahlen stehen Kombiverfahren zur Verfügung (Endres et al. 2005).

Die durch die Sterilisation entstandenen Transplantate haben lediglich osteokonduktive Eigenschaften und führen zu zahlreichen Komplikationen wie fehlende Einheilung, verminderte Substanzdichte und erhöhte Frakturneigung (Schmidt-Rohlfing et al. 2009). Aktuell werden v.a. in den USA allogene Transplantate mit Gefriertrocknung angewandt. Es werden dadurch die osteoinduktiven und biomechanischen Eigenschaften des transplantierten Knochens verbessert, was aber mit einem höheren Infektionsrisiko einhergeht.

Im klinischen Alltag haben sich demineralised bone matrix (DBM)-Transplantate durchgesetzt. Es wird durch die Dekalzifizierung demineralisierter Knochenersatz hergestellt, welcher das Infektionsrisiko und Immunogenität deutlich reduziert und verbesserte osteoinduktive Eigenschaften als gefriergetrocknete Transplantate besitzt (Graham et al. 2010). 


\subsubsection{Xenogene Transplantate}

Xenogene Transplantate stammen von einer anderen Spezies und können bovinen, equinen, porcinen und koralinen Ursprungs sein. Es handelt sich um deproteinisiertes Material, welches durch Einwachsen von Knochen in den Gerüstzwischenräumen osteokonduktiv wirkt und resorbiert werden kann (Baldini et al. 2011). Da es sich um Fremdmaterial handelt besteht grundsätzlich die Gefahr der Keimübertragung und der immunologischen Reaktion. Deshalb müssen xenogene Transplantate aufwendigen Sterilisations- und Demineralisierungsverfahren unterworfen werden um das mögliche Infektionsrisiko und Risiko der Abstoßungsreaktion zu senken (Prub und Katthagen 2008).

Eine mögliche Quelle für xenogene Transplantate bieten Meereskorallen. Das sind Kalziumcarbonate, die gute Eigenschaften in der Versorgung kleinerer Knochendefekte zeigen (Piatelli et al. 1997). Eine breite Anwendung finden xenogene bovine Transplantate. Als deproteinisierter spongioser Knochen dient es zum Auffüllen von oralen Knochendefekten (Baldini et al. 2011).

\subsubsection{Alloplastische Implantate}

Zu den alloplastischen Knochenersatzmaterialien gehören Keramiken aus Kalziumphosphat und Kalziumsulfat, Polymere und bioaktive Gläser. Es sind biokompatible und zum Teil resorbierbare Stoffe, die nicht nur am ortsständigen Knochen anwachsen sondern auch komplett von neu gebildeten Knochen ersetzt werden können. Sie dienen als Matrix für osteogene Zellen und unterstützen deren Proliferation und Differenzierung (Lane et al. 1999; Zizzari et al. 2016).

Für das erfolgreiche Einheilen der alloplastischen Materialien ist nicht nur die chemische Zusammensetzung entscheidend, vielmehr spielen die Feinstruktur, die Geometrie und mechanische Stabilität eine große Rolle (Zzzzari et al. 2016).

Zu den zwei häufig verwendeten Keramiken zählen Trikalziumphosphat (TCP) und Hydroxylapatit (HA). Auf Grund ihrer Biokompatibilität können sie in Knochen umgewandelt werden, sind druckfest jedoch spröde und nicht zugbelastungsstabil (De Long et al. 2007).

Das TCP hat sich im klinischen Alltag z.B. bei Sinusbodenaugmentationen oder zum präimplanteren Auffüllen der Extraktionsalveolen (ridge preservation) bewährt. Es zeigt einen guten Knochendurchbau mit zeitgerechtem TCP-Abbau nach 6 bis 18 Monaten. Im Vergleich wurde das HA nach 10 Jahren in situ nachgewiesen (Fillingham und Jacobs 2016; Zizzari et al. 2016).

Das HA zeigt gute osteokonduktive Eigenschaften und eignet sich als Trägerstoff für osteoinduktive Proteine (Noshi et al. 2000).

Bioaktive Gläser sind vielseitig einsetzbar und haben osteokonduktive Eigenschaften. Sie eignen sich nicht nur als Knochenersatzmaterial sondern dienen auch als Träger für Medikamente und eignen sich für den Einsatz in der Weichgewebschirurgie. Die bioaktiven Gläser haben eine niedrige Druckfestigkeit und hohe Bruchneigung. Um diesen 
entgegenzuwirken werden die Herstellungsmethoden der bioaktiven Gläser verändert. Die Integration in den Knochen vollzieht sich nach dem Kontakt der bioaktiven Gläser mit dem Blut. Es bildet sich eine Doppelschicht aus Siliziumgel und Kalziumphosphat, woran die Proteine des umgebenden Knochens binden und zum chemischen Verbund führen. Die chemisch veränderten bioaktiven Gläser mit verbesserten Eigenschaften finden nicht nur in der Wirbelsäulenchirurgie sondern auch in der Gesichtsschädelrekonstruktion Verwendung (Montazerian und Dutra Zanotto 2016).

Polymere Knochenersatzmaterialien haben ein breites Einsatzspektrum und werden in natürliche und synthetische Materialien eingeteilt. Die meisten zeigen gute mechanische Eigenschaften, sind biokompatibel und resorbierbar. Zu den Polymeren gehören Polyglykolide, Polylaktide, Polycaprolaktone und Biopolymere wie Chitosan, Kollagen und Alginat. Biopolymere bestehen aus vielen verschiedenen Bestandteilen. Sie werden mit synthetischen Polymeren, bioaktiven Gläsern, Keramiken und Wachstumsfaktoren kombiniert (Jahan und Tabrizian 2016). Das synthetische Polymer Polylaktid wird zum Teil aus Milchsäure aufgebaut. Diese wird beim Abbau des Polylaktids frei und bewirkt eine lokale Entzündungsreaktion. Deshalb wird den Polylaktid meist ein neutralisierender Stoff wie Kalziumkarbonat hinzugefügt (M einig 2010).

Ungeachtet der Fortschritte und der Ergebnisse in der Knochenersatzmaterialforschung gilt bei den meisten Chirurgen der autogene Knochen als erste Wahl für die Defektversorgung. Für den Einsatz der kombinierbaren Materialien, die osteokonduktive, -induktive und -gene Eigenschaften besitzen, fehlen kontrollierte, randomisierte und prospektive Studien (De Long et al. 2007).

\subsection{Wachstumsfaktoren}

Die Geweberegeneration ist weitgehend von der Zell-Signalgebung abhängig, die durch zelluläre Wechselwirkungen mit Wachstumsfaktoren vermittelt wird (Almubarak et al. 2016). Wachstumsfaktoren sind polypeptide Moleküle, die an spezifische Rezeptoren der Zielzelle binden und damit eine Antwortreaktion auslösen (Rassow et al. 2008). Mit Hilfe von Wachstumsfaktoren werden mesenchymale Stammzellen rekrutiert und die Osteoblastogenese induziert. Sie nehmen somit Einfluss auf die Migration, Proliferation und Differenzierung der Zellen in der Osteo- und Chondrogenese (Almubarak et al. 2016).

In den letzten Jahren wurde eine Vielzahl an Wachstumsfaktoren beschrieben, die Einfluss auf die Osteogenese nehmen. Zu den bekanntesten gehören transforming growth factor beta (TGF- $\beta$ ), bone morphogenetic proteins (BMPs), vascular endothelial growth factor (VEGF), platelet- derived grow th factor (PDGF), und fibroblast growth factor (FGF). 


\subsubsection{Gefäßneubildung}

Die Gefäßneubildung läuft in mehreren Schritten ab und wird von angiogenetischen Faktoren wie Fibroblasten-Wachstumsfaktor (FGF), Tumornekrose-Faktor alpha (TNF $\alpha$ ), Transformations-Wachstumsfaktor alpha und beta (TGF $\alpha$, B) und VEGF kontrolliert. VEGF als bekanntester und wichtigster Faktor beeinflusst die Physiologie und Pathologie der Gefäßnneubildung. Es induziert die Gefäßneubildung im Sinne der Vaskulo- und Angiogenese (Cui et al. 2013). Bei der Angiogenese werden aus vorhandenen Kapillaren neue Kapillaren durch Sprossung der neuen Zellen aus den alten gebildet. Die Vaskulogenese ist demgegenüber die Entwicklung von Gefäßzellen und Gefäßen aus endothelialen Vorläuferzellen.

\subsubsection{VEGF}

Die VEGF-Familie besteht aus 6 Mitgliedern: VEGF-A, -B, -C, -D, -E und PlazentaWachstumsfaktor. VEGF kann von vielen unterschiedlichen Zellen, wie Muskelzellen, Perizyten, Podozyten, Osteoblasten, Chondrozyten, Pneumozyten, Hepatozyten und Endothelzellen exprimiert werden (Hu und Olsen 2017). Dabei ist VEGF-A das Startprotein für die Angiogenese. Es bindet an Tyrosinkinaserezeptor VEGFR2, führt zu dessen Phosphorylierung und Aktivierung der Signalkaskade. Mit Hilfe anderer Signalmoleküle, die an den aktivierten Rezeptor binden wird die Angiogenese und Funktion der Endothelzellen kontrolliert.

Die VEGF-Rezeptoren werden nicht nur von Osteoblasten, mesenchymalen Stammzellen und Endothelzellen exprimiert sondern auch Lymphozyten und Osteoklasten können das VEGF direkt binden. Damit kann das VEGF auf die M ineralisation in Osteoprogenitorzellen Einfluss nehmen, die Aktivität der alkalischen Phosphatase ändern sowie die Migration und Differenzierung von Osteoblasten beeinflussen (Cui et al. 2013).

Durch die Blockade der VEGF-Rezeptoren konnte die Rolle des VEGF bei der Frakturheilung und Knochenmineralisierung in Tierexperimenten nachgewiesen werden (Keramaris et al. 2008).

\subsubsection{BMP}

1965 beobachtete Marshall Urist im Rahmen eines Tierversuches nach Implantation von demineralisiertem, allogenem Knochen in Muskelgewebe, dass die extrazelluläre Matrix des Knochens die Fähigkeit enthält, eine neue Knochenbildung zu induzieren. Diese Substanz wurde später aus Knochensubstanz isoliert und als bone morphogenetic protein (BMP) bezeichnet. Seit dem wurden BMP's ausführlich untersucht (Elliot Carlisle und Fischgrund 2005). 
Dabei handelt es sich um aus zwei identischen Polypeptidsträngen aufgebautes Protein. Es sind mehr als 15 unterschiedliche BM P's bekannt, wobei BM P-2 und BM P-7, als am besten untersuchte Cytokine bereits in rekombinanter (recombinant human, rh) Form in klinischer Anwendung sind. Während rhBM P-2 die mesenchymalen Stammzellen zur Differenzierung veranlasst, scheint rhBM P-7 auf reifere Knochenvorläuferzellen zu wirken (Valderrabano et al. 2009). Mehrere Studien haben gezeigt, dass weitere BMP's $(4,6,9)$ eine hohe osteoinduktive Potenz besitzen und unterschiedliche Rezeptoren an den knochenbildenden Zellen aktivieren (Murata et al. 1999; Deckers et al. 2002; Elliot Carlisle und Fischgrund 2005; Giannoudis und Einhorn 2009; Cui et al. 2013).

Es herrscht keine Einigkeit über die verwendbaren Konzentrationen zur besseren Knochenregeneration. Sie schwanken zwischen $0,1 \mu \mathrm{g}$ und $100 \mathrm{mg}$ in Tierversuchen (Gothard et al. 2014). Außerdem inhibieren die BM P's die Reifung von Osteoklasten in dem sie die Produktion von Osteoprotegerin auf den Osteoblasten stimulieren und das Osteoprotegerin die Differenzierungsfaktoren für Osteoklasten bindet (Wan et al. 2001). Trotz der Fortschritte im Verstehen der Aktivität und Effektivität der BMP's bleiben viele Fragen unbeantwortet (Cui et al. 2013).

\subsection{Trägersysteme für Wachstumsfaktoren}

Die Anwendung von Wachstumsfaktoren in der regenerativen Medizin erfordert nicht nur beste strukturelle und mechanische Eigenschaften der Trägermaterialien, sondern auch die Möglichkeit Wachstumsfaktoren an den Träger zu binden und möglichst kontrolliert bzw. verzögert freizusetzen (Schliephake 2010).

Ein adäquates Trägersystem muss neben biologischer Nachahmungsfähigkeit, biologisch abbaubar, biokompatibel und mechanisch stabil sein. Im besten Fall sollte das Trägermaterial ohne das Hervorrufen einer immunologischen Reaktion während der Gewebsintegration und ohne Entstehung von toxischen Abbauprodukten die dreidimensionale Struktur des Wirtsgewebes kopieren. Biomechanisch spielt bei der Herstellung eines Idealen Trägermaterials die Elastizität, Zerreißfestigkeit und Thermostabilität eine wichtige Rolle (Gothard et al. 2014).

Es werden anorganische und organische Trägersysteme unterschieden. Die anorganischen Träger können auf Metall (Titanimplantate) oder Mineral (Knochenersatzmaterialien) basierend sein. Wobei die Bedingungen und die Temperaturen während des Herstellungsprozesses lediglich eine Oberflächenkopplung der Wachstumsfaktoren erlauben. Die organischen Trägermaterialien sind natürlichen oder synthetischen Ursprungs. Sie bieten auf Grund variabler Abbaueigenschaften und chemischer Modifikationen ein höheres Potenzial zu unterschiedlichen Bindung von Wachstumsfaktoren. Neben Seide und Chitosan hat das Kollagen als Vertreter der natürlichen organischen Trägermaterialien als Einziger die Zulassung zur klinischen Anwendung in Verbindung mit BMP. Zu den synthetischen organischen Trägerstoffen zählen die Polymere von Poly- $\alpha$-Hydroxysäuren mit Polymilchsäure (Polylaktid) und Polyglykolsäure. In zahlreichen präklinischen Studien konnte 
vielversprechende kontrollierte bzw. verzögerte Wachstumsfaktorfreisetzung gezeigt werden, welche klinische Umsetzung erfordert (Schliephake 2010).

Eine Vielzahl von M aterialien wurde entwickelt um idealerweise die extrazelluläre $M$ atrix mit ihren Einfluss auf die Knochenregeneration zu imitieren oder zu inkorporieren. Dies bedeutet, dass ein erfolgreiches Trägersystem stadiengerechte Freigabe von angiogenen und osteogenen Faktoren enthält und dieses in physiologischer Reihenfolge abläuft (Bayer et al. 2015).

Die synthetisch hergestellten Träger können im Gegensatz zu biologischen Trägersystemen ein erhöhtes $M a ß$ an Materialeigenschaftenkontrolle aufweisen. Vor allem Polymere, die durch Begasung, Gießen und Vernetzung hergestellt werden, können durch Kombination unterschiedlicher Zerfallseigenschaften unterschiedliche Freigabeprofile erfüllen (Bayer et al. 2015). So hat die Gruppe um Kanczler 2010 ein signifikant erhöhtes enchondrales Wachstum in Knochendefekten durch die Kombination von schnell degradierbaren Alginat mit VEGF und verzögerter Freigabe von BM P-2 aus Polylaktid in einem durch superkritische Begasung entstandenen Trägern festgestellt (Kanczler et al. 2010). Andere Autoren nutzten die Durchmischung von unterschiedlich degradierbaren, mit Wachstumsfaktoren beladenen Polymermikropartikeln und erreichten eine zeitversetze Faktorenfreisetzung bei besserer Kalzifizierung in vitro (Richardson et al. 2001; Basmanav et al. 2008). Andererseits ist festgestellt worden, dass beim alleinigen Einsatz von Polymeren als Trägermaterial wichtige Trägereigenschaften, wie Osteokonduktivität und strukturelle Integrität beeinträchtigt werden. Das Kalziumphosphat erfüllt die Eigenschaft der Ostekonduktivität und kann mit inkorporierten, wachstumsfaktorbeladenen Polymermikropartikeln druckfestes, biologisch abbaubares Trägermaterial sein (Bayer et al. 2015).

Eine andere M ethode zur kontrollierten Wachstumsfaktorfreisetzung ist die Herstellung von Trägersystemen, die aus unterschiedlich degradierbaren und mit Faktoren beladenen Kernmaterial und Schalenmaterial bestehen. Dabei ist die Freisetzung der im Kern enthaltenen Wachstumsfaktoren von den Zerfalls- und Diffusionseigenschaften des Schalenmaterials abhängig (Perez und Kim 2015).

Das nächste Konzept zur Herstellung von synthetischen Trägersystemen beruht auf der Schichtung von Gerüstmaterialien mit unterschiedlichen Härtungseigenschaften, die durch das Aushärten jeder Schicht vor dem Einbringen der nächsten und durch die unterschiedliche Vernetzung ermöglicht wird. Dabei besteht der Unterschied zu KernSchalen-Gerüsten in der Verwendung von mehr als zwei nebeneinander liegenden Trägermaterialien und der Beschichtung eines nicht mit den Faktoren beladenen Kernmaterials. Mögliche Nachteile dieses Gerüstmodells können bei der Herstellung von zu dicken Schichten eine fehlende Interaktion zwischen den jeweiligen Wachstumsfaktoren für Knochen-/Gefäßneubildung und eine vorzeitige Freisetzung bei fehlender Barriere sein. Der einzigartige Vorteil des Schichtgerüstes besteht in der Herstellung von dünneren Trägern, die als M antel für andere Materialien dienen können (Bayer et al. 2015).

Die Herstellung von biologischen Trägergerüsten stellt eine Alternative zu synthetischen Materialien dar. Dazu gehört zum Beispiel autolog oder alllogen hergestellter plättchenreicher Plasma (platelet-rich plasma)-Träger, welcher bereits mehrere wichtige 
angiogene und osteogene Wachstumsfaktoren enthält, jedoch auf Grund fehlender mechanischer Stabilität mit anderen stabilen Trägern kombiniert werden muss. Dabei ist die Kontrolle über die Wachstumsfaktorenfreisetzung und die enthaltene Konzentration der Faktoren in den hergestellten Trägern schwer steuerbar. Eine andere Alternative sind gentechnisch hergestellte Träger, bei denen viral und nicht viral hergestellte Wachstumsfaktorgene kodiert und in ein Gerüst eingebaut werden. Sie bieten neben anhaltender lokaler Wachstumsfaktorexpression durch den Einbau von Promotoren ein hohes Maß an Freisetzungskontrolle. Jedoch ist die Gentechnik in der klinischen Anwendung auf Grund von Sicherheitsbedenken nur begrenzt umsetzbar (Bayer et al. 2015). Die dritte Technik zur Herstellung von biologischen Trägern beruht auf der Verwendung von kleinen Molekülen, die eine Masse unter 1000 Dalton haben und zu klein sind um eine unerwünschte immunologische Reaktion hervorzurufen. Neben der hohen thermischen Stabilität benötigt es keine strukturelle Integrität höherer Ordnung. Die größte Herausforderung bei diesem Trägersystem besteht in der Kontrolle über zeitliche und räumliche Wirkung der Kleinstmoleküle um unerwünschte Wirkung in anderen Geweben zu verhindern (Laurencin et al. 2014).

\subsection{Freisetzungsphysiologie von Wachstumsfaktoren}

Die Untersuchungen der Einzelapplikation von Wachstumsfaktoren vor allem des BM P-2 sind umfangreich und zeigen uns, dass dieser auf zellulärer Ebene nicht nur wichtiger Auslöser für die Osteoblastenproliferation ist, sondern auch zur Differenzierung von osteoblastären mesenchymalen Stammzellen führt. Die Untersuchungen in menschlichen Körper führen in den meisten Fällen zur Induktion von mineralisiertem Gewebe, jedoch gibt es große Unterschiede im Erfolg der humanen Reaktion auf die BM P-Applikation. Diese Unterschiede können durch die Desorption von Proteinen bei fehlenden Diffusionshindernissen erklärt werden. Ein weiterer limitierender Faktor stellt die Gefäßnetzbildung durch die alleinige BMP-2 Applikation dar. Die daraufhin untersuchten angiogenen Wachstumsfaktoren wie VEGF in Einzelapplikation führten zur keiner signifikant erhöhten Knochenbildung in ektop oder orthotop implantierten Trägern. (Bayer et al. 2015).

Für die erfolgreiche Unterstützung der Knochenregeneration durch Wachstumsfaktoren ist die Freisetzung mit abnehmender Geschwindigkeit, sog. slow release von angiogenen, osteogenen und chondrogenen Faktoren entscheidend (Gothard et al. 2014). Um die rasche Diffusion und Absorption der Wachstumsfaktoren nach der Applikation zu verhindern werden diese auf Trägermaterialien appliziert und können somit durch kontrollierte Freisetzung die physiologische Geweberegeneration am besten unterstützen (Takaoka et al. 1991).

Die Kombination von BMP und VEGF hat abhängig von deren Konzentrationen einen synergistischen Effekt auf Knochenbildung und Knochenheilung. Im Gegensatz zur Einzelapplikation steigert die Kombination der Wachstumsfaktoren die Knochenregeneration in Critical-size-Defekten. Sehr hohe Dosen von VEGF und VEGF/BMP-Kombination In-vivo- 
und In-vitro-Studien haben einen negativen Effekt auf die Mineralisierung (Cui et al. 2013). Dies lässt vermuten, dass die Steigerung der Knochenheilungsrate durch VEGF-Zugabe nicht nur die Angiogenese und Vaskulogenese beeinflusst, sondern einen direkten Effekt auf die Stammzellen und deren Differenzierung hat (Li et al. 2009). Der synergistische Effekt der Wachstumsfaktorenkombinationen ist abhängig von der zeitlichen Freisetzung aus dem Trägermaterial und der verwendeten Dosis (Kempen et al. 2010). Bayer und Kollegen stellten in ihrer zusammenfassenden Arbeit fest, dass zwar anfänglich die Gewebevermehrung durch duale Freisetzung von angiogenen und osteogenen Faktoren in den meisten Studien nachweisbar ist, dies jedoch nicht immer zur langfristig signifikanten Verbesserung im Gegensatz zur BMP-Einzelapplikation führt. Diese Ergebnisse deuten einerseits auf noch nicht in Gänze verstandenen Interaktionen zwischen Vielzahl der Zelltypen andererseits zu welchen Zeitpunkten die jeweiligen Faktoren im natürlichen Knochenheilungsprozess präsentiert werden (Bayer et al. 2015).

Nachwievor herrscht keine Einigkeit über die ideale Wachstumsfaktorapplikation auf den Trägermaterialien und über die verwendbaren Konzentrationen der Wachstumsfaktoren (Schliephake et al. 2007).

Es gibt Versuche Polylaktid-Träger durch Begasung mit Wachstumsfaktoren zu beimpfen. Dabei werden Wachstumsfaktoren durch Kohlendioxid-Hochdruckverfahren in das Trägermaterial eingebracht (Tschakaloff et al. 1996).

Andere versuchen die Wachstumsfaktoren in die Poren des Trägermaterials zu saugen, um eine verzögerte Freisetzung aus dem $M$ aterial zu ermöglichen. Dies führte jedoch zu einer schnellen Entladung und einer kurzen osteoinduktiven Wirksamkeit von 48 Stunden (Kanematsu et al. 2004). In weiteren Versuchen konnte durch die Begasung von Trägermaterialien die Freisetzung von Wachstumsfaktoren abhängig von der Konzentration bis zum 27. Tag erfolgen (Schliephake et al. 2007).

\subsection{Fazit und Zielsetzung der Arbeit}

Die Versorgung knöcherner Defekte, die durch Traumata, Fehlbildungen und Tumore entstanden sind stellt im klinischen Alltag eine große Herausforderung dar. Trotz neuer Therapieansätze zur Behandlung von Critical-size-Defekten ist keines der aktuell im klinischen Altag verwendeten Knochenersatzmaterialien in der Lage alle geforderten Eigenschaften vollständig zu erfüllen (Egol et al. 2015).

Neue Ansätze zur Verbesserung der Knochenregeneration durch die Kombination der Wachstumsfaktoren BMP und VEGF konnten eine Steigerung der Differenzierung und des Wachstums von osteogenen Zellen auf Trägermaterialien zeigen (Xiao et al. 2011). Es ist jedoch wichtig die Freisetzung der Wachstumsfaktoren aus dem Trägermaterial kontrolliert, im Sinne eines slow release, zu gestalten, da die langanhaltende Verfügbarkeit für den klinischen Effekt entscheidend ist (Schliephake et al. 2007). Es gibt keine Einigkeit über die notwendigen Konzentrationen der Wachstumsfaktoren für den bestmöglichen Knochenregenerationseffekt (Gothard et al. 2014). 
Im Rahmen dieser Arbeit haben wir uns mit der Möglichkeit zur Verbesserung der Knochenregeneration in vivo durch den Einsatz der Kombinationen von VEGF und BMP in unterschiedlichen Dosierungen aus den Polylaktid/Kalziumkarbonat(PDLL/ $\mathrm{CaCO}_{3}$ )Komposit-Scaffolds beschäftigt. Die neu gebildete Knochenmasse wurde mit dentalen Volumentomographien (DVT) untersucht. 


\section{Material und Methoden}

\subsection{Implantatherstellung}

\subsubsection{Wachstumsfaktoren}

In dieser Studie verwendeten wir den rekombinanten humanen Wachstumsfaktor BMP (rhBMP-2, RELIAtech GmbH, Wolfenbüttel), der mittels Escherichia-coli-Bakterienkultur gewonnen wurde (Vallejo et al. 2002). Die Wirksamkeit des rhBM P-2 wurde bereits Ende der 90er Jahre nachgewiesen (Murata et al. 1999). VEGF verwendeten wir ebenfalls in rekombinanter Form, mittels Escherichia coli-Bakterienkultur gewonnen (rhVEGF-165, RELIAtech $\mathrm{GmbH}$, Wolfenbüttel) und auch hier gibt es eine nachgewiesene Wirksamkeit (Drake et al. 2006).

\subsubsection{Implantat}

Das Implantat wurde als Komposit-Scaffold aus vier Teilen Poly(D, L)-Laktid (PDLLA) und einem Teil Kalziumkarbonat $\left(\mathrm{CaCO}_{3}\right)$ hergestellt. Das Trägermaterial wurde in wässriger Lösung angesetzt, mit Rotorschüttler durchmischt und bei $-70^{\circ} \mathrm{C}$ eingefroren. Danach erfolgten die Schockgefrierung mittels Stickstoff und die Gefriertrocknung über Nacht. Die Lyophilisierung wurde bei $-15^{\circ} \mathrm{C}$ bis $-20^{\circ} \mathrm{C}$ in einer Vakuumkammer und bei $-85^{\circ} \mathrm{C}$ in einem Eiskondensator über acht Stunden durchgeführt (Fa. Christ Alpha 2-4, Osterode am Harz). Das Lyophilisat wurde in 8x3 mm Polytetrafluorethylen (PEF) Hohlformen eingebracht. Die Kohlendioxidbegasung der Scaffolds erfolgte durch KLS-Martin (Fa. KLS-Marin, Tuttlingen) bei $37^{\circ} \mathrm{C}$ und 76,1 bar über zwei Stunden. Präoperativ erfolgte die Verkleinerung der nativen Scaffolds mittels einer Lochstanze auf $5 \mathrm{~mm}$ Durchmesser (Abbildung 4). 


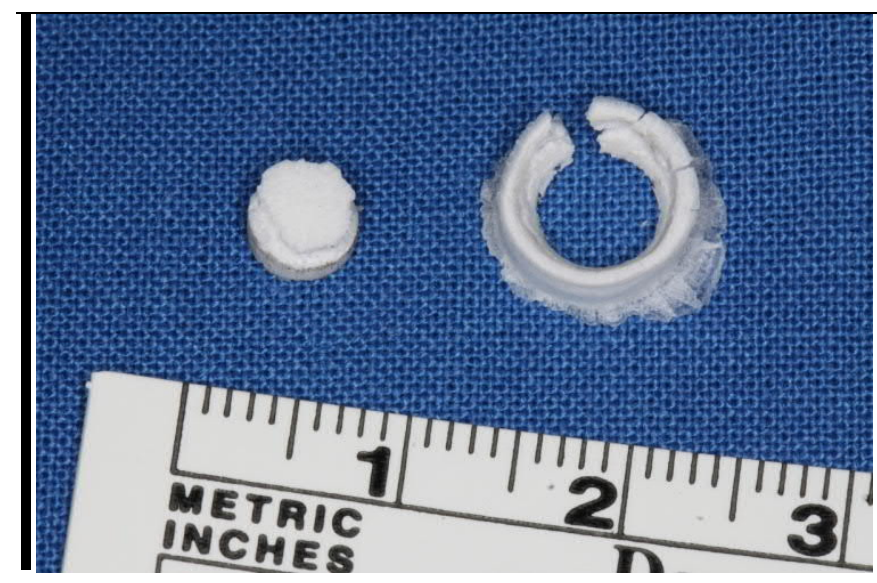

Abbildung 4: Das fertige Scaffold nach Größenanpassung mit der Lochstanze

\subsection{Versuchstiere und Tierhaltungsbedingungen}

Als Versuchstiere wurden männliche Wistar-Ratten verwendet (Rattus norvegicus, Charles River Deutschland GmbH, Sulzfeld; Tierversuchsgenehmigungsnummer: 33.9-42502-0410/0223). Die Haltung und Behandlung der Tiere erfolgte über den Versuchszeitraum im zentralen Tierlabor der Georg-August-Universität Göttingen. Die Versuchstiere wurden in Macralon-Käfigen Typ IV (EHRET Labor- und Pharmatechnik GmbH und Co. KG, Emmendingen) untergebracht, welche als Einstreu Holzfaser-Granulat (Lingucel ${ }^{\circledR}$ Select, L. Rettenmaier, Wilburgstetten) hatten. Der Wechsel der Einstreu wurde wöchentlich durchgeführt.

Die Ratten waren am Operationstag drei bis sechs Monate alt und 300 bis 600 Gramm schwer. Präoperativ wurden je fünf Tiere pro Käfig gehalten, postoperativ drei Tiere pro Käfig. Die Ratten hatten einen Hell-Dunkel-Wechsel von 12 Stunden, die Raumtemperatur betrug $20-24^{\circ} \mathrm{C}$ bei einer Raumluftfeuchte von 50-60\%. Die Fütterung erfolgte mit Nagerfutter (Ssniff Haltungsfutter, 10mm Pellets, ad libitum) und Leitungswasser.

\subsection{Einteilung und Größe der Tiergruppen}

In jede Gruppe wurden 18 Tiere, zu je 6 Tieren für 2 Zeitpunkte 4 und 13 Wochen eingeordnet. 
Tabelle 1: Einteilung der Versuchstiergruppen

\begin{tabular}{|c|c|c|c|c|c|c|}
\hline Einzeldosierung & Gruppe 1 & Gruppe 2 & Gruppe 3 & Gruppe 4 & Gruppe 5 & Gruppe 6 \\
\hline $\begin{array}{l}\text { Untergruppe A } \\
4 \text { Wochen }\end{array}$ & $\begin{array}{l}\text { Blank } \\
+24 \mu \mathrm{g} \\
\text { BM P }\end{array}$ & $\begin{array}{l}\text { Blank } \\
+48 \mu g \text { BM P }\end{array}$ & $\begin{array}{l}\text { Blank } \\
+96 \mu g \text { BM P }\end{array}$ & $\begin{array}{l}\text { Blank+0,24 } \\
\mu \mathrm{g} \text { VEGF }\end{array}$ & $\begin{array}{l}\text { Blank+1,5 } \\
\mu g \text { VEGF }\end{array}$ & 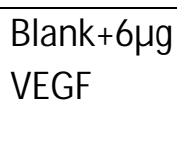 \\
\hline $\begin{array}{l}\text { Untergruppe B } \\
13 \text { Wochen }\end{array}$ & $\begin{array}{l}\text { Blank } \\
+24 \mu \mathrm{g} \\
\text { BM P }\end{array}$ & $\begin{array}{l}\text { Blank } \\
+48 \mu g \text { BM P }\end{array}$ & $\begin{array}{l}\text { Blank } \\
+96 \mu g \text { BM P }\end{array}$ & $\begin{array}{l}\text { Blank+0,24 } \\
\mu \mathrm{g} \text { VEGF }\end{array}$ & $\begin{array}{l}\text { Blank+1,5 } \\
\mu \mathrm{g} \text { VEGF }\end{array}$ & 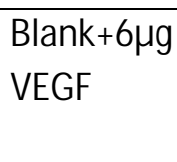 \\
\hline
\end{tabular}

\begin{tabular}{|c|c|c|c|c|c|}
\hline Kombinationen & Gruppe 7 & Gruppe 8 & Gruppe 9 & Gruppe 10 & Gruppe 11 \\
\hline $\begin{array}{l}\text { Untergruppe A } \\
4 \text { Wochen }\end{array}$ & $\begin{array}{l}\text { Blank } \\
+1,5 \mu \mathrm{g} \text { VEGF } \\
+24 \mu \mathrm{g} \text { BM P }\end{array}$ & $\begin{array}{l}\text { Blank } \\
+6 \mu \mathrm{g} \text { VEGF } \\
+24 \mu \mathrm{g} \text { BM P }\end{array}$ & $\begin{array}{l}\text { Blank } \\
+1,5 \mu \mathrm{g} \text { VEGF } \\
+48 \mu \mathrm{g} \text { BM P }\end{array}$ & $\begin{array}{l}\text { Blank } \\
+6 \mu \mathrm{g} \text { VEGF } \\
+48 \mu \mathrm{g} \text { BM P }\end{array}$ & Leer \\
\hline $\begin{array}{l}\text { Untergruppe B } \\
13 \text { Wochen }\end{array}$ & $\begin{array}{l}\text { Blank } \\
+1,5 \mu \mathrm{g} \text { VEGF } \\
+24 \mu \mathrm{g} \text { BMP }\end{array}$ & $\begin{array}{l}\text { Blank } \\
+6 \mu \mathrm{g} \text { VEGF } \\
+24 \mu \mathrm{g} \text { BM P }\end{array}$ & $\begin{array}{l}\text { Blank } \\
+1,5 \mu \mathrm{g} \text { VEGF } \\
+48 \mu \mathrm{g} \text { BM P }\end{array}$ & $\begin{array}{l}\text { Blank } \\
+6 \mu \mathrm{g} \text { VEGF } \\
+48 \mu \mathrm{g} \text { BM P }\end{array}$ & Leer \\
\hline
\end{tabular}

\subsection{Operatives Vorgehen}

Die Operationen an den Versuchstieren wurden allesamt im Operationssaal der zentralen tierexperimentellen Einrichtung der Universitätsmedizin Göttingen durchgeführt.

\subsubsection{Narkose}

Nach der Feststellung des Ausgangsgewichts wurden die Tiere mit Medetomin (Domitor ${ }^{\circledR}$, $60 \mu \mathrm{g} / \mathrm{kg}$ Körpergewicht) und Ketamin (Ketavet ${ }^{\circledR}, 14 \mathrm{mg} / \mathrm{kg}$ Körpergewicht) über einen rechtsseitigen intraperitonealen Zugang mit Tiefenstop narkotisiert. Durch das Setzen eines Schmerzreizes im Interdigitalraum erfolgte die Überprüfung der Narkosetiefe. Die Augen wurden mit Bepanthen-Augensalbe abgedeckt.

\subsubsection{Operation}

Nach Rasur, Reinigung und Desinfektion des Operationsgebietes wurden die Ratten auf der Seite gelagert. Um eine Auskühlung der Tiere zu vermeiden wurden Wärmekissen verwendet. Die Schmerzreduktion erfolgte durch subkutane präoperative Injektion mit Buprenorphin (Temgesic ${ }^{\circledR}, 0,05 \mathrm{mg} / \mathrm{kg}$ Körpergewicht). Die Operationsdauer betrug für jedes Tier etwa 45 M inuten. 
Zur Darstellung des Unterkiefers wurde ca. $1 \mathrm{~cm}$ langer submandibulärer Hautschnitt (Abbildung 5a) durchgeführt. Nach der Präparation durch den Musculus masseter unter Schonung der nervalen Strukturen und des Ausführungsganges der Glandula parotis wurde das Weichgewebe lingual und bukkal vom Unterkieferrand mittels eines Raspatoriums abgelöst sowie das Gewebe nach oben mobilisiert. Anschließend wurde im Bereich des Processus angularis ein standardisierter Critical-size-Defekt von $5 \mathrm{~mm}$ im Durchmesser, bikortikal im Bereich des aufsteigenden Unterkieferastes unter strenger Aussparung der Nervenebene gesetzt (Abbildung 5b).

In den Gruppen 1-10 wurde auf einer Unterkieferseite ein PDLLA/CaCO ${ }_{3}$-Komposit-Scaffold nach dem Auftropfen der entsprechenden Wachstumsfaktordosis im press-fit-Verfahren eingesetzt. Nachfolgend verschloss man die Wunden mehrschichtig mit Vicryl der Stärke 4. In Gruppe 11 wurde auf einer Seite ein PDLLA/CaCO 3 -Komposit-Scaffold ohne M edikamentenzusatz mit Press-fit-Verfahren eingebracht (Abbildung 5c). Auf der Gegenseite wurde der Defekt ohne weitere Therapie belassen. Hier erfolgte ebenfalls der mehrschichtige Wundverschluss mit Vicryl der Stärke 4.

Zur Identifikation der Tiere wurde ein Transponder im Nackenbereich implantiert. Postoperativ erfolgte die Gabe von Buprenorphin (Temgesic ${ }^{\circledR}, 0,05 \mathrm{mg} / \mathrm{kg}$ Körpergewicht) und die Teilantagonisierung durch Atipamezol (Antisedan ${ }^{\circledR}, 2 \mathrm{mg} / \mathrm{kg}$ Körpergewicht s.c.). Bis zum Abklingen der Narkose wurden die Versuchstiere in Einzelkäfigen gehalten.

a)

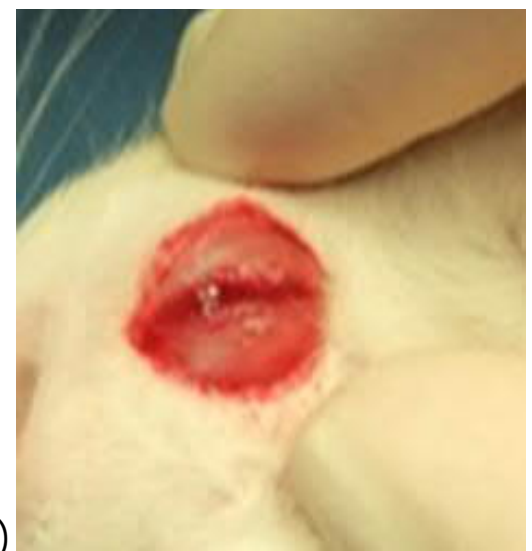

b)

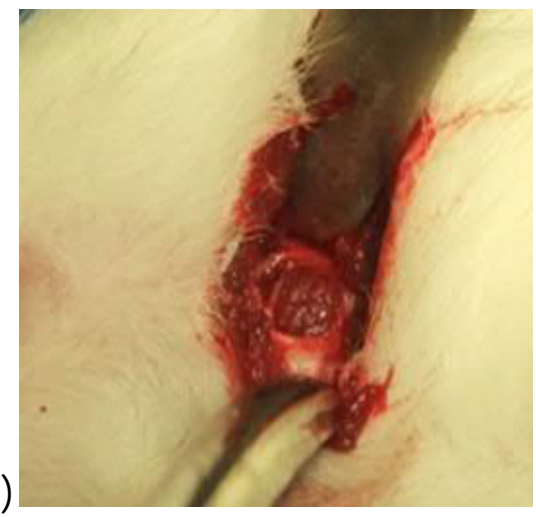




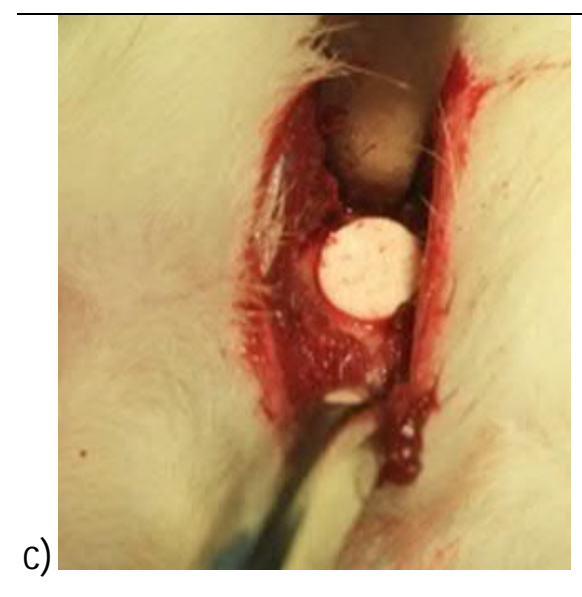

Abbildung 5: Ratte intraoperativ: a) submandibulärer Hautschnitt, b) Unterkieferknochen mit Critical-size-Defekt von $5 \mathrm{~mm}, \mathrm{c}$ ) Implantat in situ

\subsection{Postoperatives Vorgehen}

Neben den regelmäßigen klinischen Kontrollen und der Überwachung des Gesundheitszustandes der Tiere wurden Analgetika nach festgelegtem Schema verabreicht. Bis zum zweiten postoperativen Tag erfolgte zwei $M$ al täglich die Gabe von Temgesic $(0,05-$ $0,02 \mathrm{mg} / \mathrm{kg}$ Körpergewicht s.c.). Ab dem dritten postoperativen Tag wurde die Analgesie auf Carprofen (Rimadyl ${ }^{\circledR}, 5 \mathrm{mg} / \mathrm{kg}$ Körpergewicht s.c.) 1-0-0 reduziert. Das Trinkwasser wurde mit Metamizol (Metapyrin ${ }^{\circledR}, 3 \mathrm{ml} / 1$ Liter Trinkwasser) bis zum 14. postoperativen Tag angereichert. Bei Anzeichen von Schmerzen verlängerte man die M edikamentengabe.

Starke Infektionen im Bereich der Polymerträger und/oder Kieferbruch der Versuchstiere galten als Abbruchkriterien.

\subsection{Versuchsbeendigung}

Die Euthanasie der Tiere nach Ablauf der Beobachtungszeiträume erfolgte durch $\mathrm{CO}_{2}$ Applikation in einem abgeschlossenen Raum. Durch die Inhalation des Gases wurden die Tiere innerhalb weniger Sekunden bewusstlos und erlitten nach ca. einer M inute einen HerzKreislaufstillstand. Nach Todesfeststellung wurden die Unterkiefer entnommen und der weiteren Aufbereitung zugeführt (Abbildungen 6a und 6b). 
a)

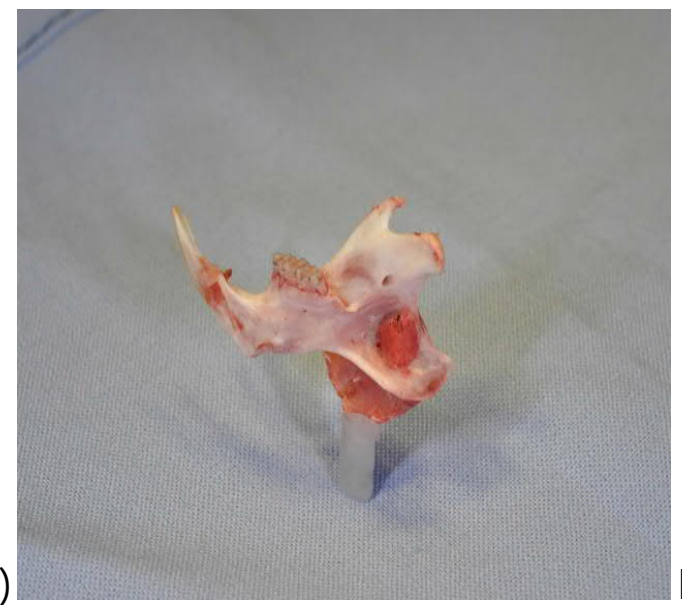

b)

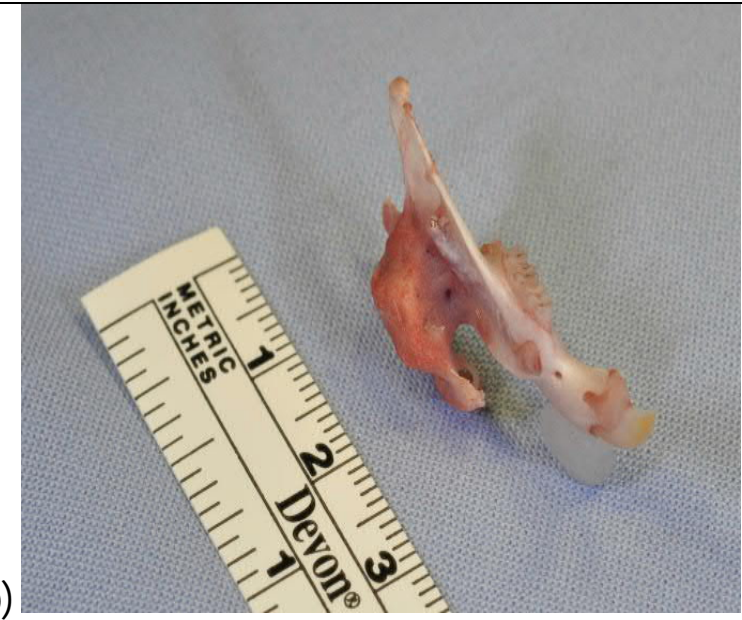

Abbildung 6: Unterkieferpräparate mit deutlichen Knochenzuwachs lateral, a) Ansicht von distomedial, b) Ansicht von ventrolateral

\subsection{Aufbereitung der Präparate}

Die Bearbeitung der Präparate wurde im Labor der Klinik für Mund-, Kiefer- und Gesichtschirurgie der Universitätsmedizin Göttingen. Die radiologische Bildgebung erfolgte mit einem digitalen Volumentomographen (PaX-Zenith 3D/ Vatech/ Republic of Korea(Hwaseong)). Nach der Entnahme der Unterkieferpräparate wurden diese zunächst in 4\% neutral gepufferter Formalinlösung fixiert. Durch die Applikation von Ethanol in aufsteigender Konzentration erfolgte der Wasserentzug (Dehydratation). Die Unterkieferpräparate wurden in Technovit 9100 (Haereus Kulzer, Wehrheim) eingebettet und nach Aushärtung im digitalen Volumentomographen gescannt.

\subsection{Digitale Volumentomographie}

Im Jahr 2000 wurde, der schon 1997 entwickelte und drei Jahre lang erprobte Tomograph unter den Namen 3DX multi-image micro-CT auf den Markt gebracht (Hashimoto et al. 2003). Im Gegensatz zur Schichtabtastung der konventionellen Computertomographie (CT) wird in der digitalen Volumentomographie (DVT, angloamerikanisch cone beam-CT) der 3DDatensatz in nur einem Umlauf mit Hilfe eines kegelförmigen Strahlenbündels aus vielen zweidimensionalen Bildern gewonnen. Anschließend erfolgt die 3D-Rekonstruktion am Computer, welche eine gute Bildqualität der Hartgewebsstrukturen ermöglicht (Terakado et al. 2000). 


\subsection{Herstellung der DVTs}

Im DVT richtete sich die Anzahl der gescannten Kiefer nach deren Größe. Das field of view (FOV) betrug 50x50 mm und die Voxelgröße $80 \mu \mathrm{m}$. Die Exposition fand bei $120 \mathrm{kV}$ und $8 \mathrm{~mA}$ statt. Das Tomogramm wurde an axialen Scans senkrecht zum Defekt und parallel zum unteren Rand des Unterkiefers durchgeführt. Die Daten wurden im DICOM-Format importiert und mittels digitalen Programms (Fiji/ Fiji is just ImageJ/ Johannes Schindelin, Albert Cardona, Mark Longair, Benjamin Schmid und andere/ Madison / 7 M arch 2011) nach dem gleichen Schema ausgewertet.

\subsection{Auswertung mit digitalen Programm}

Nach der Durchführung des DVTs konnte man den neu gebildeten Knochen von ortsständigen Knochen unterscheiden. Die Schwellenwerte für das Zählen von Pixeln der Implantatregion wurden für jedes Bild unter visueller Kontrolle angepasst (Schindelin et al. 2012). Die Pixelgröße betrug $0,016 \mathrm{~mm}^{2}$, die Ergebnisse wurden in $\mathrm{mm}^{2}$ ausgedrückt und der Prozentsatz des neu gebildeten Knochens im Verhältnis zur Gesamtfläche ermittelt.

\subsubsection{Isolation Einzelkiefer}

Nach dem Importieren des ausgewählten DVT wurde zunächst über den M enüpunkt Crop 3D $X Y-, X Z$ - und YZ-Ebene errechnet und in der jeweiligen Ebene die dargestellten Blöcke eingestellt. Der gewünschte Kiefer musste isoliert und mit Schnittlinien eingegrenzt werden (Abbildung 7a). Es folgte das Herausschneiden der Bildsequenz des eingegrenzten Kiefers und das Auswählen von Crop-Menüpunkt (Abbildung 7b). Der Unterkiefer wurde über Plugins, Transform und Interactive Stack Rotation so lange gedreht bis das Defektareal orthograd getroffen war und somit senkrecht zur Schnittebene lag (Abbildung 7c). Der so entstandene Datensatzes konnte als TIFF.file gespeichert werden.

\subsubsection{Analyse}

Zur Analyse des bearbeiteten DVT wurde eine Schicht mit dem größten Durchmesser der Knochenmasse ausgewählt und diese mit Duplicate herausgeschnitten. Der in dieser Schicht entstandene Knochen mit ggf. noch vorhandenen Defekt konnte mit Polygonfunktion umfahren und mit Clear outside herausgeschnitten werden (Abbildung 7d). Im entstandenen Polygon wurden über Image/Ajust/Treshold Grauwerte für Knochen eingestellt und gemessen (Abbildung 7e). Am Ende konnte die Gesamtfläche dieser Schicht und neu entstandene Knochenfläche der jeweiligen Schicht in $\mathrm{mm}^{2}$ durch das Programm bestimmt 
und prozentualer Anteil des neu entstandenen Knochens von dieser gesamten Schicht durch das Programm errechnet werden (Knochendichte in \%).
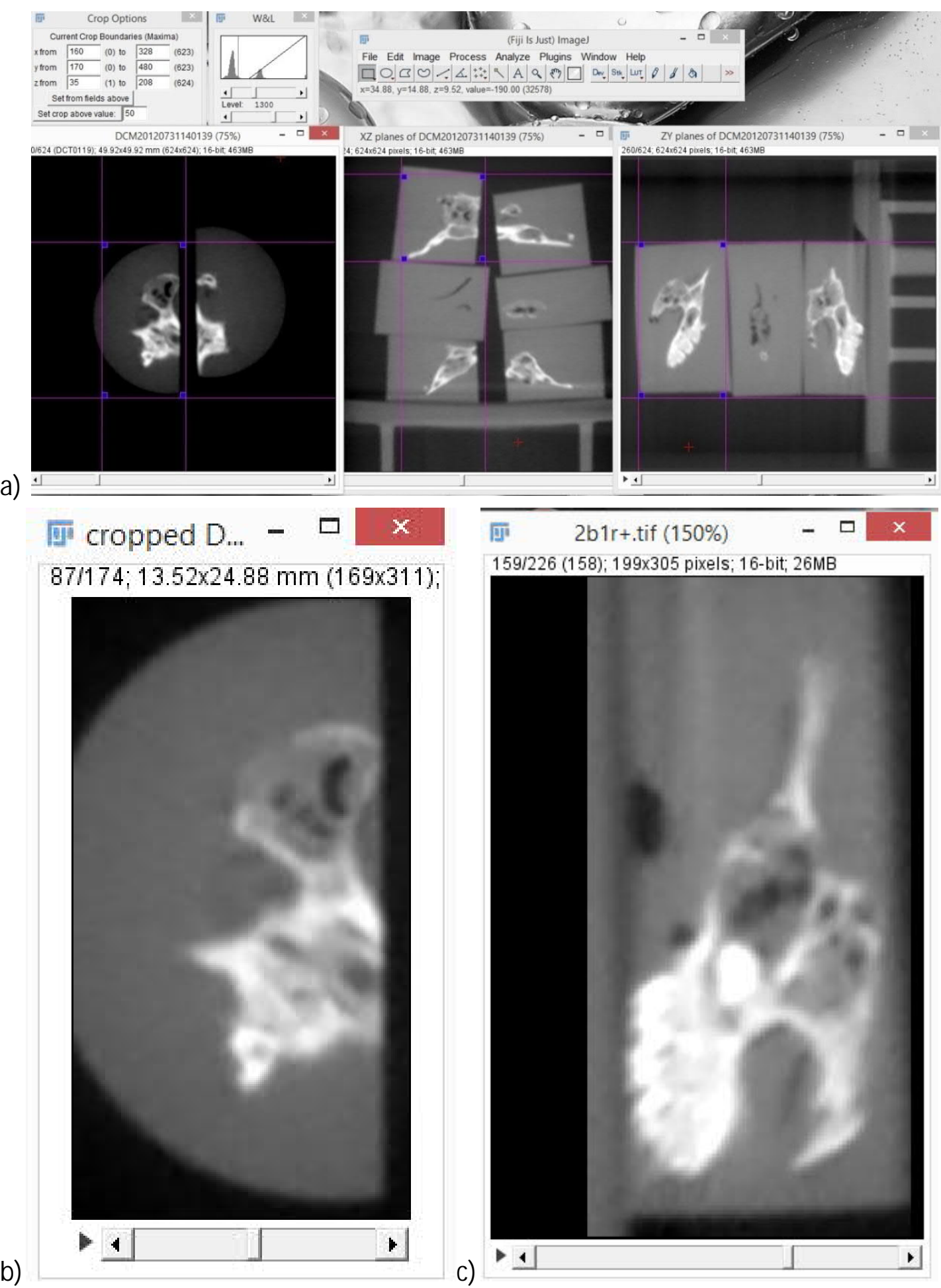


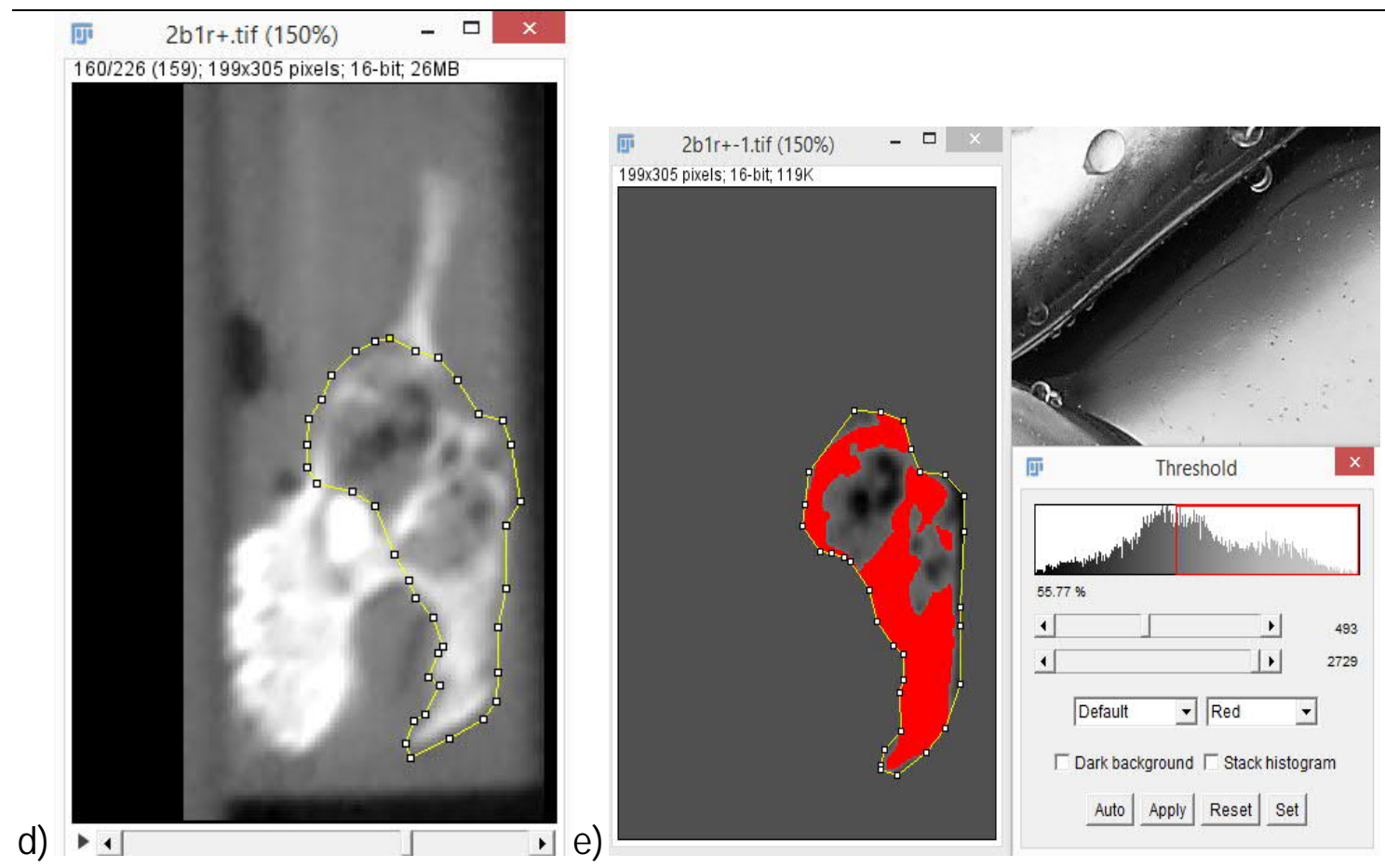

Abbildung 7: Digitale Bearbeitung des DVT a) Darstellen des gewünschten Kiefers; b) herausgeschnittener Rattenkiefer; c) orthograde Darstellung; d) Auswählen des neu entstandenen Knochens; e) M essen der Grauwerte

\subsection{Statistische Methoden}

Die statistische Aufbereitung der Ergebnisse wurde mit freundlicher Unterstützung des Instituts für Medizinische Statistik der Universitätsmedizin Göttingen (Prof. Dr. Tim Friede) durchgeführt.

Bei einer nicht normalverteilten Datenlage der Versuchsergebnisse, erfolgte die statistische Auswertung der Versuchsergebnisse mittels nichtparametrischer Varianzanalyse (ANOVA) um den Einfluss von Implantat, Zeit sowie deren Wechselwirkung zu beurteilen.

Zusätzlich wurden arithmetische Mittelwerte und Standardabweichungen bestimmt. Posthoc-Tests zum Vergleich der M ittelwerte wurden durch den Mann-Whitney-U-Test mit dem Bonferroni-Holm-Verfahren und Sidaks-Vergleichstest zur Erstellung von Signifikanzwerten durchgeführt (siehe Tabellen im Anhang).

Der Signifikanzlevel lag bei allen durchgeführten Tests bei $5 \%$. Für die Ermittlung der Varianzanalyse wurde das Statistikprogramm R (Version 3.1.2, www.r-project.org) und Statistikprogramm Graphpad Prism (GraphPad Software Inc., San Diego, CA 92108) verwendet. Für die tabellarische Darstellung verwendeten wir das Excel-Programm von M icrosoft Office 2013 (M icrosoft Corporation, Redmond, USA). 


\section{Ergebnisse}

\subsection{Knochendichte}

Die Abbildung 8 zeigt beispielhaft die radiomorphometrische Analyse der Knochenregeneration der Rattenkiefer zu den Zeitpunkten 4 Wochen und 13 Wochen. Es fand zunächst die Knochenneubildung am Implantatrand statt und im weiteren Verlauf konnte die Knochenapposition nach bukkal beobachtet werden. Wobei das Implantat teilweise resorbiert und durch Knochen ersetzt wurde.
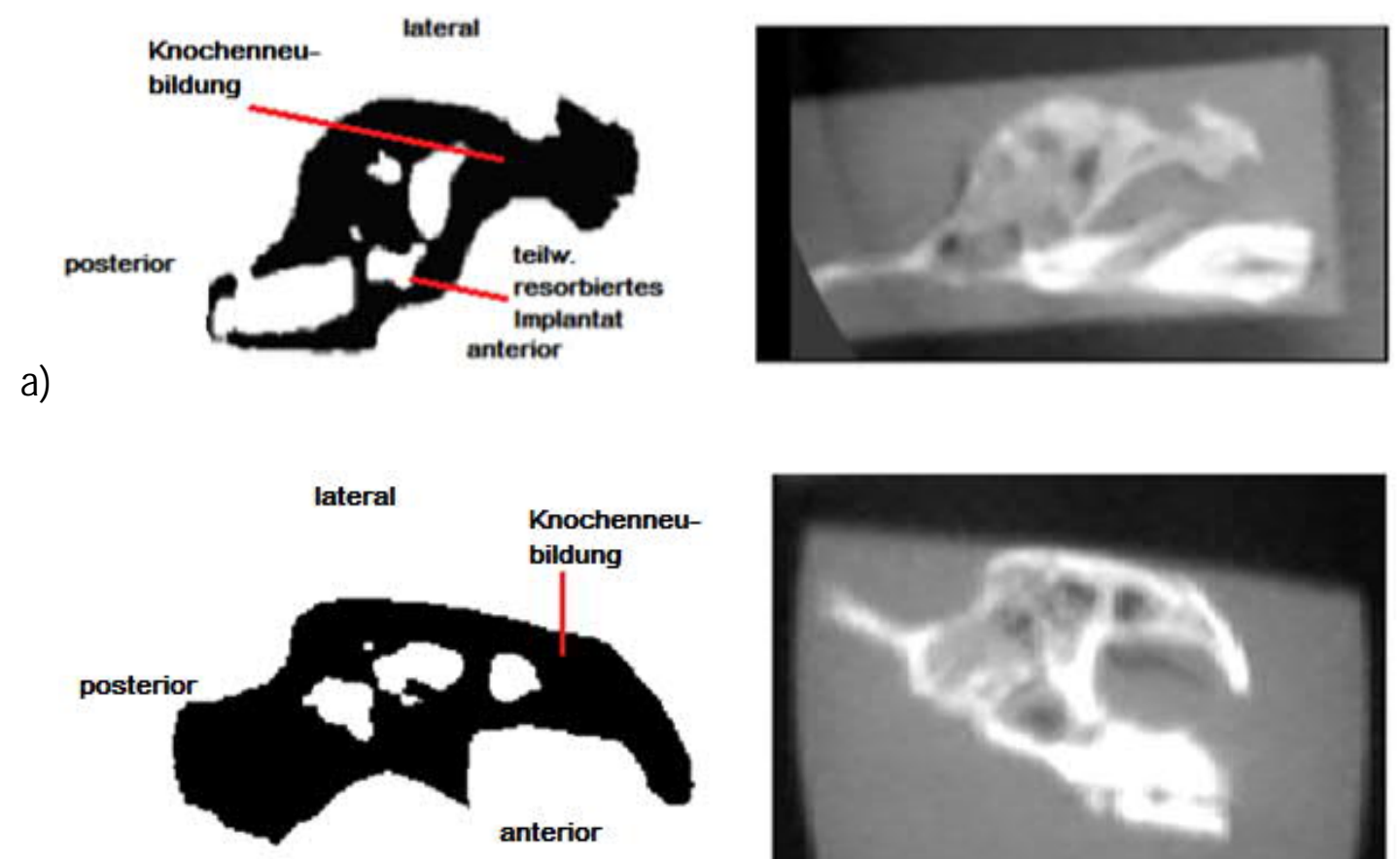

b)

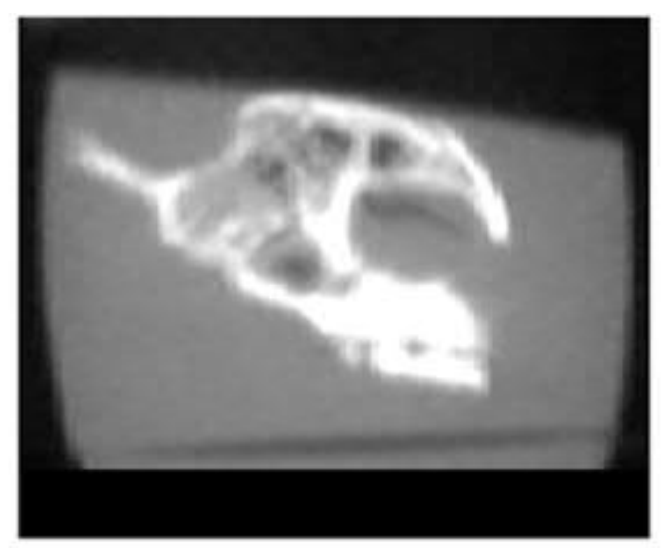

Abbildung 8: Radiomorphometrische Analyse

a) Applikationsgruppe 4 Wochen mit Darstellung des neu gebildeten Knochenvolumens

b) Applikationsgruppe 13 Wochen mit bukkaler Knochenapposition und Zunahme des Knochenvolumens

\subsubsection{BMP}

Bei der Analyse der Einzeldosierungen über die Zeit von 4 Wochen und 13 Wochen ergab sich kein signifikanter Unterschied der Knochendichte in den jeweiligen topisch applizierten 
BM P-Dosierungen von $24 \mu \mathrm{g}, 48 \mu \mathrm{g}$ und $96 \mu \mathrm{g}$. Im Vergleich zu BMP-Gruppen zeigte Kontrollgruppe (Blank) signifikant verminderte Knochendichte (Abbildung 9).

Bei der Betrachtung der Abhängigkeit der Dosierungen zu den beiden Zeitpunkten 4 Wochen und 13 Wochen ließ sich eine Steigerung der Knochendichte nur in den 4-Wochen-Gruppen erkennen. Die Knochendichte der $96 \mu \mathrm{g}$ BM P-Gruppen war nach 4 Wochen im Vergleich zu beiden anderen Gruppen signifikant hoch (Abbildung 9).

In den 13-Wochen-Gruppen unterscheiden sich die Dosisgruppen mit $24 \mu \mathrm{g} \mathrm{BMP}$ und $48 \mu \mathrm{g}$ $\mathrm{BM} P$ in der Knochendichte nicht voneinander.

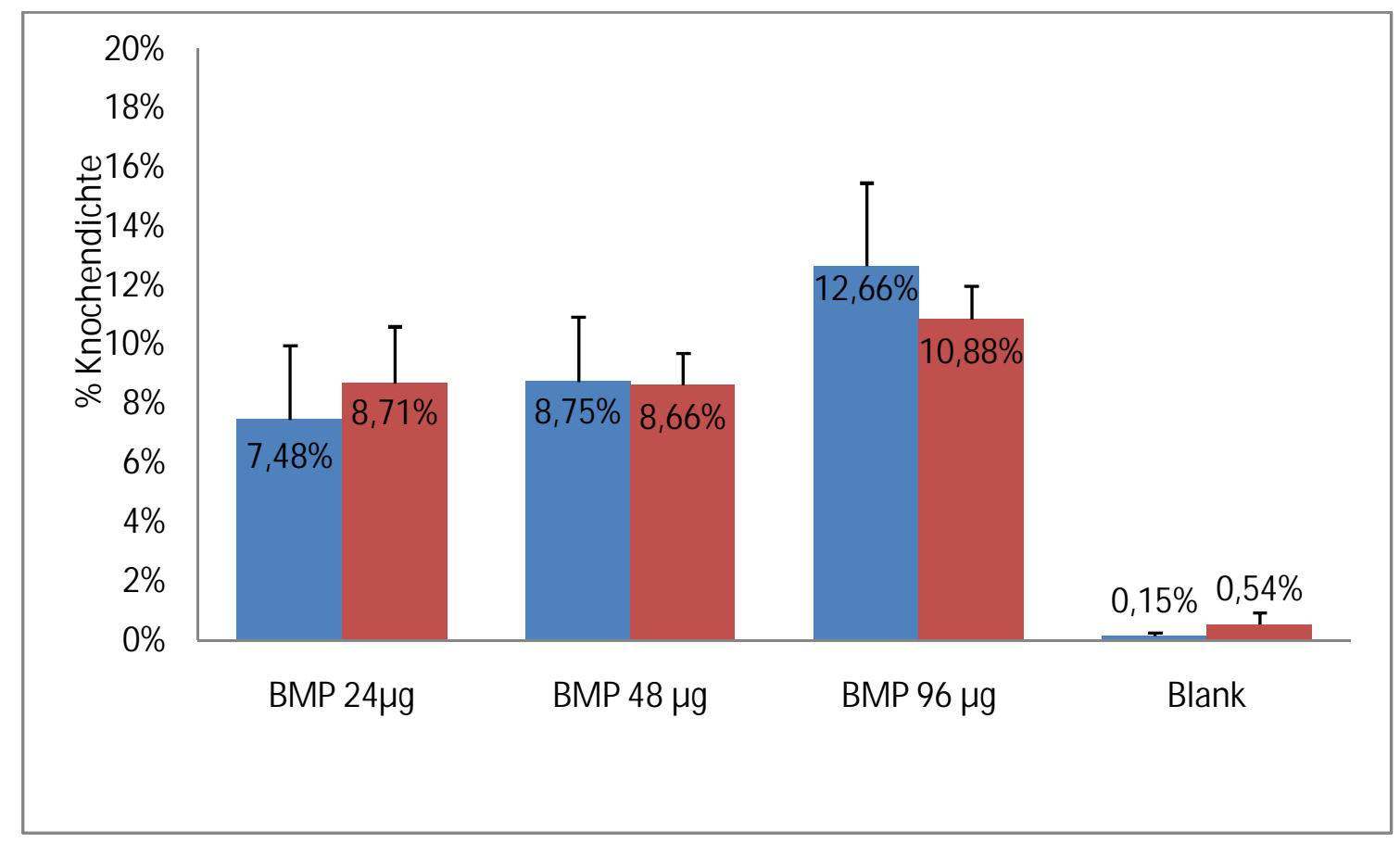

Abbildung 9: Vergleich der Mittelwerte der BMP-Einzeldosierungen und der Kontrollgruppe (Blank); blau: 4-Wochen-Gruppen; rot: 13-Wochen-Gruppen; $p<0,05, n=6$

\subsubsection{VEGF}

Die radiomorphometrische Betrachtung der Knochendichte bei der lokalen Applikation der VEGF-Einzeldosierungen von $0,24 \mu \mathrm{g}, 1,5 \mu \mathrm{g}$ über $6 \mu \mathrm{g}$ zeigte zu den Zeitpunkten 4 Wochen und 13 Wochen keinen signifikanten Unterschied. Der Vergleich Kontrollgruppe/VEGFGruppe ergab keinen signifikanten Unterschied (Abbildung 10).

Die Auswertung der Einzeldosierungen von VEGF zu den Zeitpunkten 4 Wochen und 13 Wochen ergab eine deutlich geringere Knochendichte als die mit BMP und BMP/VEGFKombinationen beladenen Implantate. Die höchste Knochendichte wies die Gruppe mit $6 \mu \mathrm{g}$ nach 4 Wochen auf (Abbildung 10). 


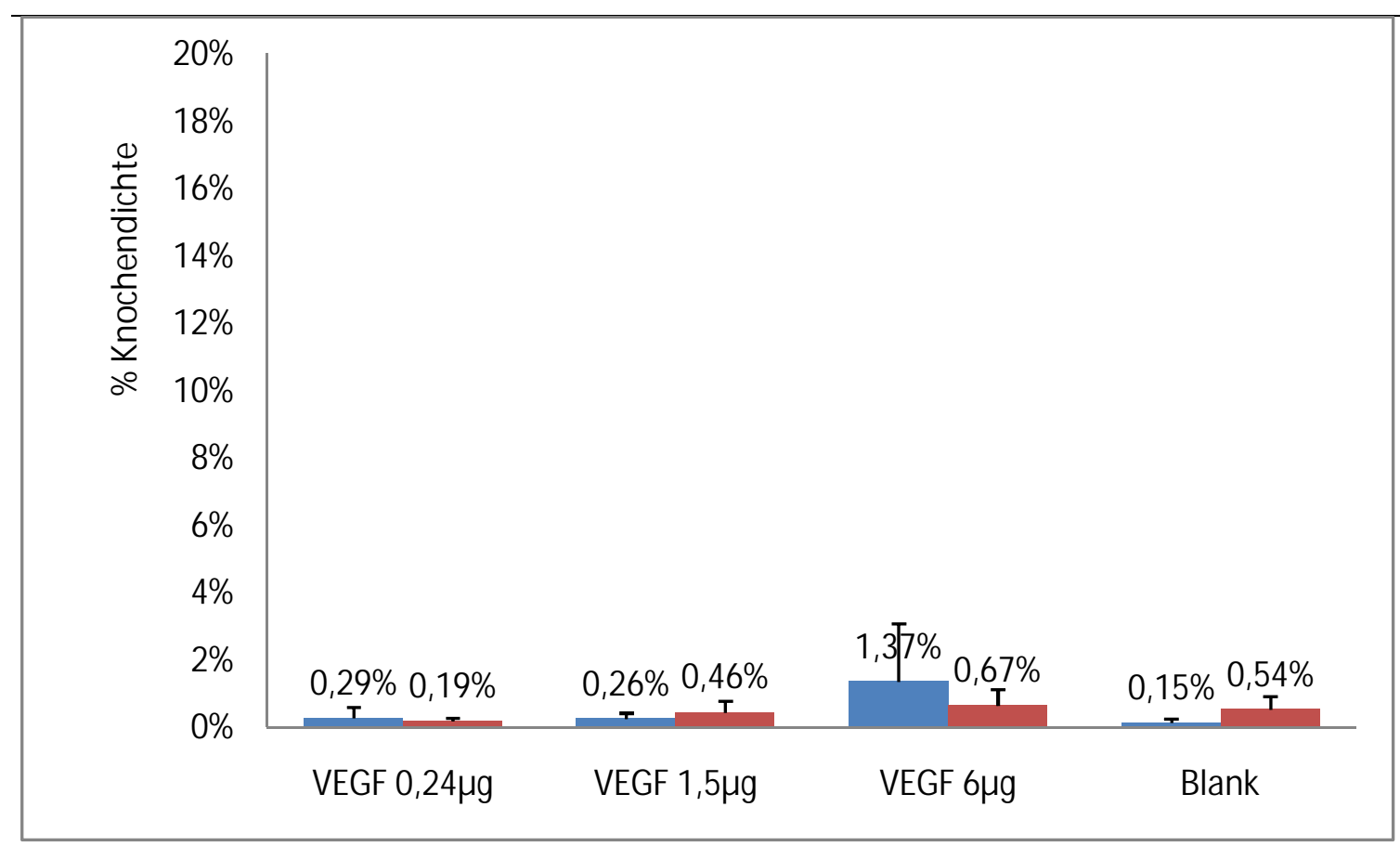

Abbildung 10: Vergleich der Mittelwerte der VEGF-Einzeldosierungen und der Kontrollgruppe (Blank); blau: 4-Wochen-Gruppen; rot: 13-Wochen-Gruppen; $p<0,05, n=6$

\subsubsection{Kombination BM P/VEGF}

Die Auswertung des Einflusses der Zeit auf die Knochendichte bei den Kombinationsdosierungen des VEGF und BMP von $1,5 \mu \mathrm{g} / 6 \mu \mathrm{g}$ und $24 \mu \mathrm{g} / 48 \mu \mathrm{g}$ ausgenommen Kombination 1,5 $\mu \mathrm{g} / 24 \mu \mathrm{g}$ ergab keinen Signifikanz relevanten Unterschied. Die Kontrollgruppe zeigte eine signifikant geringere Knochendichte (Abbildung 11).

Die Auswertung der erfassten Knochendichten bei den mit VEGF und BMP beladenen Implantaten ergab eine Steigerung der Knochendichte mit der steigenden BM P-Konzentration. Vor allem in den 4-Wochen-Gruppen war der Effekt deutlich sichtbar. Dabei wies die Kombination $6 \mu \mathrm{g}$ VEGF mit $48 \mu \mathrm{g}$ BM P die höchste Knochendichte auf. Im Verlauf der 4. bis hin zur 13. Woche hatte die Gruppe mit Kombination 1,5 $\mu \mathrm{g}$ VEGF mit $24 \mu \mathrm{g}$ BMP die größte Zunahme der Knochenneubildung. Andererseits zeigte die Gruppe $6 \mu \mathrm{g}$ VEGF mit $48 \mu \mathrm{g}$ BM P eine Abnahme der Knochenneubildung in der 13-Wochen-Gruppe. In den beiden anderen Kombinationsgruppen 1,5 $\mu \mathrm{g}$ VEGF mit $48 \mu \mathrm{g}$ BM P und $6 \mu \mathrm{g}$ VEGF mit $24 \mu \mathrm{g}$ BM P ließ sich kein Trend in der Knochenneubildungsrate erkennen (Abbildung 11). 


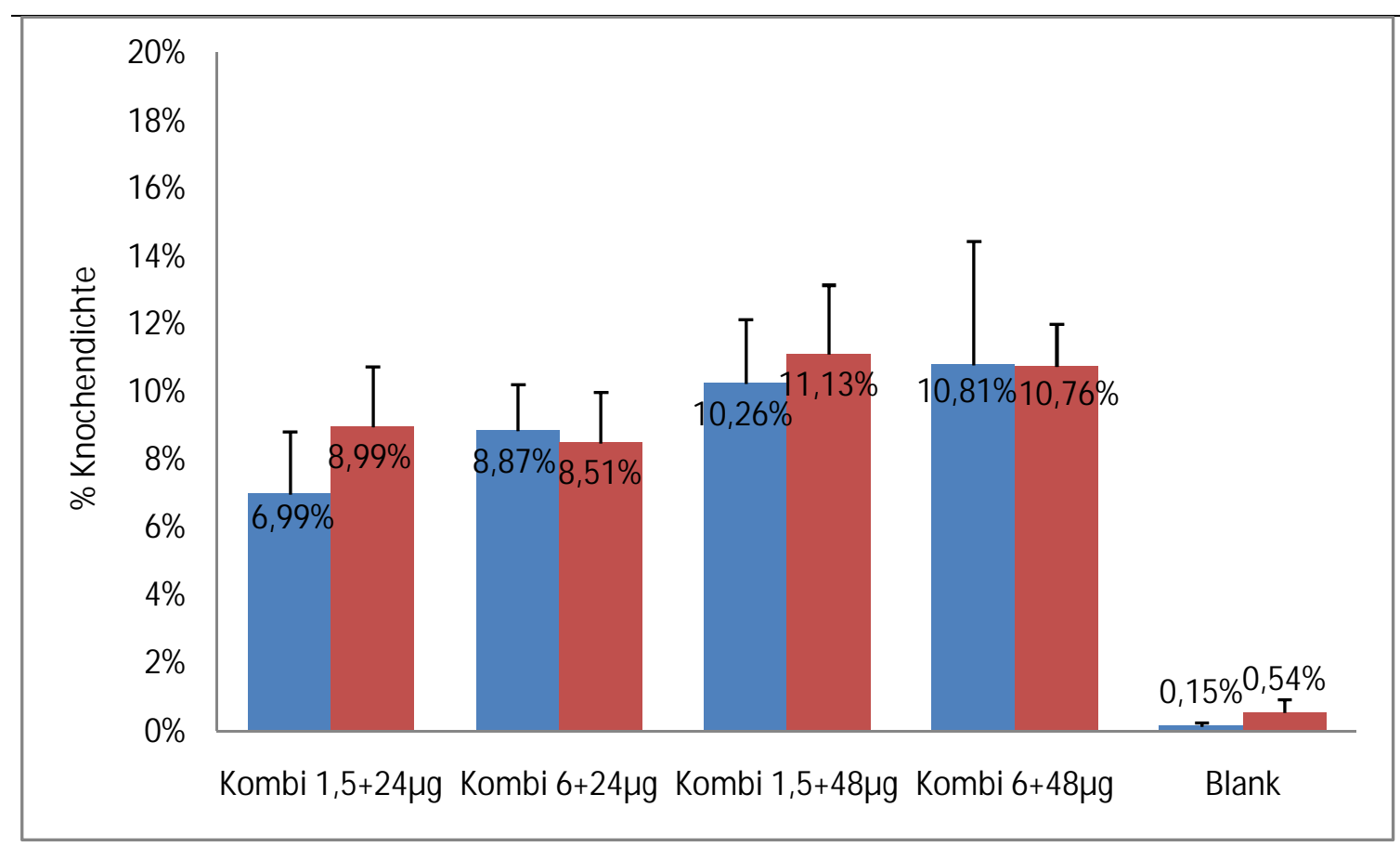

Abbildung 11: Vergleich der Mittelwerte der Kombinationsdosierungen VEGF+BM P und der Kontrollgruppe (Blank); blau: 4-Wochen-Gruppen; rot: 13-Wochen-Gruppen; $p<0,05, n=6$

\subsubsection{Vergleich der Knochendichte der Einzeldosierungen von BMP und Kombinationen VEGF/BM P}

Beim Vergleich der Kombinationsgruppen und der BMP-Gruppen wurden die beiden Zeitpunkte 4 Wochen und 13 Wochen auf Grund des bei der statistischen Auswertung (siehe Anhang Mann-Whitney-U-Test-Tabelle) festgestellten nicht signifikanten Zeiteffektes gemeinsam betrachtet. Dabei zeigten die Kombinationsgruppen mit $24 \mu \mathrm{g}$ BMP keinen signifikanten Unterschied zu den Einzeldosierungsgruppen $24 \mu \mathrm{g}$ und $48 \mu \mathrm{g} \mathrm{BMP}$, jedoch einen signifikanten Unterschied in der Knochendichte zur Einzeldosierungsgruppe mit $96 \mu \mathrm{g}$ BMP.

Die Knochendichte in den Kombinationsgruppen mit $48 \mu \mathrm{g}$ BM P war im Vergleich zu $48 \mu \mathrm{g}$ Einzeldosierung höher. Der Vergleich der Gruppen mit $96 \mu \mathrm{g}$ BMP und der Kombinationsgruppen mit $48 \mu \mathrm{g}$ BM P ergab keinen signifikanten Unterschied, d.h. durch die $1,5 \mu \mathrm{g}$ bzw. $6 \mu \mathrm{g}$ VEGF-Zugabe wurde ähnliche Knochendichte erzielt wie mit der $96 \mu \mathrm{g}$ Einzeldosierung (Abbildung 12). 


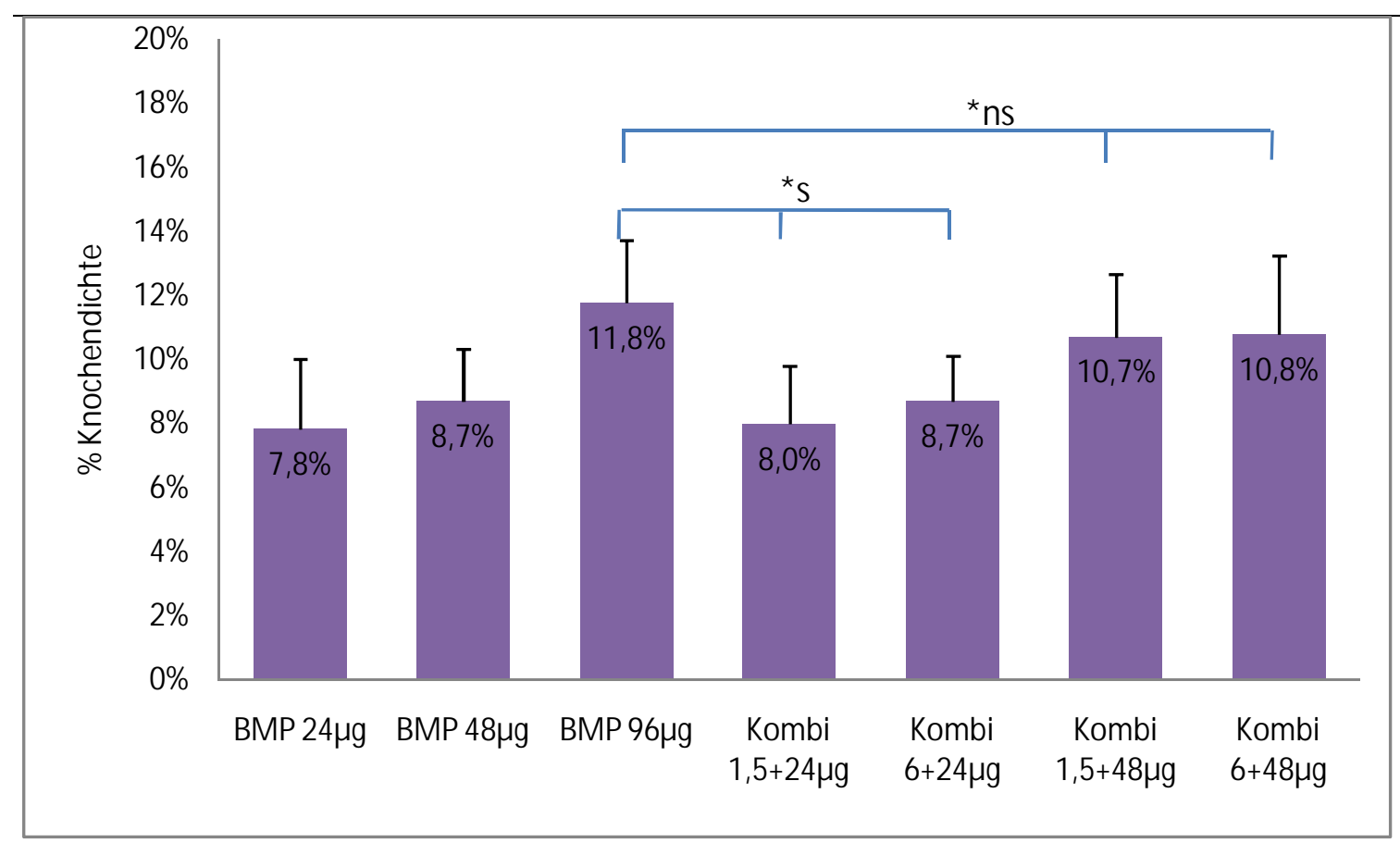

Abbildung 12: Vergleich der Mittelwerte 4-13 Wochen der Kombinationsdosierungen VEGF+BM P und der BM P-Gruppen; $\mathrm{p}<0,05, \mathrm{n}=6$; * ns nicht signifikant, *s signifikant

\subsection{Knochenfläche}

\subsubsection{BMP}

Die Auswertung der gemessenen Knochenfläche über die Zeit in den jeweiligen Gruppen ergab bis auf die Einzeldosierungsgruppe mit $24 \mu \mathrm{g}$ BM P keinen signifikanten Unterschied. In den Zeitintervallen 4 und 13 Wochen war die Knochenfläche der Gruppe Blank signifikant niedriger zu allen BMP-Einzeldosierungsgruppen. In den 4-Wochen-Gruppen war die Knochenfläche der $96 \mu \mathrm{g}$-Gruppe signifikant am größten im Vergleich zu $24 \mu \mathrm{g} / 48 \mu \mathrm{g}$ Gruppen, wobei sich in der 13. Woche keine signifikanten Unterschiede ergaben (Abbildung 13). 


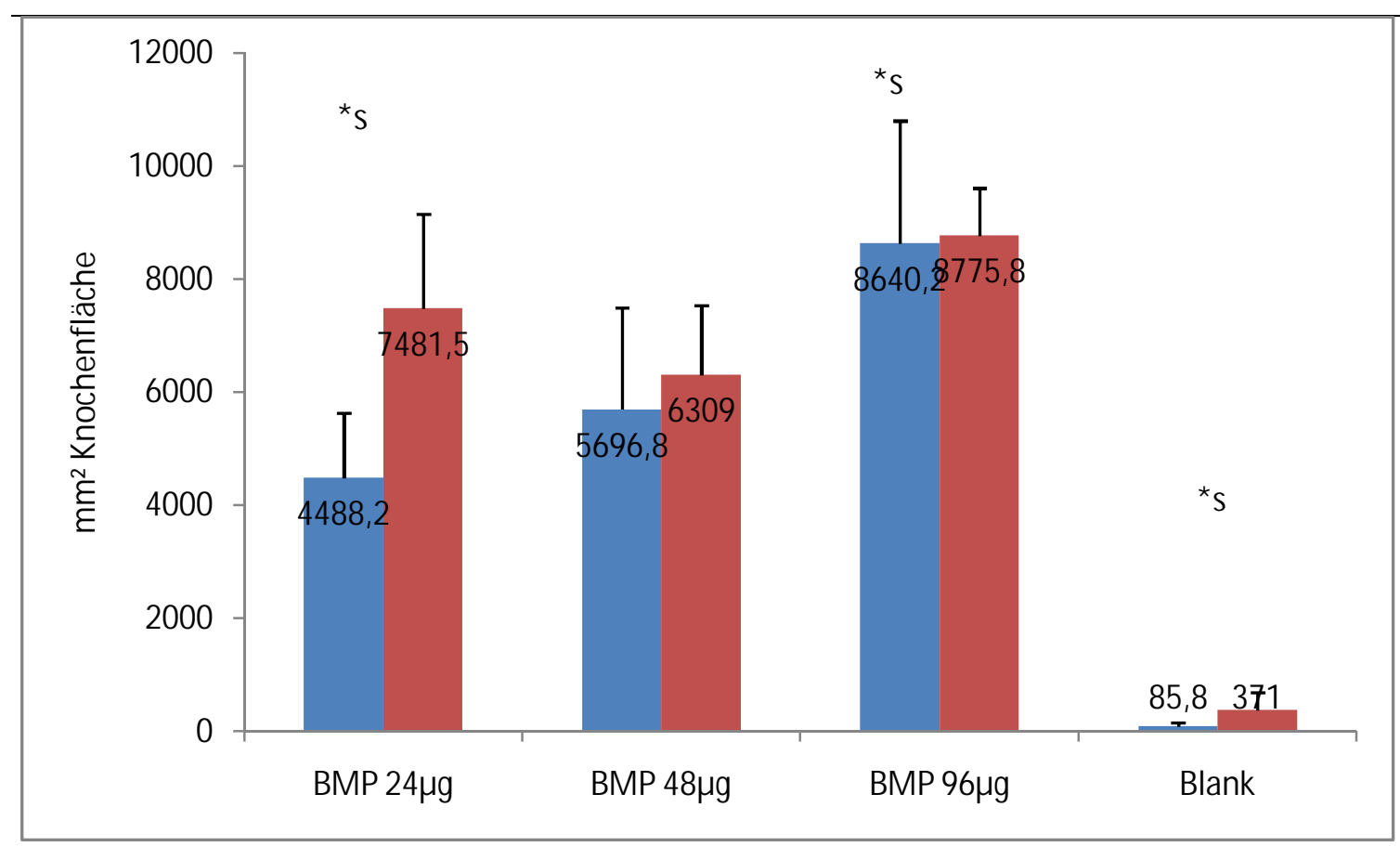

Abbildung 13: Vergleich der M ittelwerte der BM P-Einzeldosierungen und der Kontrollgruppe (Blank); blau: 4-Wochen-Gruppen; rot: 13-Wochen-Gruppen; $p<0,05, n=6$; *s signifikant

\subsubsection{VEGF}

Die Betrachtung der Knochenfläche bei den VEGF-Einzeldosierungen von 0,24 $\mu \mathrm{g}, 1,5 \mu \mathrm{g}$ und $6 \mu \mathrm{g}$ zeigte zu den Zeitpunkten 4 Wochen (blau) und 13 Wochen (rot) keinen signifikanten Unterschied. Der Vergleich Kontrollgruppe(Blank)/VEGF-Gruppen ergab keinen signifikanten Unterschied. Die Auswertung der Einzeldosierungen von VEGF zu den Zeitpunkten 4 Wochen und 13 Wochen ergab eine deutlich geringere Knochenfläche als die mit BMP und BMP/VEGF-Kombinationen beladenen Implantate. Die größte Knochenfläche wies die Gruppe mit $6 \mu \mathrm{g}$ nach 4 Wochen auf (Abbildung 14). 


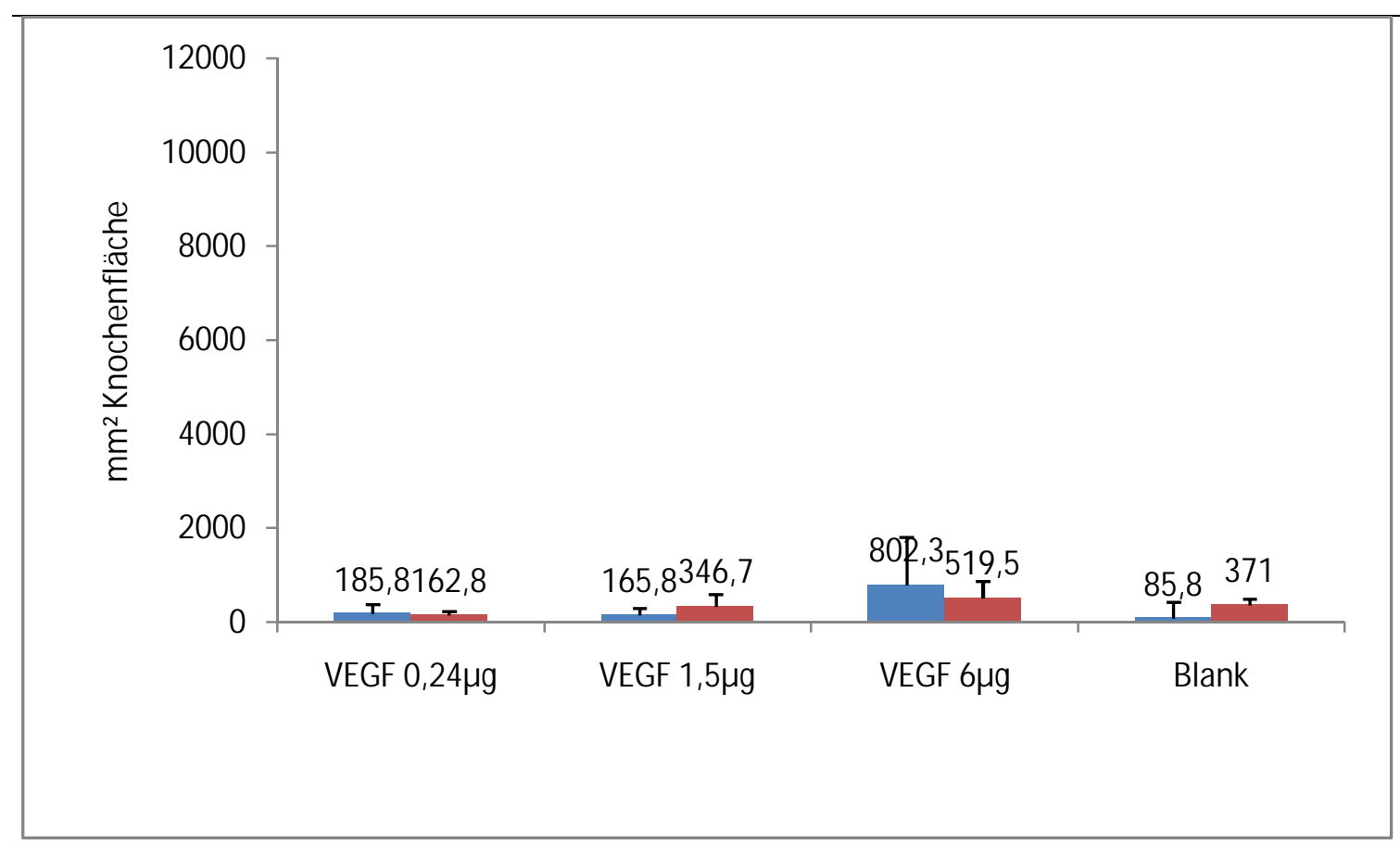

Abbildung 14: Vergleich der Mittelwerte der VEGF-Einzeldosierungen und der Kontrollgruppe (Blank); blau: 4-Wochen-Gruppen; rot: 13-Wochen-Gruppen; $p<0,05, n=6$

\subsubsection{Kombination BM P/VEGF}

Die Auswertung der Knochenfläche bei den Kombinationsdosierungen des VEGF und BMP ergab lediglich einen Signifikanz relevanten Unterschied in der 4. Woche zwischen Kombinationen $6 \mu \mathrm{g} / 24 \mu \mathrm{g}$ und $6 \mu \mathrm{g} / 48 \mu \mathrm{g}$. Die Kontrollgruppe zeigte eine signifikant geringere Knochenfläche (Abbildung 15).

Die erfassten Knochenflächen bei den mit VEGF und BMP beladenen Implantaten ergab eine Steigerung der Knochenfläche mit den steigenden BMP/VEGF-Konzentrationen ausgenommen 4-Wochen-Gruppe $6 \mu \mathrm{g} / 24 \mu \mathrm{g}$. Dabei wies die Kombination $6 \mu \mathrm{g}$ VEGF mit $48 \mu \mathrm{g} \mathrm{BM} \mathrm{P} \mathrm{die} \mathrm{höchste} \mathrm{Knochenfläche} \mathrm{auf.} \mathrm{Im} \mathrm{Verlauf} \mathrm{der} \mathrm{4.} \mathrm{bis} \mathrm{13.} \mathrm{Woche} \mathrm{hatte} \mathrm{die} \mathrm{Gruppe}$ mit Kombination 1,5 $\mu \mathrm{g}$ VEGF mit $24 \mu \mathrm{g}$ BMP die größte Zunahme der Knochenfläche (Abbildung 15). 


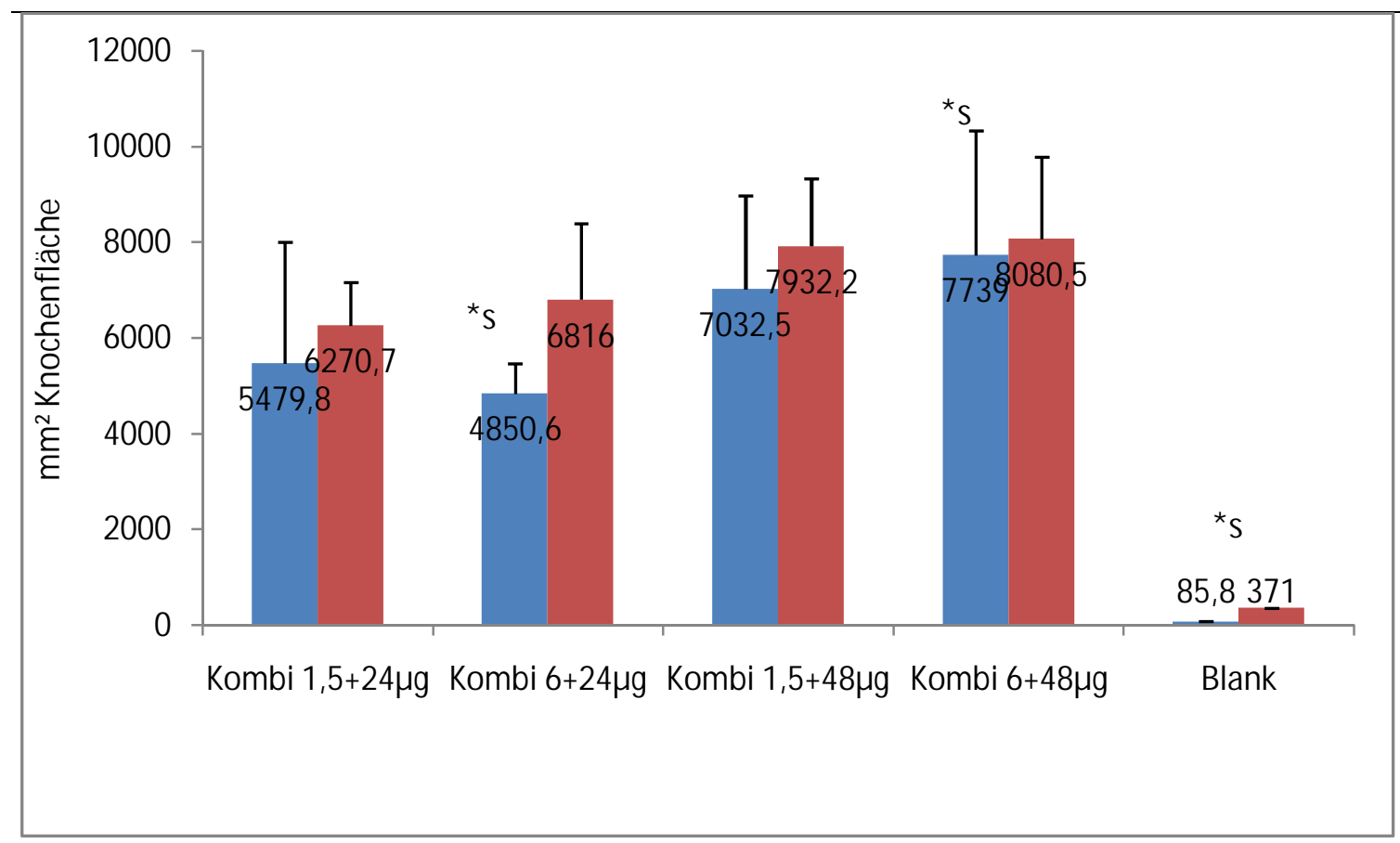

Abbildung 15: Vergleich der Mittelwerte der Kombinationsgruppen und der Kontrollgruppe (Blank); blau: 4-Wochen-Gruppen; rot: 13-Wochen-Gruppen; $p<0,05, n=6$; *s signifikant

\subsubsection{Vergleich der Knochenfläche der Einzeldosierungen von BMP und Kombinationen VEGF/BM P}

Bei der Betrachtung der 4-Wochen-Ergebnisse konnte ein signifikanter Unterschied zwischen $24 \mu \mathrm{g}$ BM P-Gruppe und der Kombinationsgruppe $6 \mu \mathrm{g}$ VEGF mit $48 \mu \mathrm{g}$ BM P nachgewiesen werden. Nach 4 Wochen war die Knochenfläche der $96 \mu \mathrm{g}$ BMP Einzeldosierungsgruppe signifikant höher als Kombinationsgruppen mit 1,5 $\mu \mathrm{g} / 24 \mu \mathrm{g}$ und $6 \mu \mathrm{g} / 24 \mu \mathrm{g}$ jedoch ohne signifikanten Unterschied zu den Kombinationen $1,5 \mu \mathrm{g} / 6 \mu \mathrm{g}$ VEGF und $48 \mu \mathrm{g} \mathrm{BMP.} \mathrm{Im}$ Vergleich der einzelnen Gruppen in der 13. Woche konnte keine Signifikanz nachgewiesen werden (Abbildung 16). 


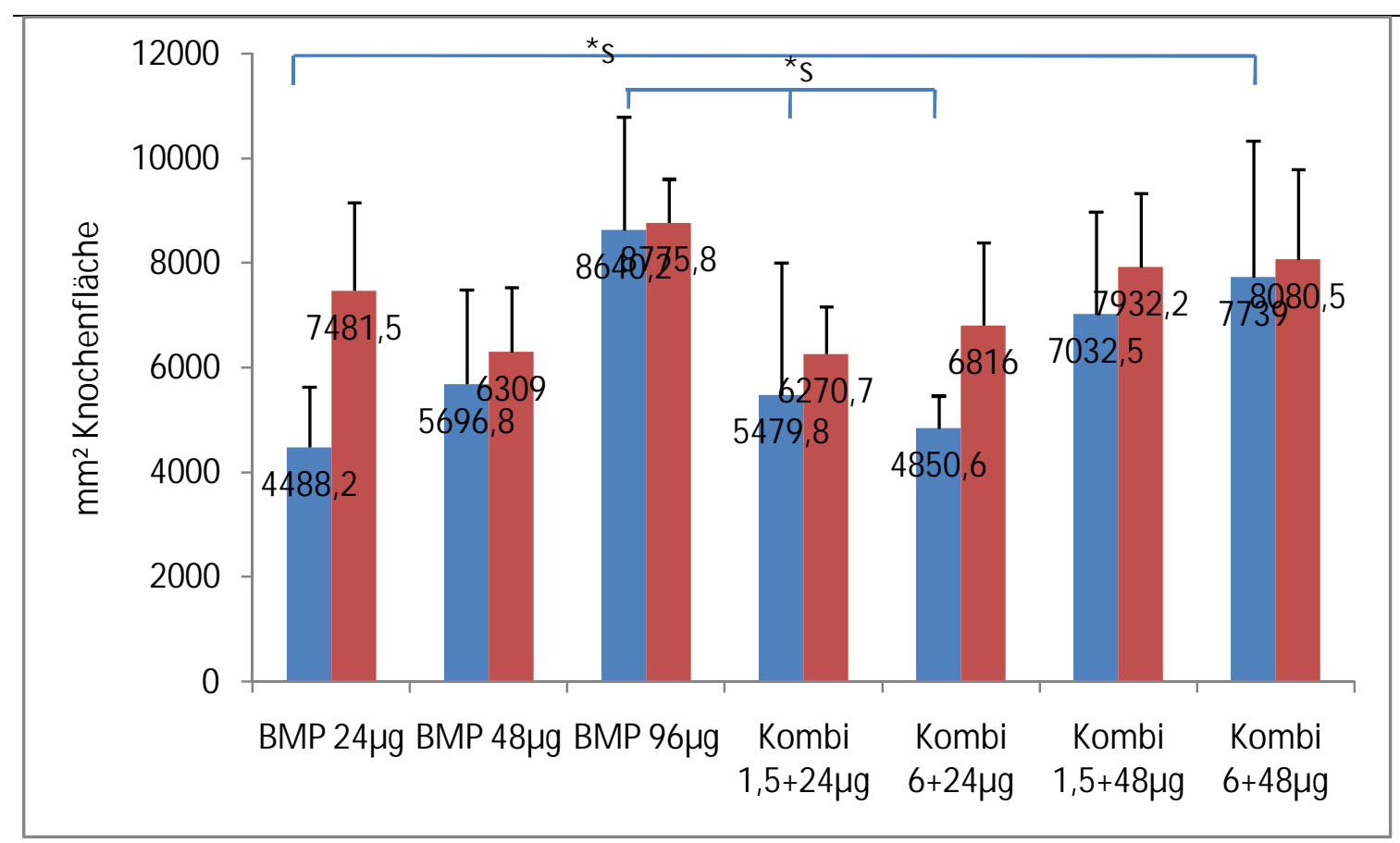

Abbildung 16: Vergleich der Mittelwerte der Knochenflächen der Kombinationsdosierungen VEGF+BMP und der BMP-Gruppen; blau: 4-Wochen-Gruppen; rot: 13-Wochen-Gruppen; $p<0,05, n=6$

\subsection{Zusammenfassung der Ergebnisse}

Die nichtparametrische ANOVA-Analyse der Knochendichte ergab keine Zeitabhängigkeit zu den beiden Zeitpunkten 4 und 13 Wochen. Die Varianz wurde mit der Analyse bestätigt. Die 2-Wege-ANOVA-Analyse der Knochenfläche ergab lediglich eine signifikante Zeitabhängigkeit zu den beiden Zeitpunkten 4 und 13 Wochen für die $24 \mu \mathrm{g}$ BM P-Gruppe.

Die lokale Applikation des Wachstumsfaktors VEGF in unterschiedlichen Dosierungen zeigte keinen Unterschied in der Knochendichte und Knochenfläche zu der Gruppe ohne Wachstumsfaktorbeladung (Blank). Die Steigerung der Knochendichte und der Knochenfläche in den Gruppen der BMP-Dosierungen war konzentrationsabhängig. Die Signifikanz wurde vor allem in der $96 \mu \mathrm{g}$ BM P-Gruppe bestätigt.

Bei den Kombinationsdosierungen VEGF/BMP ließ sich eine Steigerung der Knochendichte und Knochenfläche mit steigender BM P-Konzentration erkennen. Die Kombinationsgruppen mit $48 \mu \mathrm{g}$ BMP hatten eine ähnliche Knochendichte und Knochenfläche wie die Einzelgruppen mit $96 \mu \mathrm{g} B \mathrm{P}$. 


\section{Diskussion}

Die knöchernen Defekte entstehen nicht nur durch direkte Traumata und Tumore, sondern sind oft auch Folge der Entzündungen. Diese sind zu ca. 10\% posttraumatisch und führen zu erhöhter M orbidität (Cui et al. 2013). Die Wiederherstellung der Kontinuität und Reparatur von Critical-size-Knochendefekten durch Substitutionstherapie erfordert das Verständnis der Knochenbiologie und die Kontrolle der Knochengewebsmorphogenese. Mit Hilfe der Manipulation in der osteoinduktiven Signalgebung kann auf die Gewebeentwicklung mit ex vivo hergestellten Wachstumsfaktoren Einfluss genommen werden (Sundelacruz und Kaplan 2009).

Trotz der jahrzehntelangen Forschung und Entwicklung unzähliger alternativer Knochenersatztherapien gilt der autologe Knochenersatz als Goldstandard für die Versorgung von Knochendefekten (Moore et al. 2001). Viele Studien belegen die hohe Morbidität. So konnte 2011 in einer literaturzusammenfassenden Studie eine Morbiditätsrate von 19,37\% festgestellt werden. Die meisten bleibenden Komplikationen betrafen chronische Schmerzen der Entnahmestelle mit 7,75\% und Sensibilitätsstörungen mit 4,81\%. Die Rate an direkt postoperativen Komplikationen mit Schmerzen, Hämatombildungen, Seromen, Wunddehiszenzen, Infektionen und Frakturen der Entnahmestelle ist nicht zu vernachlässigen und bewirkt ein Umdenken im chirurgischen Vorgehen (Dimitriou et al. 2011).

Die genannten Aspekte der Behandlung knöcherner Defekte und deren klinische Relevanz bestätigt die weitere Suche nach einem idealen Knochenersatzmaterial. Die aktuelle Forschung befaßt sich mit Knochenheilung unterstützendem Gewebeersatz und benutzt Stammzellen, osteoinduktive Wachstumsfaktoren und osteokonduktive Trägermaterialien. In vielen Klein- und Großtierstudien konnten bereits vielversprechende Ergebnisse in der Regeneration der Knochendefekte erzielt werden. Einige aktuelle Studien befassen sich mit der Unterstützung der Knochenneubildung durch die Kombination von osteogenen und angiogenen Wachstumsfaktoren und konnten die Effektivität der Kombinationstherapie nachweisen. Dabei herrscht weder Einigkeit über die jeweilige Konzentrationshöhe noch über die Beladung und Auswahl des Trägermaterials (Gothard et al. 2014).

Im Rahmen dieser Studie sollte im Tiermodell der Einfluss der Kombinationstherapie auf die Knochenregeneration in vivo mit lokal applizierten osteogenen Wachstumsfaktoren BM P und angiogenen Wachstumsfaktoren VEGF auf PDLLA/CaCO ${ }_{3}$-Kompositträgern radiomorphometrisch untersucht werden. 


\subsection{Diskussion der Methode}

\subsubsection{Wachstumsfaktoren}

Wachstumsfaktoren sind Signalmoleküle, die an der Erneuerung und den Wachstum von Geweben beteiligt sind. Durch die intensive Erforschung vor allem auf dem Gebiet der Knochenregeneration sind in den letzten Jahren eine Vielzahl von Faktoren beschrieben worden (Schliephake 2002). Die am meisten erforschten Vertreter sind bone morphogenetic proteins (BM P's), welche bei der Knochenentstehung eine große Rolle spielen (Giannoudis und Einhorn 2009). Die BMPs sind in der Knochensubstanz in sehr geringer Dosierung von $1 \mu \mathrm{g} / \mathrm{g}$ Knochenmasse zu finden. In den meisten Studien wird mit einer Überdosierung gearbeitet (Schliephake 2002). Es herrscht Uneinigkeit über die richtige Dosierung der Wachstumsfaktoren. Die verwendeten BM P-Konzentrationen variieren zwischen $0,1 \mu \mathrm{g}$ bis $5 \mathrm{mg}$ in Kleintierversuchen und $5 \mu \mathrm{g}$ bis $100 \mathrm{mg}$ in Großtierversuchen (Gothard et al. 2014). Die Überbrückung größerer Knochendefekte durch Knochenersatzstoffe zeigt oft eine schlechte Knochenregeneration aufgrund unzureichender Vaskularisierung. Studien haben gezeigt, das bei eingeschränkter Vaskularisierung die alleinige Anwendung von osteoinduktiven Faktoren zu keiner erfolgreichen Heilung führte (Geiger et al. 2007). Vor allem die Entstehung von neuen Gefäßen im Bereich der inserierten Knochenersatzstoffe ist für deren Überleben entscheidend, da die Diffusionsstrecke für Nährstoffe, Sauerstoff und Abbaustoffe auf ca. $100 \mu \mathrm{m}$ begrenzt ist und nur für Gewebe mit geringer metabolischer Aktivität ausreicht (Santos und Reis 2010). Street et al. fanden mit inrer in vivo Arbeit die herausragende Bedeutung von VEGF für Angiogenese, Osteogenese und Frakturheilung durch die Inhibierung des Faktors heraus, das während der Chondro- und Osteogenese eine gestörte Knochenheilung hervorbrachte (Street et al. 2002).

Sowohl die Angiogenese als auch die Osteogenese sind entscheidend für die Knochenregeneration. Die gleichzeitige Freisetzung von osteogenen Faktoren (BMP) und angiogenen Faktoren (VEGF) haben einen additiven Effekt auf die Knochenregeneration (Zhang et al. 2011).

Jedoch in welchem Maße die Knochenneubildung durch kombinierte Freisetzung beeinflusst wird ist noch nicht abschließend geklärt. So zeigten Kempen et al. im Tiermodell eine Erhöhung der ektopen und orthotopen Knochenneubildung der BMP/VEGF-Kombination verglichen mit der alleinigen Beladung mit BMP nach acht Wochen Beobachtungszeit (Kempen et al. 2009). Geuze et al. konnten im Beobachtungszeitraum von sieben Wochen keine orthotope und ektope Verbesserung der Knochenneubildungsrate durch Zusatz von VEGF zum BM P auf einem M ikropartikel-Gelantine-Trägermaterial in vivo feststellen (Geuze et al. 2012). Auch Schmitt et al. führten ein Versuch an Tieren mit kombinierter BM P- und VEGF-Beladung eines Kollagen-Trägermaterials durch. Die histomorphometrische und mikroradiographische Auswertung zeigte nach 30 und 60 Tagen keinen signifikanten Unterschied zwischen den Kombinationsgruppen und Einzelgruppen (Schmitt et al. 2013). Wiederrum hat Zhang et al. eine Verbesserung der Knochenneubildungsrate durch 
kombinierte VEGF und BMP Freisetzung von Seiden-Hydrogel-Trägermaterial in vivo festgestellt (Zhang et al. 2011).

Letztendlich können durch die jeweiligen Versuche keine allgemeingültigen Aussagen bezüglich der Wirksamkeit der kombinierten Freisetzung der Faktoren auf die Knochenneubildungsrate getroffen werden, da die Vergleichbarkeit fehlt. Deshalb sollte das Gebiet der kontrollierten Freisetzung der Kombination von Wachstumsfaktoren weiter beforscht werden. Zusätzlich würde es das Verständnis der Prozesse in der Geweberegeneration fördern.

\subsubsection{Herstellung der Implantate}

Die Auswahl des Trägermaterials für die Beladung mit Wachstumsfaktoren ist typischerweise erforderlich um den Defekt zu füllen oder zu überbrücken und ist multifaktoriell. Das Gerüst muss bestenfalls die Knochenstruktur nachahmen, biokompatibel sein, biologisch abbaubar und gute biomechanische Eigenschaften aufweisen (Gothard et al. 2014).

Neben xenogenen Materialien, Trikalziumphosphat, Hydroxylapatit und Kollagen kommen polymerbasierte Ersatzstoffe wie das Polylactid zur Anwendung. Unzählige Studien beschäftigen sich mit der Frage nach der richtigen Zusammensetzung des Trägermaterials. So zum Beispiel Borselli et al. haben festgestellt, dass mit VEGF beladenen Polylaktid-coGlykolid (PLGA) Kopolymer in Verbindung mit Kollagengerüst höhere Rate an Vaskularisation aufwiesen als nur das mit VEGF beladene Kollagen (Borselli et al. 2010).

Andere benutzten als Trägermaterial ein natürliches Material wie Seide, Alginat oder Chitosan allein oder in Verbindung mit Polymer (Schliephake et al. 2015). De la Riva et al. führten In-vitro- und In-vivo-Untersuchungen zur Zusammensetzung des optimalen Trägermaterials durch. Dabei wurden die mit VEGF beladenen Alginat-, Chitosan- und Chitosan-Polymer-Träger auf deren Freisetzungskinetik untersucht. Die besten Ergebnisse brachten die kombinierten Träger mit Polymer (De la Riva et al. 2009). Kandziora et al. fanden 2002 heraus, dass in vivo die mit BM P beladenen PDLLA-Träger im Vergleich zu mit BM P beladenen Kollagenträger höhere Verknöcherungsraten aufwies, was auf die Fähigkeit zur kontrollierten Freisetzung des Trägermaterials hinweist (Kandziora et al. 2002)

Polylaktidbasierte Materialien erfüllen zwar viele der Kriterien für einen optimalen Trägerstoff, jedoch wirken sie bei deren Degradation der Knochenneubildung entgegen. Sie setzen beim Zerfall Milchsäure frei, die eine Entzündungsreaktion im Gewebe verursacht (Bergsma et al. 1995). Die In-vitro-Studie von Schliephake et al. stellte den Zeitpunkt des pHAbfalls mit 18 bis 21 Wochen fest (Schliephake et al. 2007). Um den pH-Abfall entgegen zu wirken setzte man Kalziumkarbonate oder Kalziumphosphate in unterschiedlicher Dosierung hinzu und bewirkte eine Neutralisierung der Milchsäure. Die so produzierten PolylaktidKalziumkarbonat-Implantate zeigten nach vollständigen Abbau einen Ersatz durch Knochen (Schiller et al. 2004; Backhaus et al. 2013). Zur Verbesserung der Freisetzung und der biologischen Wirksamkeit der Wachstumsfaktoren verwendete die In-vitro-Studie von Schliephake et al. eine lösungsmittelfreie Herstellung der Polylaktid-Kalziumkarbonat- 
Scaffolds mit Kohlendioxid-Überdruck-Behandlung. Sie stellten fest, dass die biologische Wirksamkeit und die Freisetzung des rhBMP2 im Vergleich zur lösungsmittelhaltigen Herstellung der Träger signifikant verbessert werden konnte (Schliephake et al. 2015).

Infolgedessen verwendeten wir als Trägerstoff für Wachstumsfaktoren VEGF und BMP lösungsmittelfreie Polylaktid-Kalziumkarbonat-Scaffolds um die Freisetzung in vivo zu untersuchen. Obwohl es zahlreiche Studien zum Einsatz von Polylaktid in der Literatur zu finden sind ist das vollständige Verstehen des Degradationsverhaltens, deren vollständiger Abbau, Ersatz durch Knochengewebe und die Freisetzungskinetik der Wachstumsfaktoren notwendig und sollte in weiteren In-vivo-Langzeitstudien untersucht werden.

\subsubsection{Tiermodell}

Ungeachtet der Fortschritte der In-vitro-Gewebeersatzforschung müssen Studien an Tieren durchgeführt werden um die Komplexität des Organismus in Gänze zu verstehen und das Verhalten der neuen M aterialien zu untersuchen.

Die Tiermodelle werden sorgfältig für das jeweilige zu untersuchende Material ausgewählt und können unter Studienbedingungen dazu beitragen das klinische Potential neuer Technologien wie den Einsatz von Wachstumsfaktoren zu beurteilen (Khan und Lane 2004). Yousefi et al. fanden in ihrer literaturzusammenfassenden Arbeit heraus, dass die Simulation der biomechanischen und biochemischen Vorgänge nur in vivo möglich ist (Yousefi et al. 2015). Das Tiermodell Ratte eignet sich gut zur Untersuchung der komplexen ineinandergreifenden Vorgänge der Knochenregeneration und kann Aussagen zur Biokompatibilität, Gewebeantwort (d.h. Einwachsen des Knochens in das Konstrukt), Abbaueigenschaften von Implantatmaterialien, Überleben von transplantierten Zellen und mechanische Funktion liefern (Muschler et al. 2010).

Gothard et al. führten in ihrer Übersichtsarbeit einen Vergleich zwischen verschiedenen Tiermodellen in Hinblick auf die Fragestellung der knöchernen Regeneration auf und stellten fest, dass Ratten als akzeptierte Spezies für die Imitierung von menschlichen Knochenstoffwechselvorgängen gelten (Gothard et al. 2014). Auch Untersuchungen an erkrankten Knochengewebe ( $z$. B. osteoporotischer Knochen), welches ein anderes Regenerationsmuster zeigt muss in vivo durchgeführt werden, da die veränderten Stoffwechselvorgänge in vitro nicht imitierbar sind (Poser et al. 2014).

Bei der Erforschung der Knochenregeneration im Rahmen dieser Studie war es besonders wichtig die Auswirkung der osteokonduktiven Trägermaterialien und osteoinduktiven Wachstumsfaktoren zur Unterstützung der osteogenen Regenerationsfähigkeit am lebenden Organismus zu untersuchen. Dieses ist unerlässlich in der Entwicklung geeigneter klinischer Therapiekonzepte. Wir verwendeten zur Durchführung der Experimente Sprague-DawleyRatten, die bereits in mehreren anderen Studien als geeignetes Tiermodell für die Untersuchung der Wirkung der Wachstumsfaktoren angewendet werden konnten (Saito et al. 2003; M uschler et al. 2010). Schlussendlich ist die Übertragbarkeit der Ergebnisse für die Anwendung im menschlichen Körper nicht vollständig möglich, da jedes Tiermodell nur 
teilweise die biomechanischen und biochemischen Verhältnisse im M enschen darstellt. Es ist also notwendig die Untersuchungen an verschiedenen Tiermodellen durchzuführen um die Vorhersagbarkeit in der späteren humanen Anwendung zu erhöhen (Horner et al. 2010).

\subsubsection{Durchführung der Auswertung}

Da das Digitale Volumentomogramm (DVT) in der Mund-, Kiefer- und Gesichtschirurgie zur alltäglichen Routine der Beurteilung des Knochens seit vielen Jahren gehört und als etabliertes Verfahren zur Auswertung des Knochens gilt wurde es von uns zur Beurteilung des neu gebildeten Knochens eingesetzt.

Kröpil et al. stellten fest, dass das DVT zur quantitativen M essung des Knochens nicht nur im Bereich der Gesichtsregion sondern auch im Bereich der Röhrenknochen eines Tiermodells eignet. Sie führten radiographische und histomorphometrische Auswertung des neu entstandenen Knochens durch und fanden heraus, dass die beiden Auswertungsmethoden zu 75\% übereinstimmten (Kröpil et al. 2012). Auch Cankaya et al. fanden heraus, dass die Ergebnisse der Knochenmessung einer Knochennekrose beim Rattenmodell im DVT mit den histomorphometrischen Ergebnissen korrelierten (Cankaya et al. 2011).

Jedoch bieten das DVT und deren Einstellungen wie auch andere radiologische Verfahren Fehlerquellen, was zur Fehlinterpretationen führen kann. Größere Voxelgrößen (0,3-0,4 mm) führen zur geringeren räumlichen Auflösung als kleinere Voxelgrößen. Es sollten möglichst kleine FOVs verwendet werden um das Seitenrauschen zu minimieren. Die Artefakte durch Zähne oder M etall müssen berücksichtigt werden. Eine möglichst lange Scanzeit verhindert Unterabtastung und schlechtere Auflösung. Die Computermonitore sollten möglichst hochauflösend sein. Bei der Auswertung muss man bedenken, dass in Umbau befindlicher Knochen mit osteoklastischer Aktivität weniger dicht dargestellt wird und fehlinterpretiert werden kann. Auch durch die Einführung von Kontrollgruppe und mehreren Versuchsgruppen können Fehlinterpretationen vermieden werden (M olen 2010).

In der von uns durchgeführten Untersuchung wurden alle oben genannten Kriterien berücksichtigt. Anschließend erfolgte die Auswertung des dreidimensionalen Scans mit Fiji/ImageJ-Programm. Schindelin et al. beschrieben bereits 2012 die Anwendung und die Vorteile des Programms (Schindelin et al. 2012).

\subsection{Diskussion der Ergebnisse}

Die Betrachtung der unterschiedlichen BM P-Konzentrationen in der lokalen Applikation der Faktoren gab die bereits bekannte Dosisabhängigkeit der Knochendichte und Knochenfläche von der BMP-Konzentration wieder. Vor allem die $96 \mu \mathrm{g}$-Gruppen unterschieden sich signifikant in radiographisch festgestellter Knochendichte und Knochenfläche nach vier Wochen. In der 13. Woche war keine Signifikanz beim erkennbaren Unterschied in der Dichte und Fläche nachweisbar (Abbildungen 9, 13). Die $24 \mu \mathrm{g}$ - und $48 \mu \mathrm{g}$-BM P-Gruppen 
ließen lediglich nach vier Wochen einen Unterschied in der Knochendichte erkennen, jedoch

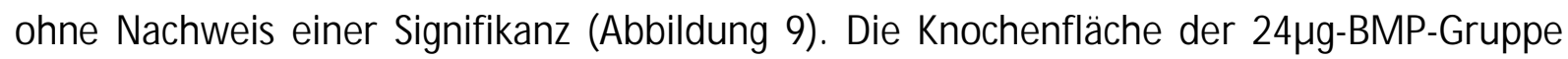
war signifikant unterschiedlich in der 4. und 13. Woche (Abbildung 13). Auch zahlreiche andere Studien belegten diese Dosisabhängigkeit der Knochenneubildung zu unterschiedlichen Zeitpunkten wie Gothard et.al. zusammengefasst hatte, wobei die Unterschiede in den BM P-Dosierungen stark voneinander abweichten (Gothard et al. 2014).

Bei der Untersuchung der Gruppen mit VEGF-Einzeldosierungen zeigten sich deutlich niedrigere Raten an Knochendichte und Knochenfläche im Vergleich zu Gruppen mit BM PEinzeldosierungen. Es konnte weder nach 4 Wochen noch nach 13 Wochen eine verbesserte Knochenneubildung nachgewiesen werden (Abbildungen 10, 14). Zum ähnlichen Ergebnis kamen Patel et al. und Xiao et al. in ihren In-vivo-Studien (Patel et al. 2008; Xiao et al. 2011). Die Kombinationsgruppen zeigten nach 4 und 13 Wochen in den Gruppen mit $48 \mu \mathrm{g}$ BM P

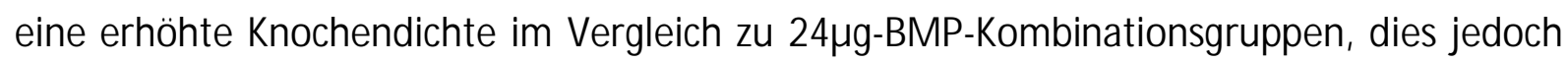
unabhängig von der VEGF-Konzentration und bei fehlender Signifikanz. Nach 13 Wochen hatte die Kombination aus 1,5 $\mu \mathrm{g}$ VEGF und $48 \mu \mathrm{g}$ BM P den größten Knochendichtezuwachs (Abbildung 11). Die Knochenfläche ergab lediglich einen Signifikanz relevanten Unterschied in der vierten Woche zwischen Kombinationen $6 \mu \mathrm{g} / 24 \mu \mathrm{g}$ und $6 \mu \mathrm{g} / 48 \mu \mathrm{g}$. Es zeigte sich eine Steigerung der Knochenfläche mit den steigenden BMP/VEGF-Konzentrationen. Dabei wies die Kombination $6 \mu \mathrm{g}$ VEGF mit $48 \mu \mathrm{g}$ BM P die größte Knochenfläche auf (Abbildung 15).

Im Vergleich der Kombinationsgruppen zu den Einzeldosierungen des BMP hat die

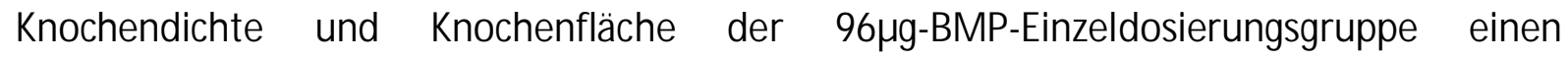
vergleichbaren Zuwachs über den Beobachtungszeitraum wie die Kombinationsgruppen mit $48 \mu \mathrm{g} \mathrm{BMP}$ (Abbildungen 12, 16). Auf Grund dieser Ergebnisse kann man vermuten, dass durch die Zugabe von geringen Dosen von VEGF die BMP-Konzentration halbiert werden kann. Dieses kann Vorteile in der Nebenwirkungsrate bringen, da die aktuell hohen klinisch eingesetzten Dosen von BMP Nebenwirkungen wie Schwellung, Wundheilungsstörungen und Knochenresorption hervorrufen (Carreira et al. 2014).

Auch Lohse und Mitarbeiter stellten in Ihrer histomorphometrischen und radiomorphometrischen slow release In-vivo-Untersuchung fest, dass geringe Dosen von VEGF in Kombination mit BMP im Bereich des Trägermaterials zu erhöhten Knochenvolumen und Knochendichte im Vergleich zu Einzeldosierungen von BM P führten. Im Gegensatz zur aktuellen Beobachtung in der Zeitabhängigkeit gab es hier einen Unterschied beim Knochenvolumen und Knochendichte. Die Knochendichte nahm zu und das Knochenvolumen $a b$, wobei der Unterschied der Kombinationsdosierungen zu den Einzeldosierungen bei beiden signifikant gewesen ist (Lohse et al. 2015).

Die Studien von Hernandez et al. und Patel et al. stellten ähnliche und signifikante Abhängigkeiten in den Untersuchungen der kombinierten Freisetzung von VEGF und BM $P$ fest (Patel et al. 2008; Hernàndez et al. 2012). Hernandez et al. fanden heraus, dass die kontrollierte Freisetzung von VEGF in Verbindung mit BMP für die Knochenregeneration vorteilhaft sein kann (Hernàndez et al. 2012). Im Gegensatz dazu zeigten die Untersuchungen von Young et al. und Kempen et al. eine Freisetzungssteigerung von VEGF in den ersten 24 Stunden in vitro bzw. drei Tagen in vivo und anschließenden raschen Abfall. 
Sie konnten zudem keinen signifikanten Unterschied der Kombinationsgruppen zu den BM PEinzelgruppen in den Auswertungszeitraum von 12 Wochen bzw. 8 Wochen feststellen (Kempen et al. 2009; Young et al. 2009). Das lässt vermuten, dass die kombinierte kontrollierte und langsame Freisetzung nicht nur von BMP sondern auch von VEGF für den Effekt der Knochenvolumenzunahme entscheidend ist.

Auch Vempati et al. stellten in ihrer Literaturrecherche fest, dass die Geschwindigkeit der VEGF-Sekretion ein wichtiger Treiber für die VEGF-induzierte Angiogenese ist. Diese wird durch unterschiedliche Prozesse unter anderem durch Diffusion, Sequestierung in der extrazellulären Matrix, enzymatische Freisetzung und kompetitive Bindung beeinflusst. Es besteht unterschiedliche Affinität der VEGF-Isoformen zur Bindung an extrazelluläre $M$ atrixproteine. Das von uns verwendete $\mathrm{VEGF}_{165}$ zeigt im Vergleich zu anderen Isoformen eine höhere Affinität zur in der Matrix befindlichen Heparinsulfat-Proteoglykanen, welche VEGF sequestrieren. Das bedeutet die Erhöhung des Gradienten und dadurch schnellere Induktion der Angiogenese (Vempati et al. 2014).

Diese Fakten bringen Unklarheit bezüglich des richtigen Zeitpunktes für die Gewebebildung durch VEGF und deren Auswertung. Durch die unterschiedlichen Mechanismen der Angiogenese vor allem durch das intussuszeptive Wachstum (Teilung der Kapillaren durch Bildung transkapillärer Säulen in zwei Tochterkapillaren) führt das VEGF zu rascher und umfangreicher Vaskularisierung im Bereich des Trägermaterials, begleitender Knochendifferenzierung und daraus resultierender Knochenvolumenzunahme (Vempati et al. 2014). Festzustellen ist, dass dieser Effekt nur dann zur Knochenvolumenzunahme führt, wenn ausreichend osteoinduktive Stoffe durch Freisetzung von BM P vorhanden sind (Lohse et al. 2015).

Peng et al. fanden 2005 durch eine in vitro/in vivo-Studie heraus, dass ein bestimmtes Verhältnis zwischen BMP und VEGF Auswirkungen auf die Höhe des Knochenvolumens hat und ein hoher Anteil an VEGF sogar die Knochenregeneration hemmt (Peng et al. 2005). Dies kann auf ein erhöhtes Rekrutieren von Osteoklasten beim Verwenden von hohen Dosen von VEGF zurückzuführen sein. Außerdem weist es darauf hin, dass VEGF-induziertes Knochenwachstum nicht nur von der Gefäßdichte und der Nährstoffversorgung abhängig ist. Die Literaturrecherche verdeutlicht, dass nicht nur BMP sondern auch VEGF einen direkten Effekt auf die Stammzellen ausübt und zur Differenzierung der Stammzellen beiträgt (Cui et al. 2013; M oser et al. 2018).

Andererseits können die von den Osteoblasten produzierten VEGF's unter Anwesenheit von BMP die notwendige Angiogenese für die Knochenregeneration assoziieren (Deckers et al. 2002). Das bedeutet, dass der Effekt der durch BM $P$ allein hervorgerufen wird bei niedrigen Konzentrationen von VEGF größer oder gleich ist zur Kombinationen der Faktoren.

Ein weiterer Grund für die Unterschiede in den Ergebnissen der Studien zur Knochenregeneration können neben den VEGF/BM P-Verhältnis die Möglichkeit zur kontrollierten Freisetzung aus den Trägermaterialien und die Verwendung unterschiedlicher Auswertungszeiten sein. So haben Hernandez et al. in ihrer Studie nicht nur BMP sondern auch VEGF verzögert freigesetzt und daraus resultierende erhöhte Knochenregeneration erzielt (Hernàndez et al. 2012). Die Untersuchung von Kempen et al. unterstützt diese 
Aussage, denn von ihm verwendetes Trägermaterial führte nur zur initialen VEGFFreisetzung was zur Abwesenheit der vermehrten Knochenregeneration in den VEGF/BM PGruppen durch fehlende kontrollierte VEGF-Freisetzung führte (Kempen et al. 2009).

Die Auswertungszeiten haben ebenfalls eine entscheidende Rolle in der Feststellung von Unterschieden. So haben Young et al. und Patel et al. zwar gleiches Trägermaterial für die Beladung mit Faktoren gewählt, jedoch erfolgte die Auswertung von Patel et al. nach 4 Wochen und 12 Wochen, wobei die signifikanten Ergebnisse nach 4 Wochen festzustellen waren. Während Young et al. ihre Studie nur zu einem Zeitpunkt, nach 12 Wochen auswerteten, wobei hier kein Effekt mehr festellbar war (Patel et al. 2008; Young et al. 2009).

\subsection{Ausblick}

Effektive Strategien auf dem Gebiet der Knochengewebsherstellung und -heilung, welche biochemische, biomechanische und physikalische Aspekte berücksichtigen, erfordern zur Imitierung der natürlichen Knochenregeneration eine Umgebung mit kontrollierter Freisetzung von mehreren unterschiedlichen Wachstumsfaktoren (Carreira et al. 2014). Dieses wissenschaftliche Gebiet hat in den letzten Jahren zwar gute Ergebnisse bezüglich verschiedener Kombinationen von angiogenen und osteogenen Wachstumsfaktoren mit und ohne Einsatz von Stammzellen erbracht, jedoch ohne sicheres Handling mit den jeweiligen Verhältnis der Faktorenkonzentrationen. Zudem bleibt die Herausforderung der Heilung und Rekonstruktion von Knochendefekten kritischer Größe durch Knochenersatzmaterialien, die auf Grund ihrer Größe eingeschränkte Gefäßversorgung aufweisen. Auch die gegenseitige Beeinflussung der Angio- und Osteogenese, Festlegung des potentesten Wachstumsfaktors für die Knochenregeneration und das Verbessern der Materialien für die kontrollierte Freisetzung der Faktoren sollte Gegenstand der zukünftigen Forschung auf den Gebiet der Knochenregeneration sein (Cui et al. 2013).

Die Ergebnisse dieser Studie können zum besseren Verständnis der Wechselwirkung der Wachstumsfaktoren beitragen. Der Effekt der Steigerung der Knochengeweberegeneration bei der die BM P-Konzentration durch die Zugabe von VEGF halbiert werden kann, wurde in dieser Studie gezeigt. Jedoch fehlt die notwendige Signifikanz, welche nur durch kontrollierte Freisetzung der Faktoren erreicht werden kann (Lohse et al. 2015). 


\section{Zusammenfassung}

Die vorliegende In-vivo-Studie an männlichen Wistar-Ratten hatte als Ziel eine Verbesserung der Knochenregeneration an Unterkieferdefekten kritischer Größe durch kombinierte Freisetzung von osteogenen (BMP) und angiogenen (VEGF) Faktoren. Die verwendeten $\mathrm{PDLLA} / \mathrm{CaCO}_{3}$-Komposit-Scaffolds wurden jeweils in Einzeldosierungen und kombiniert mit $24 \mu \mathrm{g}, 48 \mu \mathrm{g}$ und $96 \mu \mathrm{g}$ BMP sowie $1,5 \mu \mathrm{g}$ und $6 \mu \mathrm{g}$ VEGF durch Auftropfen und Adsorption beladen. Die so entstandenen Implantate konnten anschließend in die Kieferdefekte von Wistar-Ratten inseriert werden. Die Beobachtungszeiträume wurden auf 4 Wochen und 13 Wochen festgelegt. Nach dem Ablauf der festgelegten Zeiträume und der Präparation der Kiefer führten wir die radiologische Untersuchung mittels DVT und anschließende computergestützte radiomorphometrische Auswertung an rekonstruierten axialen Schnittbildern durch. Das dabei neu entstandene Knochenvolumen wurde in Prozent der Gesamtfläche der Kiefer angegeben und als Knochendichte statistisch mittels nichtparametrischer Varianzanalyse überprüft. Die neu entstandene Knochenfläche wurde in $\mathrm{mm}^{2}$ ausgedrückt und mittels 2-Wege-anova-Analyse bezüglich der Signifikanz verifiziert.

Der paarweise Vergleich der Ergebnisse ergab eine signifikant hohe Knochendichte für $96 \mu \mathrm{g} \mathrm{BM} \mathrm{P} \mathrm{im} \mathrm{Vergleich} \mathrm{zu} \mathrm{allen} \mathrm{anderen} \mathrm{Einzeldosierungen} \mathrm{und} \mathrm{Kombinationen} \mathrm{außer}$ für Kombinationen $1,5 \mu \mathrm{g} / 6 \mu \mathrm{g}$ VEGF mit $48 \mu \mathrm{g}$ BMP $(p \varangle 0,05)$. Keines der Implantate zeigte einen signifikanten Unterschied in der Knochendichte zwischen 4 Wochen und 13 Wochen. Der zeitabhängige Vergleich der Knochenfläche in den 4-Wochen-Gruppen

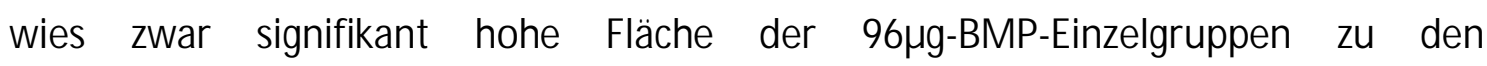
Einzeldosierungsgruppen und Kombinationsgruppen mit $24 \mu \mathrm{g}$ BMP nach. Jedoch fehlte der signifikante Unterschied zu den $48 \mu$ g-Kombinationsgruppen $(p \varangle 0,05)$. Nach 13 Wochen konnte dieser Effekt beim Vergleich der Knochenflächen nicht nachgewiesen werden.

Es konnte also gezeigt werden, dass in dem verwendeten Modell durch die kombinierte Freisetzung von VEGF und höheren Dosen von BMP mit einer Dosisreduktion des BM P um die Hälfte der gleiche Effekt der Knochenregeneration in Verbindung mit VEGF erzielt werden kann. 


\section{Anhang}

\subsection{Tabellen zur statistischen Analyse der Knochendichte}

Tabelle 2: Mittelwert + - Standardabweichung; Median (M inimum, Maximum) des Knochenvolumens in Prozent für 4 und 13 Wochen

\begin{tabular}{|c|c|c|}
\hline Implantat & 4 Wo & $13 \mathrm{Wo}_{0}$ \\
\hline BMP 24 & $7.48+/-2.49 ; 7.71(3.71,10.58)$ & $8.71+/-1.91 ; 8.7(6.14,10.85)$ \\
\hline BM P 48 & $8.75+-2.2 ; 8.25(6.55,12.82)$ & $8.66+/-1.07 ; 9(6.55,9.45)$ \\
\hline BMP 96 & $12.66+-2.83 ; 13.36(8.42,15.53)$ & $10.88+-1.11 ; 10.59(9.85,12.61)$ \\
\hline Blank & $0.15+/-0.11 ; 0.13(0.03,0.32)$ & $0.54+/-0.4 ; 0.46(0.09,1.05)$ \\
\hline Kombi $1.5+24$ & $6.99+/-1.86 ; 6.72(4.29,8.83)$ & $8.99+/-1.77 ; 9.09(6.54,11.29)$ \\
\hline Kombi $1.5+48$ & $10.26+1-1.9 ; 10.95(6.86,12.27)$ & 11.13 H- $2.04 ; 11.15(8.47,13.71)$ \\
\hline Kombi $6+24$ & $8.87+-1.36 ; 8.99(6.64,10.31)$ & $8.51+/-1.5 ; 8.63(6.51,10.57)$ \\
\hline Kombi $6+48$ & 10.81 H- $3.65 ; 11.04(6.98,15.49)$ & 10.76 t- $1.26 ; 10.46(9.44,12.71)$ \\
\hline VEGF 0,24 & $0.29+/-0.33 ; 0.09(0.04,0.77)$ & $0.19+-0.11 ; 0.15(0.13,0.42)$ \\
\hline VEGF 1,5 & $0.26+/-0.19 ; 0.17(0.1,0.55)$ & $0.46+/-0.34 ; 0.41(0.11,0.99)$ \\
\hline VEGF 6 & $1.37+/-1.72 ; 0.49(0.26,3.35)$ & $0.67+-0.49 ; 0.55(0.23,1.59)$ \\
\hline
\end{tabular}


Tabelle 3: Nichtparametrische ANOVA-Analyse

\begin{tabular}{|l|l|l|l|l|}
\hline Effect & Sum Sq & Df & F value & -value \\
\hline Implantat & 115755 & 10 & 37.8 & $<0.001$ \\
\hline Laufzeit & 529.6 & 1 & 0.3637 & 0.5478 \\
\hline Implantat:Laufzeit & 10980 & 10 & 0.8101 & 0.6195 \\
\hline
\end{tabular}


Tabelle 4: Mann-Whitney U-Test zum paarweisen Vergleich, P-Wertberechnung nach Bonferroni-Holm-M ethode

\begin{tabular}{|c|c|c|c|c|c|c|c|c|c|c|}
\hline & $\begin{array}{l}\text { BM P } \\
24\end{array}$ & $\begin{array}{l}\text { BM P } \\
48\end{array}$ & $\begin{array}{l}\text { BM P } \\
96\end{array}$ & Blank & $\begin{array}{l}\text { Kombi } \\
1.5+24\end{array}$ & $\begin{array}{l}\text { Kombi } \\
1.5+48\end{array}$ & $\begin{array}{l}\text { Kombi } \\
6+24\end{array}$ & $\begin{array}{l}\text { Kombi } \\
6+48\end{array}$ & $\begin{array}{l}\text { VEGF } \\
0,24\end{array}$ & $\begin{array}{l}\text { VEGF } \\
1,5\end{array}$ \\
\hline BM P 48 & 1 & & & & & & & & & \\
\hline BMP 96 & 0.0504 & 0.047 & & & & & & & & \\
\hline Blank & 0.0029 & 0.0022 & $\begin{array}{r}< \\
0.001\end{array}$ & & & & & & & \\
\hline $\begin{array}{l}\text { Kombi } \\
1.5+24\end{array}$ & 1 & 1 & 0.0281 & $\begin{array}{r}< \\
0.001\end{array}$ & & & & & & \\
\hline $\begin{array}{l}\text { Kombi } \\
1.5+48\end{array}$ & 0.1916 & 0.3201 & 1 & $\begin{array}{r}< \\
0.001\end{array}$ & $=0.1916$ & & & & & \\
\hline $\begin{array}{l}\text { Kombi } \\
6+24\end{array}$ & 1 & & 0.0364 & $\begin{array}{r}< \\
0.001\end{array}$ & 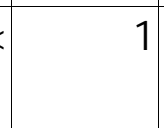 & 0.2439 & & & & \\
\hline $\begin{array}{l}\text { Kombi } \\
6+48\end{array}$ & 0.4617 & 0.4453 & 1 & $\begin{array}{r}< \\
0.001\end{array}$ & $=0.2115$ & 1 & 0.5613 & & & \\
\hline $\begin{array}{l}\text { VEGF } \\
0,24\end{array}$ & 0.0029 & 0.0022 & 0.0029 & 1 & 0.0029 & 0.0029 & 0.0029 & 0.0022 & & \\
\hline $\begin{array}{l}\text { VEGF } \\
1,5\end{array}$ & 0.0029 & 0.0022 & $\begin{array}{r}< \\
0.001\end{array}$ & $=$ & $<0.001$ & $<0.001$ & $<0.001$ & $<0.001$ & 1 & \\
\hline VEGF 6 & 0.0055 & 0.0041 & $\begin{array}{r}< \\
0.001\end{array}$ & $=0.9442$ & $<0.001$ & $<0.001$ & $<0.001$ & $<0.001$ & 0.1916 & 1 \\
\hline
\end{tabular}




\subsection{Tabellen zur statistischen Analyse der Knochenfläche}

Tabelle 5: Zwei-Wege-ANOVA-Analyse, Sidak's multiple comparisons test für 4 Wochen und 13 Wochen. ns nicht signifikant, * signifikant

\begin{tabular}{|c|c|c|c|c|c|}
\hline & $\begin{array}{l}\text { Mean } \\
\text { Differenc } \\
\text { e }\end{array}$ & $\begin{array}{l}95 \% \\
\text { Confidenc } \\
\text { e Interval } \\
\text { of } \\
\text { Difference }\end{array}$ & $\begin{array}{l}\text { Significan } \\
\mathrm{t}\end{array}$ & $\begin{array}{l}\text { Summar } \\
\mathrm{y}\end{array}$ & $\begin{array}{l}\text { Adjuste } \\
\text { d P } \\
\text { Value }\end{array}$ \\
\hline \multicolumn{6}{|l|}{4 Wochen } \\
\hline BM P $24 \mu \mathrm{g}$ vs. BM P $48 \mu \mathrm{g}$ & -1209 & $\begin{array}{l}-4066 \text { to } \\
1649\end{array}$ & No & ns & 0,9999 \\
\hline BM P $24 \mu \mathrm{g}$ vs. BM P $96 \mu \mathrm{g}$ & -4152 & $\begin{array}{l}-7137 \text { to }- \\
1167\end{array}$ & Yes & $* * *$ & 0,0004 \\
\hline BM P $24 \mu \mathrm{g}$ vs. VEGF $0,24 \mu \mathrm{g}$ & 4302 & $\begin{array}{l}1318 \text { to } \\
7287\end{array}$ & Yes & $* * *$ & 0,0002 \\
\hline BM P $24 \mu \mathrm{g}$ vs. VEGF $1,5 \mu \mathrm{g}$ & 4322 & $\begin{array}{l}1338 \text { to } \\
7307\end{array}$ & Yes & $* * *$ & 0,0002 \\
\hline BM P $24 \mu \mathrm{g}$ vs. VEGF $6 \mu \mathrm{g}$ & 3686 & $\begin{array}{l}239,6 \text { to } \\
7132\end{array}$ & Yes & $*$ & 0,0229 \\
\hline $\begin{array}{l}\text { BM P } 24 \mu \mathrm{g} \text { vs. Kombi } \\
1.5+24 \mu \mathrm{g}\end{array}$ & $-991,6$ & $\begin{array}{l}-3976 \text { to } \\
1993\end{array}$ & No & ns & $>0,9999$ \\
\hline $\begin{array}{l}\text { BM P } 24 \mu \mathrm{g} \text { vs. Kombi } \\
6+24 \mu \mathrm{g}\end{array}$ & $-362,4$ & $\begin{array}{l}-3347 \text { to } \\
2622\end{array}$ & No & ns & $>0,9999$ \\
\hline $\begin{array}{l}\text { BM P } 24 \mu \mathrm{g} \text { vs. Kombi } \\
1.5+48 \mu \mathrm{g}\end{array}$ & -2544 & $\begin{array}{l}-5402 \text { to } \\
313,2\end{array}$ & No & ns & 0,154 \\
\hline $\begin{array}{l}\text { BM P } 24 \mu \mathrm{g} \text { vs. Kombi } \\
6+48 \mu \mathrm{g}\end{array}$ & -3251 & $\begin{array}{l}-6108 \text { to }- \\
393,3\end{array}$ & Yes & $*$ & 0,0102 \\
\hline BM P $24 \mu \mathrm{g}$ vs. Blank & 4402 & $\begin{array}{l}1418 \text { to } \\
7387\end{array}$ & Yes & $* * *$ & 0,0001 \\
\hline BM P $48 \mu \mathrm{g}$ vs. BM P $96 \mu \mathrm{g}$ & -2943 & $\begin{array}{l}-5801 \text { to - } \\
85,86\end{array}$ & Yes & $*$ & 0,0359 \\
\hline BM P $48 \mu \mathrm{g}$ vs. VEGF $0,24 \mu \mathrm{g}$ & 5511 & $\begin{array}{l}2654 \text { to } \\
8369\end{array}$ & Yes & $* * * *$ & $\varangle, 0001$ \\
\hline 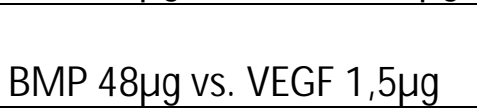 & 5531 & $\begin{array}{l}2674 \text { to } \\
8389\end{array}$ & Yes & $* * * *$ & $\varangle, 0001$ \\
\hline BM P $48 \mu \mathrm{g}$ vs. VEGF $6 \mu \mathrm{g}$ & 4895 & $\begin{array}{l}1558 \text { to } \\
8231\end{array}$ & Yes & $* * *$ & 0,0001 \\
\hline $\begin{array}{l}\text { BM P } 48 \mu \mathrm{g} \text { vs. Kombi } \\
1.5+24 \mu \mathrm{g}\end{array}$ & 217 & $\begin{array}{l}-2640 \text { to } \\
3075\end{array}$ & No & ns & $>0,9999$ \\
\hline $\begin{array}{l}\text { BM P } 48 \mu \mathrm{g} \text { vs. Kombi } \\
6+24 \mu \mathrm{g}\end{array}$ & 846,2 & $\begin{array}{l}-2011 \text { to } \\
3704\end{array}$ & No & ns & $>0,9999$ \\
\hline
\end{tabular}




\begin{tabular}{|c|c|c|c|c|c|}
\hline & $\begin{array}{l}\text { Mean } \\
\text { Differenc } \\
\text { e }\end{array}$ & $\begin{array}{l}95 \% \\
\text { Confidenc } \\
\text { e Interval } \\
\text { of } \\
\text { Difference }\end{array}$ & $\begin{array}{l}\text { Significan } \\
t\end{array}$ & $\begin{array}{l}\text { Summar } \\
\text { y }\end{array}$ & $\begin{array}{l}\text { Adjuste } \\
d P \\
\text { Value }\end{array}$ \\
\hline $\begin{array}{l}\text { BM P } 48 \mu \mathrm{g} \text { vs. Kombi } \\
1.5+48 \mu \mathrm{g}\end{array}$ & -1336 & $\begin{array}{l}-4060 \text { to } \\
1389\end{array}$ & No & ns & 0,9964 \\
\hline $\begin{array}{l}\text { BM P } 48 \mu \mathrm{g} \text { vs. Kombi } 6+48 \mu \\
\mathrm{g}\end{array}$ & -2042 & $\begin{array}{l}-4767 \text { to } \\
682,4\end{array}$ & No & ns & 0,4863 \\
\hline BM P 48ug vs. Blank & 5611 & $\begin{array}{l}2754 \text { to } \\
8469\end{array}$ & Yes & $* * * *$ & $\varangle 0,0001$ \\
\hline BM P $96 \mu \mathrm{g}$ vs. VEGF $0,24 \mu \mathrm{g}$ & 8454 & $\begin{array}{l}5470 \text { to } \\
11439\end{array}$ & Yes & $* * * *$ & $\varangle, 0001$ \\
\hline BM P $96 \mu \mathrm{g}$ vs. VEGF $1,5 \mu \mathrm{g}$ & 8474 & $\begin{array}{l}5490 \text { to } \\
11459\end{array}$ & Yes & $* * * *$ & $\varangle 0,0001$ \\
\hline 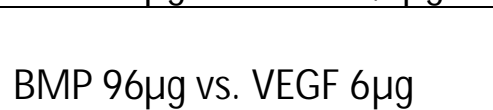 & 7838 & $\begin{array}{l}4392 \text { to } \\
11284\end{array}$ & Yes & $* * * *$ & $\varangle, 0001$ \\
\hline $\begin{array}{l}\text { BM P 96ug vs. Kombi } \\
1.5+24 \mu \mathrm{g}\end{array}$ & 3160 & $\begin{array}{l}175,8 \text { to } \\
6145\end{array}$ & Yes & * & 0,0258 \\
\hline 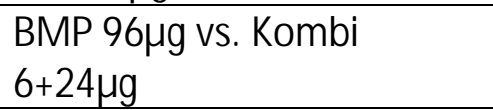 & 3790 & $\begin{array}{l}805 \text { to } \\
6774\end{array}$ & Yes & $* *$ & 0,0019 \\
\hline $\begin{array}{l}\text { BM P } 96 \mu \mathrm{g} \text { vs. Kombi } \\
1.5+48 \mu \mathrm{g}\end{array}$ & 1608 & $\begin{array}{l}-1250 \text { to } \\
4465\end{array}$ & No & ns & 0,962 \\
\hline $\begin{array}{l}\text { BM P } 96 \mu \mathrm{g} \text { vs. Kombi } \\
6+48 \mu \mathrm{g}\end{array}$ & 901,2 & $\begin{array}{l}-1956 \text { to } \\
3759\end{array}$ & No & ns & $>0,9999$ \\
\hline 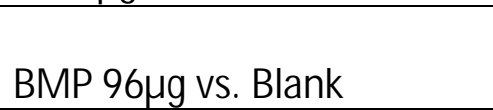 & 8554 & $\begin{array}{l}5570 \text { to } \\
11539\end{array}$ & Yes & $* * * *$ & $\varangle 0,0001$ \\
\hline $\begin{array}{l}\text { VEGF } 0,24 \mu \mathrm{g} \text { vs. VEGF } \\
1,5 \mu \mathrm{g}\end{array}$ & 20 & $\begin{array}{l}-2965 \text { to } \\
3005\end{array}$ & No & ns & $>0,9999$ \\
\hline VEGF $0,24 \mu \mathrm{g}$ vs. VEGF $6 \mu \mathrm{g}$ & $-616,5$ & $\begin{array}{l}-4063 \text { to } \\
2830\end{array}$ & No & ns & $>0,9999$ \\
\hline $\begin{array}{l}\text { VEGF } 0,24 \mu \mathrm{g} \text { vs. Kombi } \\
1.5+24 \mu \mathrm{g}\end{array}$ & -5294 & $\begin{array}{l}-8279 \text { to }- \\
2309\end{array}$ & Yes & $* * * *$ & $\varangle, 0001$ \\
\hline $\begin{array}{l}\text { VEGF } 0,24 \mu \mathrm{g} \text { vs. Kombi } \\
6+24 \mu \mathrm{g}\end{array}$ & -4665 & $\begin{array}{l}-7649 \text { to }- \\
1680\end{array}$ & Yes & $* * * *$ & $\varangle, 0001$ \\
\hline $\begin{array}{l}\text { VEGF } 0,24 \mu \mathrm{g} \text { vs. Kombi } \\
1.5+48 \mu \mathrm{g}\end{array}$ & -6847 & $\begin{array}{l}-9704 \text { to - } \\
3989\end{array}$ & Yes & $* * * *$ & $\varangle, 0001$ \\
\hline $\begin{array}{l}\text { VEGF } 0,24 \mu \mathrm{g} \text { vs. Kombi } \\
6+48 \mu \mathrm{g}\end{array}$ & -7553 & $\begin{array}{l}-10411 \text { to } \\
-4696\end{array}$ & Yes & $* * * *$ & $\varangle, 0001$ \\
\hline VEGF $0,24 \mu \mathrm{g}$ vs. Blank & 100 & $\begin{array}{l}-2885 \text { to } \\
3085\end{array}$ & No & ns & $>0,9999$ \\
\hline VEGF $1,5 \mu \mathrm{g}$ vs. VEGF $6 \mu \mathrm{g}$ & $-636,5$ & $\begin{array}{l}-4083 \text { to } \\
2810\end{array}$ & No & ns & $>0,9999$ \\
\hline $\begin{array}{l}\text { VEGF } 1,5 \mu \mathrm{g} \text { vs. Kombi } \\
1.5+24 \mu \mathrm{g}\end{array}$ & -5314 & $\begin{array}{l}-8299 \text { to }- \\
2329\end{array}$ & Yes & $* * * *$ & $\varangle, 0001$ \\
\hline $\begin{array}{l}\text { VEGF } 1,5 \mu \mathrm{g} \text { vs. Kombi } \\
6+24 \mu \mathrm{g}\end{array}$ & -4685 & $\begin{array}{l}-7669 \text { to }- \\
1700\end{array}$ & Yes & $* * * *$ & $\varangle 0,0001$ \\
\hline
\end{tabular}




\begin{tabular}{|c|c|c|c|c|c|}
\hline & $\begin{array}{l}\text { Mean } \\
\text { Differenc } \\
\text { e }\end{array}$ & $\begin{array}{l}95 \% \\
\text { Confidenc } \\
\text { e Interval } \\
\text { of } \\
\text { Difference }\end{array}$ & $\begin{array}{l}\text { Significan } \\
\mathrm{t}\end{array}$ & $\begin{array}{l}\text { Summar } \\
\mathrm{y}\end{array}$ & $\begin{array}{l}\text { Adjuste } \\
\text { d P } \\
\text { Value }\end{array}$ \\
\hline $\begin{array}{l}\text { VEGF } 1,5 \mu \mathrm{g} \text { vs. Kombi } \\
1.5+48 \mu \mathrm{g}\end{array}$ & -6867 & $\begin{array}{l}-9724 \text { to }- \\
4009\end{array}$ & Yes & $* * * *$ & $\varangle, 0001$ \\
\hline $\begin{array}{l}\text { VEGF } 1,5 \mu \mathrm{g} \text { vs. Kombi } \\
6+48 \mu \mathrm{g}\end{array}$ & -7573 & $\begin{array}{l}-10431 \text { to } \\
-4716\end{array}$ & Yes & $* * * *$ & $\varangle, 0001$ \\
\hline VEGF $1,5 \mu \mathrm{g}$ vs. Blank & 80 & $\begin{array}{l}-2905 \text { to } \\
3065\end{array}$ & No & ns & $>0,9999$ \\
\hline $\begin{array}{l}\text { VEGF } 6 \mu \mathrm{g} \text { vs. Kombi } \\
1.5+24 \mu \mathrm{g}\end{array}$ & -4677 & $\begin{array}{l}-8124 \text { to }- \\
1231\end{array}$ & Yes & $* * *$ & 0,0006 \\
\hline $\begin{array}{l}\text { VEGF } 6 \mu \mathrm{g} \text { vs. Kombi } \\
6+24 \mu \mathrm{g}\end{array}$ & -4048 & $\begin{array}{l}-7495 \text { to }- \\
602\end{array}$ & Yes & $* *$ & 0,0065 \\
\hline $\begin{array}{l}\text { VEGF } 6 \mu \mathrm{g} \text { vs. Kombi } \\
1.5+48 \mu \mathrm{g}\end{array}$ & -6230 & $\begin{array}{l}-9567 \text { to - } \\
2893\end{array}$ & Yes & $* * * *$ & $\varangle, 0001$ \\
\hline $\begin{array}{l}\text { VEGF } 6 \mu \mathrm{g} \text { vs. Kombi } \\
6+48 \mu \mathrm{g}\end{array}$ & -6937 & $\begin{array}{l}-10274 \text { to } \\
-3600\end{array}$ & Yes & $* * * *$ & $\varangle, 0001$ \\
\hline VEGF $6 \mu \mathrm{g}$ vs. Blank & 716,5 & $\begin{array}{l}-2730 \text { to } \\
4163\end{array}$ & No & ns & $>0,9999$ \\
\hline $\begin{array}{l}\text { Kombi } 1.5+24 \mu g \text { vs. Kombi } \\
6+24 \mu g\end{array}$ & 629,2 & $\begin{array}{l}-2355 \text { to } \\
3614\end{array}$ & No & ns & $>0,9999$ \\
\hline $\begin{array}{l}\text { Kombi } 1.5+24 \mu \mathrm{g} \text { vs. Kombi } \\
1.5+48 \mu \mathrm{g}\end{array}$ & -1553 & $\begin{array}{l}-4410 \text { to } \\
1305\end{array}$ & No & ns & 0,9775 \\
\hline $\begin{array}{l}\text { Kombi } 1.5+24 \mu \mathrm{g} \text { vs. Kombi } \\
6+48 \mu \mathrm{g}\end{array}$ & -2259 & $\begin{array}{l}-5117 \text { to } \\
598,3\end{array}$ & No & ns & 0,364 \\
\hline Kombi $1.5+24 \mu \mathrm{g}$ vs. Blank & 5394 & $\begin{array}{l}2409 \text { to } \\
8379\end{array}$ & Yes & $* * * *$ & $\varangle, 0001$ \\
\hline $\begin{array}{l}\text { Kombi } 6+24 \mu \mathrm{g} \text { vs. Kombi } \\
1.5+48 \mu \mathrm{g}\end{array}$ & -2182 & $\begin{array}{l}-5039 \text { to } \\
675,6\end{array}$ & No & ns & 0,4427 \\
\hline $\begin{array}{l}\text { Kombi } 6+24 \mu \mathrm{g} \text { vs. Kombi } \\
6+48 \mu \mathrm{g}\end{array}$ & -2888 & $\begin{array}{l}-5746 \text { to }- \\
30,89\end{array}$ & Yes & $*$ & 0,0444 \\
\hline Kombi $6+24 \mu \mathrm{g}$ vs. Blank & 4765 & $\begin{array}{l}1780 \text { to } \\
7749\end{array}$ & Yes & $* * * *$ & $\varangle, 0001$ \\
\hline $\begin{array}{l}\text { Kombi } 1.5+48 \mu g \text { vs. Kombi } \\
6+48 \mu g\end{array}$ & $-706,5$ & $\begin{array}{l}-3431 \text { to } \\
2018\end{array}$ & No & ns & $>0,9999$ \\
\hline Kombi $1.5+48 \mu \mathrm{g}$ vs. Blank & 6947 & $\begin{array}{l}4089 \text { to } \\
9804\end{array}$ & Yes & $* * * *$ & $\varangle, 0001$ \\
\hline Kombi $6+48 \mu \mathrm{g}$ vs. Blank & 7653 & $\begin{array}{l}4796 \text { to } \\
10511 \\
\end{array}$ & Yes & $* * * *$ & $\varangle, 0001$ \\
\hline \multicolumn{6}{|l|}{13 Wochen } \\
\hline BM P $24 \mu \mathrm{g}$ vs. BM P $48 \mu \mathrm{g}$ & 1173 & $\begin{array}{l}-1552 \text { to } \\
3897\end{array}$ & No & ns & 0,9998 \\
\hline BM P $24 \mu \mathrm{g}$ vs. BM P $96 \mu \mathrm{g}$ & -1294 & $\begin{array}{l}-4019 \text { to } \\
1430\end{array}$ & No & ns & 0,9982 \\
\hline
\end{tabular}




\begin{tabular}{|c|c|c|c|c|c|}
\hline & $\begin{array}{l}\text { Mean } \\
\text { Differenc } \\
\text { e }\end{array}$ & $\begin{array}{l}95 \% \\
\text { Confidenc } \\
\text { e Interval } \\
\text { of } \\
\text { Difference }\end{array}$ & $\begin{array}{l}\text { Significan } \\
t\end{array}$ & $\begin{array}{l}\text { Summar } \\
\mathrm{y}\end{array}$ & $\begin{array}{l}\text { Adjuste } \\
\text { d P } \\
\text { Value }\end{array}$ \\
\hline BM P $24 \mu \mathrm{g}$ vs. VEGF $0,24 \mu \mathrm{g}$ & 7319 & $\begin{array}{l}4594 \text { to } \\
10043\end{array}$ & Yes & $* * * *$ & $\varangle, 0001$ \\
\hline BM P $24 \mu \mathrm{g}$ vs. VEGF $1,5 \mu \mathrm{g}$ & 7135 & $\begin{array}{l}4410 \text { to } \\
9859\end{array}$ & Yes & $* * * *$ & $\varangle, 0001$ \\
\hline 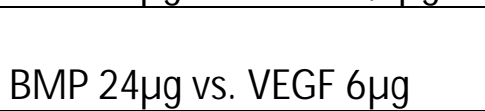 & 6962 & $\begin{array}{l}4237 \text { to } \\
9687\end{array}$ & Yes & $* * * *$ & $\varangle, 0001$ \\
\hline $\begin{array}{l}\text { BM P } 24 \mu \mathrm{g} \text { vs. Kombi } \\
1.5+24 \mu \mathrm{g}\end{array}$ & 1211 & $\begin{array}{l}-1514 \text { to } \\
3935\end{array}$ & No & ns & 0,9996 \\
\hline $\begin{array}{l}\text { BM P } 24 \mu \mathrm{g} \text { vs. Kombi } \\
6+24 \mu \mathrm{g}\end{array}$ & 665,5 & $\begin{array}{l}-2059 \text { to } \\
3390\end{array}$ & No & ns & $>0,9999$ \\
\hline $\begin{array}{l}\text { BM P } 24 \mu \mathrm{g} \text { vs. Kombi } \\
1.5+48 \mu \mathrm{g}\end{array}$ & $-450,7$ & $\begin{array}{l}-3308 \text { to } \\
2407\end{array}$ & No & ns & $>0,9999$ \\
\hline $\begin{array}{l}\text { BM P } 24 \mu \mathrm{g} \text { vs. Kombi } \\
6+48 \mu \mathrm{g}\end{array}$ & -599 & $\begin{array}{l}-3324 \text { to } \\
2126\end{array}$ & No & ns & $>0,9999$ \\
\hline BM P $24 \mu \mathrm{g}$ vs. Blank & 7111 & $\begin{array}{l}4386 \text { to } \\
9835\end{array}$ & Yes & $* * * *$ & $\varangle, 0001$ \\
\hline 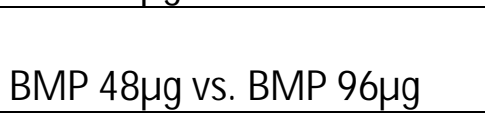 & -2467 & $\begin{array}{l}-5191 \text { to } \\
257,7\end{array}$ & No & ns & 0,1333 \\
\hline BM P $48 \mu \mathrm{g}$ vs. VEGF $0,24 \mu \mathrm{g}$ & 6146 & $\begin{array}{l}3422 \text { to } \\
8871\end{array}$ & Yes & $* * * *$ & $\varangle, 0001$ \\
\hline BM P $48 \mu \mathrm{g}$ vs. VEGF $1,5 \mu \mathrm{g}$ & 5962 & $\begin{array}{l}3238 \text { to } \\
8687\end{array}$ & Yes & $* * * *$ & $\varangle, 0001$ \\
\hline BM P $48 \mu \mathrm{g}$ vs. VEGF $6 \mu \mathrm{g}$ & 5790 & $\begin{array}{l}3065 \text { to } \\
8514\end{array}$ & Yes & $* * * *$ & $\varangle, 0001$ \\
\hline $\begin{array}{l}\text { BM P } 48 \mu \mathrm{g} \text { vs. Kombi } \\
1.5+24 \mu \mathrm{g}\end{array}$ & 38,33 & $\begin{array}{l}-2686 \text { to } \\
2763\end{array}$ & No & ns & $>0,9999$ \\
\hline $\begin{array}{l}\text { BM P } 48 \mu \mathrm{g} \text { vs. Kombi } \\
6+24 \mu \mathrm{g}\end{array}$ & -507 & $\begin{array}{l}-3232 \text { to } \\
2218\end{array}$ & No & ns & $>0,9999$ \\
\hline $\begin{array}{l}\text { BM P } 48 \mu \mathrm{g} \text { vs. Kombi } \\
1.5+48 \mu \mathrm{g}\end{array}$ & -1623 & $\begin{array}{l}-4481 \text { to } \\
1234\end{array}$ & No & ns & 0,9564 \\
\hline $\begin{array}{l}\text { BM P } 48 \mu \mathrm{g} \text { vs. Kombi } \\
6+48 \mu \mathrm{g}\end{array}$ & -1772 & $\begin{array}{l}-4496 \text { to } \\
953\end{array}$ & No & ns & 0,7991 \\
\hline BM P $48 \mu \mathrm{g}$ vs. Blank & 5938 & $\begin{array}{l}3213 \text { to } \\
8663\end{array}$ & Yes & $* * * *$ & $\varangle, 0001$ \\
\hline BM P $96 \mu \mathrm{g}$ vs. VEGF $0,24 \mu \mathrm{g}$ & 8613 & $\begin{array}{l}5888 \text { to } \\
11338\end{array}$ & Yes & $* * * *$ & $\varangle, 0001$ \\
\hline BM P $96 \mu \mathrm{g}$ vs. VEGF $1,5 \mu \mathrm{g}$ & 8429 & $\begin{array}{l}5705 \text { to } \\
11154\end{array}$ & Yes & $* * * *$ & $\varangle, 0001$ \\
\hline 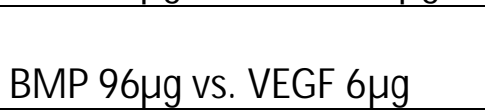 & 8256 & $\begin{array}{l}5532 \text { to } \\
10981\end{array}$ & Yes & $* * * *$ & $\varangle, 0001$ \\
\hline $\begin{array}{l}\text { BM P } 96 \mu \mathrm{g} \text { vs. Kombi } \\
1.5+24 \mu \mathrm{g}\end{array}$ & 2505 & $\begin{array}{l}-219,4 \text { to } \\
5230\end{array}$ & No & ns & 0,116 \\
\hline
\end{tabular}




\begin{tabular}{|c|c|c|c|c|c|}
\hline & $\begin{array}{l}\text { Mean } \\
\text { Differenc } \\
\text { e }\end{array}$ & $\begin{array}{l}95 \% \\
\text { Confidenc } \\
\text { e Interval } \\
\text { of } \\
\text { Difference }\end{array}$ & $\begin{array}{l}\text { Significan } \\
\mathrm{t}\end{array}$ & $\begin{array}{l}\text { Summar } \\
\text { y }\end{array}$ & $\begin{array}{l}\text { Adjuste } \\
\text { d P } \\
\text { Value }\end{array}$ \\
\hline $\begin{array}{l}\text { BM P 96 } \mu \mathrm{g} \text { vs. Kombi } \\
6+24 \mu \mathrm{g}\end{array}$ & 1960 & $\begin{array}{l}-764,7 \text { to } \\
4684\end{array}$ & No & ns & 0,5842 \\
\hline $\begin{array}{l}\text { BM P } 96 \mu \mathrm{g} \text { vs. Kombi } \\
1.5+48 \mu \mathrm{g}\end{array}$ & 843,6 & $\begin{array}{l}-2014 \text { to } \\
3701\end{array}$ & No & ns & $>0,9999$ \\
\hline $\begin{array}{l}\text { BM P } 96 \mu \mathrm{g} \text { vs. Kombi } \\
6+48 \mu \mathrm{g}\end{array}$ & 695,3 & $\begin{array}{l}-2029 \text { to } \\
3420\end{array}$ & No & ns & $>0,9999$ \\
\hline 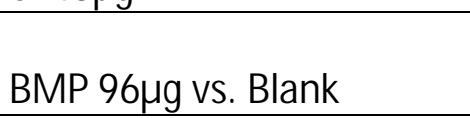 & 8405 & $\begin{array}{l}5680 \text { to } \\
11129\end{array}$ & Yes & $* * * *$ & $\varangle, 0001$ \\
\hline $\begin{array}{l}\text { VEGF } 0,24 \mu \mathrm{g} \text { vs. VEGF } \\
1,5 \mu \mathrm{g}\end{array}$ & $-183,8$ & $\begin{array}{l}-2908 \text { to } \\
2541\end{array}$ & No & ns & $>0,9999$ \\
\hline VEGF $0,24 \mu \mathrm{g}$ vs. VEGF $6 \mu \mathrm{g}$ & $-356,7$ & $\begin{array}{l}-3081 \text { to } \\
2368\end{array}$ & No & ns & $>0,9999$ \\
\hline $\begin{array}{l}\text { VEGF } 0,24 \mu \mathrm{g} \text { vs. Kombi } \\
1.5+24 \mu \mathrm{g}\end{array}$ & -6108 & $\begin{array}{l}-8832 \text { to - } \\
3383\end{array}$ & Yes & $* * * *$ & $\varangle, 0001$ \\
\hline $\begin{array}{l}\text { VEGF } 0,24 \mu \mathrm{g} \text { vs. Kombi } \\
6+24 \mu \mathrm{g}\end{array}$ & -6653 & $\begin{array}{l}-9378 \text { to - } \\
3929\end{array}$ & Yes & $* * * *$ & $\varangle, 0001$ \\
\hline $\begin{array}{l}\text { VEGF } 0,24 \mu \mathrm{g} \text { vs. Kombi } \\
1.5+48 \mu \mathrm{g}\end{array}$ & -7769 & $\begin{array}{l}-10627 \text { to } \\
-4912\end{array}$ & Yes & $* * * *$ & $\varangle, 0001$ \\
\hline $\begin{array}{l}\text { VEGF } 0,24 \mu \mathrm{g} \text { vs. Kombi } \\
6+48 \mu \mathrm{g}\end{array}$ & -7918 & $\begin{array}{l}-10642 \text { to } \\
-5193\end{array}$ & Yes & $* * * *$ & $\varangle, 0001$ \\
\hline VEGF $0,24 \mu \mathrm{g}$ vs. Blank & $-208,2$ & $\begin{array}{l}-2933 \text { to } \\
2516\end{array}$ & No & ns & $>0,9999$ \\
\hline VEGF $1,5 \mu \mathrm{g}$ vs. VEGF $6 \mu \mathrm{g}$ & $-172,8$ & $\begin{array}{l}-2897 \text { to } \\
2552\end{array}$ & No & ns & $>0,9999$ \\
\hline $\begin{array}{l}\text { VEGF } 1,5 \mu \mathrm{g} \text { vs. Kombi } \\
1.5+24 \mu \mathrm{g}\end{array}$ & -5924 & $\begin{array}{l}-8649 \text { to - } \\
3199\end{array}$ & Yes & $* * * *$ & $\varangle, 0001$ \\
\hline $\begin{array}{l}\text { VEGF } 1,5 \mu \mathrm{g} \text { vs. Kombi } \\
6+24 \mu \mathrm{g}\end{array}$ & -6469 & $\begin{array}{l}-9194 \text { to }- \\
3745\end{array}$ & Yes & $* * * *$ & $\varangle, 0001$ \\
\hline $\begin{array}{l}\text { VEGF } 1,5 \mu \mathrm{g} \text { vs. Kombi } \\
1.5+48 \mu \mathrm{g}\end{array}$ & -7586 & $\begin{array}{l}-10443 \text { to } \\
-4728\end{array}$ & Yes & $* * * *$ & $\varangle, 0001$ \\
\hline $\begin{array}{l}\text { VEGF } 1,5 \mu \mathrm{g} \text { vs. Kombi } \\
6+48 \mu \mathrm{g}\end{array}$ & -7734 & $\begin{array}{l}-10458 \text { to } \\
-5009\end{array}$ & Yes & $* * * *$ & $\varangle, 0001$ \\
\hline VEGF $1,5 \mu \mathrm{g}$ vs. Blank & $-24,33$ & $\begin{array}{l}-2749 \text { to } \\
2700\end{array}$ & No & ns & $>0,9999$ \\
\hline $\begin{array}{l}\text { VEGF } 6 \mu \mathrm{g} \text { vs. Kombi } \\
1.5+24 \mu \mathrm{g}\end{array}$ & -5751 & $\begin{array}{l}-8476 \text { to - } \\
3027\end{array}$ & Yes & $* * * *$ & $\varangle, 0001$ \\
\hline $\begin{array}{l}\text { VEGF } 6 \mu \mathrm{g} \text { vs. Kombi } \\
6+24 \mu \mathrm{g}\end{array}$ & -6297 & $\begin{array}{l}-9021 \text { to - } \\
3572\end{array}$ & Yes & $* * * *$ & $\varangle, 0001$ \\
\hline $\begin{array}{l}\text { VEGF } 6 \mu \mathrm{g} \text { vs. Kombi } \\
1.5+48 \mu \mathrm{g}\end{array}$ & -7413 & $\begin{array}{l}-10270 \text { to } \\
-4555\end{array}$ & Yes & $* * * *$ & $\varangle, 0001$ \\
\hline $\begin{array}{l}\text { VEGF } 6 \mu \mathrm{g} \text { vs. Kombi } \\
6+48 \mu \mathrm{g}\end{array}$ & -7561 & $\begin{array}{l}-10286 \text { to } \\
-4836\end{array}$ & Yes & $* * * *$ & $\varangle, 0001$ \\
\hline
\end{tabular}




\begin{tabular}{|c|c|c|c|c|c|}
\hline & $\begin{array}{l}\text { Mean } \\
\text { Differenc } \\
\text { e }\end{array}$ & $\begin{array}{l}95 \% \\
\text { Confidenc } \\
\text { e Interval } \\
\text { of } \\
\text { Difference }\end{array}$ & $\begin{array}{l}\text { Significan } \\
\mathrm{t}\end{array}$ & $\begin{array}{l}\text { Summar } \\
\mathrm{y}\end{array}$ & $\begin{array}{l}\text { Adjuste } \\
\text { d P } \\
\text { Value }\end{array}$ \\
\hline VEGF $6 \mu \mathrm{g}$ vs. Blank & 148,5 & $\begin{array}{l}-2576 \text { to } \\
2873\end{array}$ & No & ns & $>0,9999$ \\
\hline $\begin{array}{l}\text { Kombi } 1.5+24 \mu g \text { vs. Kombi } \\
6+24 \mu g\end{array}$ & $-545,3$ & $\begin{array}{l}-3270 \text { to } \\
2179\end{array}$ & No & ns & $>0,9999$ \\
\hline $\begin{array}{l}\text { Kombi } 1.5+24 \mu \mathrm{g} \text { vs. Kombi } \\
1.5+48 \mu \mathrm{g}\end{array}$ & -1662 & $\begin{array}{l}-4519 \text { to } \\
1196\end{array}$ & No & ns & 0,9403 \\
\hline $\begin{array}{l}\text { Kombi } 1.5+24 \mu \mathrm{g} \text { vs. Kombi } \\
6+48 \mu \mathrm{g}\end{array}$ & -1810 & $\begin{array}{l}-4534 \text { to } \\
914,7\end{array}$ & No & ns & 0,7592 \\
\hline Kombi $1.5+24 \mu \mathrm{g}$ vs. Blank & 5900 & $\begin{array}{l}3175 \text { to } \\
8624\end{array}$ & Yes & $* * * *$ & $\varangle, 0001$ \\
\hline $\begin{array}{l}\text { Kombi } 6+24 \mu \mathrm{g} \text { vs. Kombi } \\
1.5+48 \mu \mathrm{g}\end{array}$ & -1116 & $\begin{array}{l}-3974 \text { to } \\
1741\end{array}$ & No & ns & $>0,9999$ \\
\hline $\begin{array}{l}\text { Kombi } 6+24 \mu \mathrm{g} \text { vs. Kombi } \\
6+48 \mu \mathrm{g}\end{array}$ & -1265 & $\begin{array}{l}-3989 \text { to } \\
1460\end{array}$ & No & ns & 0,9989 \\
\hline Kombi $6+24 \mu \mathrm{g}$ vs. Blank & 6445 & $\begin{array}{l}3720 \text { to } \\
9170\end{array}$ & Yes & $* * * *$ & $\varangle, 0001$ \\
\hline $\begin{array}{l}\text { Kombi } 1.5+48 \mu g \text { vs. Kombi } \\
6+48 \mu g\end{array}$ & $-148,3$ & $\begin{array}{l}-3006 \text { to } \\
2709\end{array}$ & No & ns & $>0,9999$ \\
\hline Kombi $1.5+48 \mu \mathrm{g}$ vs. Blank & 7561 & $\begin{array}{l}4704 \text { to } \\
10419\end{array}$ & Yes & $* * * *$ & $\varangle, 0001$ \\
\hline Kombi $6+48 \mu \mathrm{g}$ vs. Blank & 7710 & $\begin{array}{l}4985 \text { to } \\
10434\end{array}$ & Yes & $* * * *$ & $\varangle, 0001$ \\
\hline
\end{tabular}


Tabelle 6: Zwei-Wege-ANOVA-Analyse, Sidak's multiple comparisons test im Zeitintervall 4 bis 13 Wochen. ns nicht signifikant, * signifikant

\begin{tabular}{|c|c|c|c|c|c|}
\hline & $\begin{array}{l}\text { Mean } \\
\text { Difference }\end{array}$ & $\begin{array}{l}95 \% \text { Confidence } \\
\text { Interval of } \\
\text { Difference }\end{array}$ & Significant & Summary & $\begin{array}{l}\text { Adjusted P } \\
\text { Value }\end{array}$ \\
\hline \multicolumn{6}{|l|}{$\begin{array}{l}4 \text { Wochen - } 13 \\
\text { Wochen }\end{array}$} \\
\hline BM P 24 $\mu \mathrm{g}$ & -2993 & -5418 to $-568,7$ & Yes & ** & 0,006 \\
\hline BM P 48 $\mu \mathrm{g}$ & $-612,2$ & -2924 to 1700 & No & ns & 0,9985 \\
\hline 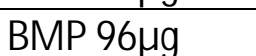 & $-135,6$ & -2560 to 2289 & No & ns & $>0,9999$ \\
\hline VEGF $0,24 \mu \mathrm{g}$ & 22,97 & -2402 to 2448 & No & ns & $>0,9999$ \\
\hline VEGF $1,5 \mu \mathrm{g}$ & $-180,9$ & -2605 to 2244 & No & ns & $>0,9999$ \\
\hline VEGF $6 \mu \mathrm{g}$ & 282,8 & -2549 to 3114 & No & ns & $>0,9999$ \\
\hline $\begin{array}{l}\text { Kombi } \\
1.5+24 \mu \mathrm{g}\end{array}$ & $-790,9$ & -3215 to 1634 & No & ns & 0,9908 \\
\hline Kombi $6+24 \mu \mathrm{g}$ & -1965 & -4390 to 459,2 & No & ns & 0,2072 \\
\hline $\begin{array}{l}\text { Kombi } \\
1.5+48 \mu \mathrm{g}\end{array}$ & $-899,7$ & -3324 to 1525 & No & ns & 0,9751 \\
\hline Kombi $6+48 \mu \mathrm{g}$ & $-341,5$ & -2653 to 1970 & No & ns & $>0,9999$ \\
\hline Blank & $-285,2$ & -2710 to 2139 & No & ns & $>0,9999$ \\
\hline
\end{tabular}




\section{Literaturverzeichnis}

Albrektsson T, J ohansson C (2001): Osteoinduction, osteoconduction and osseointegration. J Eur Spine 10(2), 96-101

Almubarak S, Nethercott $H$, Freeberg M, Beaudon C, Jha A, Jackson W, M arcucio R, M iclau T, Healy K, Bahney C (2016): Tissue engineering strategies for promoting vascularized bone regeneration. J Bone $\underline{83}$, 197-209

Backhaus S, Annen T, Epple M (2013): A porous pH-stabilized compositematerial consisting of poly (D,L-lactide), calcium carbonate and gentamicin for bone substitution. Materialwiss Werkst $\underline{44}, 107-111$

Baldini N, de Sanctis M, Ferrari M (2011): Deproteinized bovine bone in periodontal and implant surgery. Dent M ater 27(1), 61-70

Basmanav F, Kose G, Hasirci V (2008): Sequential growth factor delivery from comlexed microspheres for bone tissue engineering. Biomaterials 29 , 4195-4204

Bayer EA, Gottardi R, Fedorchak MV, Little SR (2015): The scope and sequence of growth factor delivery for vascularized bone tissue regeneration. J Control Release 219, 129-40

Bergsma JE, de Brruijn WC, Rozema FR, Bos RR, Boering G (1995): Late degradation tissue response to poly(L-lactide) bone plates and screws. Biomaterials $\underline{16}, 25-$ 31

Biberthaler P, van Griensven M : Knochendefekte und Pseudarthrosen. Springer Verlag Deutschland, Berlin 2017

Black CRM, Goriainov V, Gibbs D, Kanczler J, Tare RS, Oreffo ROC (2015): Bone Tissue Engineering. J Curr Mol Biol Rep 1(3), 132-40

Borselli C, Ungaro F, Oliviero O, d’Angelo I, Quaglia F, la Rotonda MI, Netti PA (2010): Bioactivation of collagen matrices through sustained VEGF release from PLGA microspheres. J Biomed M ater Res A 92, 94-102

Cankaya AB, Erdem M A, Isler SC, Demircan S, Soluk M , Kasapoglu C, Oral CK (2011): Use of cone-beam computerized tomography for evaluation of bisphosphonate-associated osteonecrosis of the jaws in an experimental rat model. Int J Med Sci $\underline{8}, 667-72$

Carreira AC, Lojudice FH, Halcsik E, Navarro RD, Sogayar M C, Granjeiro JM (2014): Bone morphogenetic proteins: facts, challenges, and future perspectives. J Dent Res $\underline{93}, 335-45$ 
Cho TJ, Gerstenfeld LC, Einhorn TA (2002): Differential temporal expression of members of the transforming growth factor beta superfamily during murine fracture healing. J Bone \& M ineral Research 17(3), 513-20

Cui Q, Dighe AS, Irvine JNJ (2013): Combined angiogenic and osteogenic factor delivery for bone regenerative engineering. J Curr Pharm Des $\underline{19}$, 3374-83

De la Riva B, Nowak C, Sànchez E, Hernàndez A, Schulz-Siegmund M, Pec MK, Delgado A, Evora C (2009): VEGF-controlled release within a bone defect from alginate/chitosan/PLA-H scaffolds. Eur J Pharm Biopharm 73, 50-58

De Long WGJ, Einhorn TA, Koval K, M cKee M, Smith W, Sanders R, Watson T (2007): Bone grafts and bone graft substitutes in orthopaedic trauma surgery. A critical analysis. J Bone Joint Surg Am 89(3), 649-58

Deckers M M , van Bezooijen RL, van der Horst G, Hoogendam J, van der Bent C, Papapoulos SE, Löwik CW (2002): Bone morphogenetic proteins stimulate angiogenesis through osteoblast-derived vascular endothelial growth factor $A$. Endocrinology 143, 1545-53

Dimitriou R, M ataliotakis GI, Angoules AG, Kanakaris NK, Giannoudis PV (2011): Complications following autologous bone graft harvesting from the iliac crest and using the RIA: a systematic review. Injury $\underline{42}$, 3-15

Drake CJ, Wessels A, Trusk T, Little CD (2006): Elevated vascular endothelial cell growth factor affects mesocardial morphogenesis and inhibits normal heart bending. J Dev Dyn $\underline{1}, 10-18$

Egol KA, Nauth A, Lee M, Pape HC, Watson JT, Borrelli JJ (2015): Bone Grafting: Sourcing, Timing, Strategies, and Alternatives. J Orthop Trauma 29(12), 10-14

Elliot Carlisle E, Fischgrund JS (2005): Bone morphogenetic proteins for spinal fusion. Spine J $\underline{5}, 240-49$

Endres S, Kratz M, Heinz M, Herzberger C, Reichel S, v.Garrel T, Gotzen L, Wilke A (2005): Biocompatibility testing of different sterilised or disinfected allogenous bone grafts in comparison to the gold standard of autologous bone grafts-an „in vitro" analysis of immunomodulation. J Orthop Ihre Grenzgeb 143(6), 66068

Fan L, Li J, Dang X, Wang K (2014): The hypoxia-inducible factor pathway, prolyl hydroxylase domain protein inhibitors, and their roles in bone repair and regeneration. J Biomed Res Int $\underline{239356}$

Fillingham Y, Jacobs J (2016): Bone grafts and their substitutes. J Bone Joint $\underline{98,6-9}$

Finkemeier CG (2002): Bone-grafting and bone-graft substitutes. J Bone Joint Surg Am 84, 454-64 
Geiger F, Lorenz H, Xu W, Szalay K, Kasten P, Claes L, Augat P, Richter W (2007): VEGF producing bone marrow stromal cells (BM SC) enhance vascularization and resorption of a natural coral bone substitute. Bone $\underline{41}, 516-22$

Gerstenfeld LC, Cullinane DM, Barnes GL, Graves DT, Einhorn TA (2003): Fracture healing as a postnatal developmental process: molecular, spatial and temporalaspects of its regulation. J Cell Biochem 88(5), 873-84

Geuze RE, Theyse LF, Kempen DH, Hazewinkel HA, Kraak HY, Oner FC, Dhert WJ, Alblas $J$ (2012): A differential effect of bone morphogenetic protein-2 and vascularendothelial growth factor release timing on osteogenesis at ectopic andorthotopic sites in a large-animal model. Tissue Eng Part A 18, 2052-62

Giannoudis PV, Einhorn TA (2009): Bone morphogenetic proteins in musculoskeletal medicine. Injury $\underline{40}, 1-3$

Gielkens PF, Schortinghuis J, de Jong JR, Paans AM, Ruben JL, Raghoebar GM , Stegenda $B$, Bos RR (2008): The influence of barrier membranes on autologous bone grafts. J Dent Res $\underline{87}, 1048-52$

Gothard D, Smith EL, Kanczler JM , Rashidi H, Qutachi O, Henstock J, Rotherham M, El Haj A, Shakesheff KM , Oreffo RO (2014): Tissue engineered bone using select growth factors: A comprehensive review of animal studies and clinical translation studies in man. J Eur Cell Mater 28, 166-208

Gradinger R, Gollwitzer H: Ossäre Integration. 1. Auflage; Springer M edizin Verlag, Heidelberg 2006

Graham SM , Leonidou A, Aslam-Pervez N, Hamza A, Panteliadis P, Heliotis M, Mantalaris A, Tsiridis E (2010): Biological therapy of bone defects: the immunology of bone allo-transplantation. J Expert Opin Biol Ther 10(6), 885-90

Green E, Lubahn JD, Evans J (2005): Risk factors, treatment, and outcomes associated with nonunion of the midshaft humerus fracture. J Surgical Orthopaedic Advances 14(2), 64-72

Hannik G, Arts JJ (2011): Bioresorbability, porosity and mechanical strength of bone substitutes: what is optimal for bone regeneration? Injury 42(2), 22-5

Hashimoto K, Arai Y, Iwai K, Araki M, Kawashima S, Terakado M (2003): A comparison of a new limited cone beam computed tomography machine for dental use with a multidetector row helical CT machine. Oral Surg Oral M ed Oral Pathol Oral Radiol Endod $\underline{95}$, 371-77

Hernàndez A, Reyes R, Sànchez E, Rodriguez-Èvora M, Delgado A, Evora C (2012): In vivo osteogenic response to different ratios of BM P-2 and VEGF released from a biodegradable porous system. J Biomed M ater Res A 100, 2382-91 
Horner EA, Kirkham J, Wood D, Curran S, Smith M, Thomson B, Yang XB (2010): Long bone defect models for tissue engineering applications: criteria for choice. Tissue Eng Pt B Rev 16, 263-71

Hu K, Olsen BR (2017): Vascular endothelial growth factor control mechanism in skeletal growth and repair. J Dev Dyn 246(4), 227-34

Jahan K, Tabrizian M (2016): Composite biopolymers for bone regeneration enhancement in bony defects. J Biomater Sci 4(1), 25-39

Junqueira LC, Carneiro J: Histologie. 6. Auflage; Springer M edizin Verlag, Heidelberg 2005

Kanczler J, Ginty P, White L, Howdle S, Shakesheff K, Oreffo R (2010): The effect of the delivery of vascular endothelial growth factor and bone morphogentic protein2 to osteoprogenitor cell populations on bone formation. Biomaterials $31(6)$, $1242-1250$

Kandziora F, Bail H, Schmidmaier G, Schollmeier G, Scholz M, Knispel C, Hiller T, Pflugmacher R, M ittlmeier T, Raschke M, Haas NP (2002): Bone morphogenetic protein-2 application by a poly(D,L-lactide)-coated interbody cage: in vivo results of a new carrier for growth factors. J Neurosurg 97, 40-48

Kanematsu A, Yamamoto S, Ozeki M, Nopguchi T, Kanatani I, Ogawa O, Tabata Y (2004): Collagenous marices as release carriers of exogenous growth factors. Biomaterials $\underline{25}, 4513-20$

Kempen DH, Lu L, Heijink A, Hefferan TE, Creemers LB, M aran A, Yaszemski MJ, Dhert WJ (2009): Effect of local sequential VEGF and BM P-2 delivery on ectopic and orthotopic bone regeneration. Biomaterials 30, 2816-25

Kempen DH, Creemers LB, Alblas J, Lu L, Verbout AJ, Yaszemski MJ, Dhert WJ (2010): Growth factor interactions in bone regeneration. Tissue Eng Part B Rev 16(6), $551-66$

Keramaris NC, Calori GM , Nikolaou VS (2008): Fracture vascularity and bone healing: a systematic review of the role of VEGF. Injury $\underline{39(2)}$, 45-57

Khan SN, Lane JM (2004): Spinal fusion surgery: animal models for tissue-engineered bone constructs. Biomaterials. Biomaterials $\underline{25}$, 1475-85

Kon T, Cho TJ, Aizawa T (2001): Expression of osteoprotegerin, receptor activator of NF-kappaB ligand (osteoprotegerin ligand) and related proinflammatory cytokines during fracture healing. J Bone \& M ineral Research 16(6), 1004-14

Kröpil P, Riegger C, Rubbert C, Lanzmann RS, M iese FR, Hakimi AR, Jungbluth P, Becker J, Hakimi M, Antoch G, Scherer A (2012): Quantitative M essung der Knochendefektheilung mittels Digitaler Volumentomographie (DVT) am Tiermodell. Fortschr Röntgenstr 184, 404 
Lane JM, Tomin E, Bostrom M P (1999): Biosynthetic bone grafting. J Clin Orthop Relat Res $\underline{367}, 107-17$

Laurencin C, Ashe K, Henry N, Kan H, Lo K (2014): Delivery of small molecules for bone regenerative engineering: preclinical studies and potential clinical applications. Drug DiscovToday 19, 794-800

Lee SK, Lorenzo J (2006): Cytokines regulating osteoclast formation and function. Curr Opin Rheumatol 18(4), 411-8

Li G, Corsi-Payne K, Zheng B, Usas A, Peng H, Huard J (2009): The dose of growth factors influences the synergistic effect of vascular endothelial growth factor on bone morphogenetic protein 4-induced ectopic bone formation. Tussue Eng Part 15(8), 2123-33

Lohse N, M oser N, Backhaus S, Annen T, Epple M , Schliephake H (2015): Continuous delivery of rhBM P2 and rhVEGF165 at a certain ratio enhances bone formation in mandibular defects over the delivery of rhBM P2 alone - an experimental study in rats. J Control Release $\underline{220}, 201-9$

Lüllmann-Rauch R: Histologie. 2. Auflage; Georg Thieme Verlag, Stuttgart, New York 2006

Marsell R, Einhorn TA (2011): The biology of fracture healing. Injury 42(6), 551-55

M einig RP (2010): Clinical use of resorbable polymeric membranes in the treatment of bone defects. J Orthop Clin North Am 41(1), 39-47

Molen AD (2010): Considerations in the use of cone-beam computed tomography for buccal bone measurements. Am J Orthod Dentofac 137, 130-35

Montazerian M, Dutra Zanotto E (2016): History and trends of bioactive glass-ceramics. J Biomed M ater Res 104(5), 1231-49

M oore WR, Graves SE, Bain GI (2001): Synthetic bone graft substitutes. ANZJ Surg $\underline{71(6)}, 354-61$

Moser N, Goldstein J, Kauffmann P, Epple M, Schliephake H (2018): Experimental variation of the level and the ratio of angiogenic and osteogenic signaling affects the spatiotemporal expression of bone-specific markers and organization of bone formation in ectopic sites. Clin Oral Investig 22(3), 122334

Murata M, Huang BZ, Shibata T, Imai S, Nagai N, Arisue M (1999): Bone augmentation by recombinant human BM P-2 and collagen on adult rat parietal bone. Int J Oral Max Surg $\underline{3}, 232-37$

Muschler GF, Raut VP, Patterson TE, Wenke JC, Hollinger JO (2010): The design and use of animal models for translational research in bone tissue engineering and regenerative medicine. Tissue Eng Part B 16, 123-145 
Noshi T, Yoshikawa T, Ikeuchi M, Dohi Y, Ohgushi H, Horiuchi K, Sugimura M, Ichijima K, Yonemasu K (2000): Enhancement of the in vivo osteogenic potential of marrow/hydroxyapatite composites by bovine bone morphogenetic protein. J Biomed Mater Res $\underline{4}, 621-630$

Patel ZS, Yuong S, Tabata Y, Jansen JA, Wong ME, M ikos AG (2008): Dual delivery of an angiogenic and an osteogenic growth factor for bone regeneration in a critical size defect model. Bone $\underline{43}, 931-40$

Peng H, Usas A, Olshanski A, Ho AM, Gearhart B, Cooper GM , Huard J (2005): VEGF improves, whereas SFIt1 inhibits, BM P2-induced bone formation and bone healing through modulation of angiogenesis. J Bone M iner Res 20, 2017-27

Perez R, Kim H (2015): Core-shell designed scaffolds for drug delivery and tissue engineering. Acta Biomater 21, 2-19

Piatelli A, Podda G, Scarano A (1997): Clinical and histological results in alveolar ridge enlargement using coralline calcium carbonate. Biomaterials 18(8), 623-27

Poser L, M atthys R, Schawalder P, Pearce S, Alini M, Zeiter S (2014): A standardized critical size defect model in normal and osteoporotic rats to evaluate bone tissue engineered constructs. J Biomed Res Int 348635

Prub A, Katthagen BD (2008): M usculoskeletal tissue banks. Legal foundations and graft safety. Orthopäde 37(8), 749-55

Rassow J, Hauser K, Netzker R, Deutzmann R: Biochemie. 2. Auflage; Georg Thieme Verlag, Stuttgart 2008

Richardson T, Peters M, Ennett A, M ooney D (2001): Polymeric system for dual growth factor delivery. Nat Biotechnol 1029-1034

Rueger JM : Knochenersatzmittel (Hefte zur Unfallheilkunde). Springer-Verlag, Berlin, New York 1992

Saito N, Okada T, Horiuchi H, Ota H, Takahashi J, M urakami N, Nawata M, Kojima S, Nozaki K, Takaoka K (2003): Local bone formation by injection of recombinant human bone morphogenetic protein-2 contained in polymer carriers. Bone $\underline{4}$, 381-86

Santos M I, Reis RL (2010): Vascularization in bone tissue engineering: physiology, current strategies, major hurdles and future challenges. Macromol Biosci $\underline{10}$, $12-27$

Schiller C, Rasche C, Wehmöller M, Beckmann F, Eufinger H, Epple M, Weihe S (2004): Geometrically structured implants for cranial reconstruction made of biodegradable polyesters and calcium phosphate/ calcium carbonate. Biomaterials $\underline{25}, 1239-47$ 
Schindelin J, Arganda-Carreras I, Frise E, Kaynig V, Longair M , Pietzsch T, Preibisch S, Rueden C, Saalfeld S, Schmid B, et al. (2012): Fiji: an open-source platform for biological-imageanalysis. Nat M ethods $\underline{9}, 676-82$

Schliephake H (2002): Bone growth factors in maxillofacial skeletal reconstruction. Int J Oral Max Surg 31, 469-84

Schliephake H (2010): Application of bone growth factors-the potential of different carrier systems. Oral M axillofac Surg 14(1), 17-22

Schliephake H, Weich HA, Schulz J, Gruber RM (2007): In vitro characterization of a slow release system of polylactic acid and rhBM P2. J Biomed Mater Res 83 , 455-462

Schliephake H, Vucak M , Boven J, Backhaus S, Annen T, Epple M (2015): Solvent free production of porous PDLLA/calcium carbonate composite scaffolds improves the release of bone growth factors. Oral Maxillofac Surg 19(2), 133-41

Schmidt-Rohlfing B, Tzioupis C, M enzel CL, Pape HC (2009): Tissue engineering of bone tissue. Principles and clinical applications. Unfallchirurg 112(9), 785-94

Schmitt C, Lutz R, Doering H, Lell M, Ratky J, Schlegel KA (2013): Bio-Oss ®blocks combined with BM P-2 and VEGF for the regeneration of bony defects and vertical augmentation. Clin Oral Implan Res 24 , 450-60

Speckmann E-J: Physiologie. 5. Auflage; Urban\&Fischer, München 2008

Street J, Bao M, de Guzman L, Bunting S, Peale FV, Ferrara N, Steinmetz H, Hoeffel J, Cleland JL, Daugherty A, et al. (2002): Vascular endothelial growth factor stimulates bone repair by promoting angiogenesis and bone turnover. Proc Natl Acad Sci USA 99, 9656-61

Summers RB (1994): A new concept in maxillary implant surgery: the osteotome technique. 15(2), 152, 154-6, 158

Sundelacruz S, Kaplan DL (2009): Stem cell- and scaffold-based tissue engineering approaches to osteochondral regenerative medicine. Semin Cell Dev Biol 20, 646-55

Takaoka K, Koezuka H, Nakahara H (1991): Telopetide-depleted bovine skin collagen as a carrier for bone morphogenetic protein. J Orthop Res $\underline{9}$, 902-07

Terakado M, Hashimoto K, Arai Y, Honda M, Sekiwa T, Sato H (2000): Diagnostic imaging with newly developed ortho cubic super-high resolution computed tomography (Ortho-CT). Oral Surg Oral M ed Oral Pathol Oral Radiol Endod $\underline{89}$, $509-18$

Towfigh H, Hiemer R, Langer M , Friedel R: Handchirurgie. Band 2; Springer-Verlag, Berlin Heidelberg 2011 
Tschakaloff A, Von Oepen R, Seibt S, Vieting M (1996): Das Begasungsverfahren zur Beladung resorbierbarer Polymere mit thermolabilen Substanzen. Dtsch Z Mund Kiefer GesichtsChir 20, 47-50

Valderrabano V, Engelhardt M, Küster H-H: Fuß \& Sprunggelenk und Sport. Deutscher Ärzte-Verlag, Köln 2009

Vallejo LF, Brokelmann M , M arten S, Trappe S, Cabrera-Crespo J, Hoffmann A, Gross G, Weich HA, Rinas U (2002): Renaturation and purification of bone morphogenetic protein-2 produced as inclusion bodies in high-cell-density cultures of recombinant Escherichia coli. J Biotechnol 2, 185-94

Vempati P, Popel AS, M ac Gabhann F (2014): Extracellular regulation of VEGF: isoforms, proteolysis, and vascular patterning. Cytokine Growth F R 25, 1-19

Wan M, Shi X, Feng X, Cao X (2001): Transcriptional mechanisms of bone morphogenetic protein-induced osteoprotegrin gene expression. J Biol Chem 276(13), 10119-25

Welsch U: Lehrbuch der Histologie. 2. Auflage; Urban\&Fischer, M ünchen 2006

Wippermann BW, Schratt HE, Steeg S, Tscherne H (1997): Complications of spongiosa harvesting of the ilial crest. A retrospective analysis of 1191 cases. Chirurg $\underline{68(12)}, 1286-91$

Wu M, Chen G, Li Y-P (2016): TGF- $\beta$ and BM P signaling in osteoblast, skeletal development, and bone formation, homeostasis and disease. J Bone Res $\underline{4}$, 16009

Xiao C, Zhou H, Liu G, Zhang P, Fu Y, Gu P, Hou H, Tang T, Fan X (2011): Bone marrow stromal cells with a combined expression of BM P-2 and VEGF-165 enhanced Bone regeneration. J Biomed Mater $\underline{6}, 015013$

Yang X, Ricciardi BF, Hernandez-Soria A (2007): Callus mineralization and maturation are delayed during fracture healing in interleukin- 6 knockout mice. J Bone 41(6), $928-36$

Young S, Patel ZS, Kretlow JD, M urphy MB, M ountziaris PM, Baggett LS, Ueda H, Tabata Y, Jansen JA, Wong M, M ikos AG (2009): Dose effect of dual delivery of vascular endothelial growth factor and bone morphogenetic protein-2 on bone regeneration in a rat critical-size defect model. Tissue Eng Part A 15, 2347-62

Yousefi AM, Hoque ME, Prasad RG, Uth N (2015): Current strategies in multiphasic scaffold design for osteochondral tissue engineering: A review. J Biomed Mater Res A 103, 2460-81

Zhang C (2010): Transcriptional regulation of bone formation by the osteoblast-specific transcription factor Osx. J Orthop Surg Res $\underline{5}, 37$ 
Zhang W, Wang X, Wang S, Zhao J, Xu L, Zhu C, Zeng D, Chen J, Zhang Z, Kaplan DL, Jiang $X$ (2011): The use of injectable sonication-induced silk hydrogel for VEGF(165) and BM P-2 delivery for elevation of the maxillary sinus floor. Biomaterials 32, 9415-24

Zizzari VL, Zara S, Tetè G, Vinci R, Gherlone E, Cataldi A (2016): Biologic and clinical aspects of integration of different bone substitutes in oral surgery: a literature review. Oral Surg Oral M ed Oral Pathol Oral Radiol 122(4), 392-402 